\title{
A survey on modeling dynamic business processes
}

\author{
Diana Kalibatiené ${ }^{\text {Corresp., } 1}{ }^{,}$Olegas Vasilecas ${ }^{2}$ \\ ${ }^{1}$ Department of Information Systems, Vilnius Gediminas Technical University, Vilnius, Lithuania \\ 2 Institute of Applied Computer Science, Vilnius Gediminas Technical University, Vilnius, Lithuania \\ Corresponding Author: Diana Kalibatiené \\ Email address: diana.kalibatiene@vilniustech.It
}

Dynamic and flexible systems offer huge advantages for businesses in addressing dynamic uncertain factors and implementing dynamic business processes (DBP). However, DBP remains a challenge from the perspectives of modeling, simulation, and implementation because of a nontrivial understanding of "What is a dynamic business process?". A variety of approaches for DBP modeling and implementation have been proposed over the past years, yet few comprehensive studies analyzing DBP from different particular perspectives (e.g., business process (BP) variability, aspect oriented BP, service compositions, etc.) and research questions that lay the foundation for the development of a meaning of a DBP have been reported. The motivation behind this review is to examine DBP meaning from a global perspective and, consequently, answer the previously presented research question. Therefore, in this paper, we present a systematic literature review (SLR) comprised of 67 papers from five respective digital libraries, which index Computer Science (CS), Information Systems (IS), and Software Engineering (SE) journals and conference proceedings. Two points of view are analyzed in the selected papers. First, we observe the similarities and differences between the proposed approaches to DBP modeling and implementation. From these observations, we define six main requirements for DBP (DBPR). In addition, the comparison of the selected papers according to DBPR shows that most of the approaches analyzed limit BP dynamicity, since they use partially predefined BP models. Secondly, we analyze the papers based on a visualization perspective that shows the less explored areas as follows: more flexible process modeling approach and its implementation in IS should be developed; usage of historic data should be extended; domain knowledge usage, like goal-orientation, multi-criteria optimization, domain knowledge, artificial intelligence, etc., should be included and extended to ensure BP dynamicity. As such, this study makes important contributions and serves as a useful resource for future DBP studies and practice. Moreover, we expect that our results could inspire researchers and practitioners towards further work aimed at bringing forward the field of DBP modeling and implementation. 


\section{A survey on modeling dynamic business processes}

2

3

4

5

6

7

8

9

10

11

12

13

14

15

16

17

18

19

20

21

22

23

24

25

26

27

28

29

30

31

32

33

34

35

36

37

38

39

40

Diana Kalibatiene $^{1}$, Olegas Vasilecas ${ }^{2}$

${ }^{1}$ Department of Information Systems, Faculty of Fundamental Sciences, Vilnius Gediminas

Technical University, Vilnius, Lithuania

${ }^{2}$ Institute of Applied Computer Science, Faculty of Fundamental Sciences, Vilnius Gediminas

Technical University, Vilnius, Lithuania

Corresponding Author:

Diana Kalibatiene ${ }^{1}$

Sauletekio al. 11, Vilnius, LT-10223, Lithuania

Email address: diana.kalibatiene@,vilniustech.lt

\section{Abstract}

Dynamic and flexible systems offer huge advantages for businesses in addressing dynamic uncertain factors and implementing dynamic business processes (DBP). However, DBP remains a challenge from the perspectives of modeling, simulation, and implementation because of a nontrivial understanding of "What is a dynamic business process?". A variety of approaches for DBP modeling and implementation have been proposed over the past years, yet few comprehensive studies analyzing DBP from different particular perspectives (e.g., business process (BP) variability, aspect oriented BP, service compositions, etc.) and research questions that lay the foundation for the development of a meaning of a DBP have been reported. The motivation behind this review is to examine DBP meaning from a global perspective and, consequently, answer the previously presented research question. Therefore, in this paper, we present a systematic literature review (SLR) comprised of 67 papers from five respective digital libraries, which index Computer Science (CS), Information Systems (IS), and Software Engineering (SE) journals and conference proceedings. Two points of view are analyzed in the selected papers. First, we observe the similarities and differences between the proposed approaches to DBP modeling and implementation. From these observations, we define six main requirements for DBP (DBPR). In addition, the comparison of the selected papers according to DBPR shows that most of the approaches analyzed limit BP dynamicity, since they use partially predefined BP models. Secondly, we analyze the papers based on a visualization perspective that shows the less explored areas as follows: more flexible process modeling approach and its implementation in IS should be developed; usage of historic data should be extended; domain knowledge usage, like goal-orientation, multi-criteria optimization, domain knowledge, artificial intelligence, etc., should be included and extended to ensure BP dynamicity. As such, this study makes important contributions and serves as a useful resource for future DBP studies and practice. Moreover, we expect that our results could inspire researchers and practitioners towards further work aimed at bringing forward the field of DBP modeling and implementation.

PeerJ Comput. Sci. reviewing PDF | (CS-2020:12:56750:2:0:NEW 24 May 2021) 


\section{Keywords}

42 Dynamic business process; flexible business process; variable business process; declarative

43 business process; adaptive business process; business process modeling; survey; systematic

44 literature review.

45

46

47

48

49

50

51

52

53

54

55

56

57

58

59

60

61

62

63

64

65

66

67

68

69

70

71

72

73

74

75

76

77

78

79

80

\section{Introduction}

Business processes (BP) are dynamic due to the changing nature of their environment (van der Aalst, Pesic \& Schonenberg, 2009; Pang et al., 2011; Vasilecas, Kalibatiene \& Lavbič, 2016). This can include regulatory adaptations (e.g., changes in raw material prices), market evolution (e.g., stock price changes), changes in customer behavior (e.g., rapid change in customer needs), process improvement, enterprise policy shifts, and exceptions defined through business rules (BR). Therefore, as presented in (Pang et al., 2011), BPs must be able to support structural and functional changes, such as adding a new activity, substituting an activity, and changing the execution order of multiple activities. Consequently, the models that represent them should be able to reflect this dynamicity. However, classical BP models are intended to represent predefined processes that are more or less structured, and thus do not incorporate enough flexibility. Moreover, dynamic changes usually take place in a run-time environment, i.e., involve making changes "on the fly", and we cannot abort BPs and restart them from the beginning after changes. In this context, BP dynamicity is defined across a spectrum. This ranges from completely static BP (a dynamicity level of zero percent), where all activities and their sequences are predefined in the model without the possibility of changing them, to completely dynamic BP (a dynamicity level of $100 \%$ ), where each subsequent process activity is chosen from a predefined set of activities, or even defined as required (according to the internal or external context, or historical data) by rules.

Some level of dynamicity is represented by ad-hoc (Reichert \& Dadam, 2009), agile (Gong \& Janssen, 2012), flexible (Rosa et al., 2017; Reichert \& Weber, 2012), adaptive (Reichert \& Dadam, 2009), variable (Rosa et al., 2017), customizable (Rosa et al., 2017), declarative (Jimenez-Ramirez, Barba \& Del Valle, 2018; Eshuis, 2018), and dynamic BP (Vasilecas et al., 2016). However, as outlined in (Gong \& Janssen, 2012), the concepts of agility and flexibility overlap nevertheless, and in representing a system's ability to respond to environmental changes, agility has a stronger influence than flexibility on the characteristic of speed. According to (Pucher, 2010), dynamic BP are meant to be a variant of agile processes and enable a business user to make changes in the process at run-time, e.g., by selecting a different sub-process at predefined decision points. Author of (Kiedrowicz, 2017) has noted that dynamics are obtained during process implementation, with an initially non-defined form of such processes completely or in part. In (Vasilecas et al., 2016a), authors define dynamic BP as a set of activities, which might change at a certain point in time due to the changes occurring in the BP context. Therefore, in dynamic BP a sequence of activities cannot be predefined in advance. According to some (Rosa et al., 2017; Reichert \& Weber, 2012), processes in which customization decisions are made at run-time are known as flexible processes. 
81 According to (Rosa et al., 2017), variable BP models families of BP variants, where a family of

82

83

84

85

86

87

88

89

90

91

92

93

94

95

96

97

98

99

100

101

102

103

104

105

106

107

108

109

110

111

112

113

114

115

116

117

118

119
$\mathrm{BP}$ variants is presented via a single model, from which each variant can be derived via certain transformations of the model. Moreover, Rosa et al. (2017) have named a consolidated model of process variants by concept customizable process model, from which the individual variants can be derived via transformations, for example, adding or deleting fragments. Decisions between process variants can be made either at design time or during run-time. A design-time customization affects all instances of the customized process executed in this setting. In contrast, a run-time customization is punctual and affects only one or very few process instances. However, all types of variable processes have predefined process models. A variable BP consists of variable and non-variable segments and only the variable segments of a process could be changed (Alférez et al., 2014), at run-time. In (Aiello et al., 2010), authors remark that variability is very closely related to flexibility. Flexibility offers adaptation and the potential change of a process, whereas variability deals with different versions of a process. According to some (Jimenez-Ramirez, Barba \& Del Valle, 2018; Eshuis, 2018), declarative models specify what should be done without specifying how it should be done. Authors of (Goedertier, Vanthienen, \& Caron, 2015) state that these models specify a set of constraints, BRs, event conditions, or other (logical) expressions that define the properties of, and dependencies between, activities in a BP. So, BP instances are constructed according to predefined BRs and do not violate them. These rules restrict the final execution path without defining the process model. Authors of (Eshuis, 2018) states that declarative artifact-centric process models, which present knowledge-intensive processes, use BRs that define how knowledge experts can make progress in a process. However, in many business situations knowledge experts have to deal with uncertainty, which cannot be modelled by BRs in a classical way, assuming clear-cut boundaries between di $\square$ erent states of the world. Therefore, in (Eshuis, 2018), the author proposes to model uncertain situations using fuzzy logic and to extend declarative artifact-centric process models with fuzzy sentries.

Declarative BP modeling approaches are based on rules, such as (Eshuis, 2018; Zugal et al., 2015), etc. However, as stated in (Goedertier, Vanthienen \& Caron, 2015), the differences between declarative BP modeling approaches lie in a different perception of main elements as the following. Business concerns, including the ConDec language (Pesic \& van der Aalst, 2006; Pesic, Schonenberg \& van der Aalst, 2007), and the PENELOPE language (Goedertier \& Vanthienen, 2006), only allow the expression of BRs relating to sequence and timing constraints, i.e., the control flow aspects (Heinl et al., 1999). The state space describes a discrete set of relevant BP states in terms of the entity types that occur in that space, such as the event history in ConDec and the system time in PENELOPE. Constraint types in ConDec express temporal constraints that must hold between activities in a trace, and PENELOPE discusses business constraint types that are essentially temporal deontic assignments. Knowledge representation and reasoning paradigms can also differ, like Linear Temporal Logic (LTL) in ConDec and the Event Calculus in PENELOPE. 
120 In summarizing the definitions above, some authors use terms such as "adaptive" and "flexible"

121

122

123

124

125

126

127

128

129

130

131

132

133

134

135

136

137

138

139

140

141

142

143

144

145

146

147

148

149

150

151

152

153

154

155

156

157

158

as synonyms, whilst others hold those concepts as distinct. Therefore, there is still some uncertainty around which approach maps to which level of dynamicity of a BP. Consequently, one of the objectives of this research is to analyze the level of dynamicity achieved in the proposed approaches, and thereafter the subsequent degree of implementation achieved. So, the main research questions of this study are the following:

RQ1: What level of dynamicity is achieved by the existing approaches?

RQ2: What are the differences between approaches to modeling dynamic BP?

RQ3: What are the features of a dynamic BP?

RQ4: What are the general limitations or research gaps that exist in the literature on dynamic

$B P$ modeling that may require further work?

RQ5: What literature reviews on $B P$ dynamicity are known?

RQ6: What are the levels of description and refinement of the BP dynamicity approaches analyzed?

A comprehensive state-of-the-art review is needed to better understand the current state of knowledge in the field of dynamic BP (DBP), and to answer the questions formulated. Although there are a number of scattered studies reviewing different approaches to achieving some level of dynamicity, there is a need to analyze them collectively, and thus to obtain a global view of modeling such BP. Put simply, there is a need to compare levels of dynamicity of BP.

Therefore, this paper draws together a systematic literature review (SLR) of approaches to modeling BP with some level of dynamicity, identifies and classifies main approaches in the field, and provides a comparative evaluation.

\section{Rationale for the review}

Nowadays, BP are dynamic due to the changing nature of their environment, which include regulatory adaptations (e.g., changes in raw material prices), market evolution (e.g., stock price changes), changes in customer behavior (e.g., rapid change in customer needs), process improvement, enterprise policy shifts, and exceptions defined through business rules (BR).

Therefore, BPs must be able to support structural and functional changes. However, classical BP models are intended to represent predefined processes that are more or less structured and do not incorporate enough flexibility. Moreover, dynamic changes usually occur in a run-time environment, and we cannot abort BPs and restart them from the beginning after changes. Some dynamicity level is represented by ad-hoc, agile, flexible, adaptive, variable, customizable, declarative, and dynamic BP (DBP). However, there is still some uncertainty around which approach maps to which level of dynamicity of a BP. In the absence of a clear understanding of what is DBP, a comprehensive analytical study is necessary. This SLR provides a clear and comprehensive overview of the available evidence. In addition, our work helps to identify research gaps in our current understanding of the field. The objective of this review is to provide a basis for the developers of DBP models. Our findings laid the foundation for intelligent BP.

\section{Intended audience}

Peer) Comput. Sci. reviewing PDF | (CS-2020:12:56750:2:0:NEW 24 May 2021) 
159 The article is intended to support academic and industry researchers working on DBP. We expect 160 that our results inspire researchers and practitioners for further work aiming at bringing forward 161 DBP modeling and implementation.

162

163

164

165

166

167

168

169

170

171

172

173

174

175

176

177

178

179

180

181

182

183

184

185

186

187

188

189

190

191

192

193

The remainder of this paper is organized into a number of sections. Section 2 presents the scope of the survey by defining the main terms and concepts associated with BP and their level of dynamicity. Section 3 presents related works and existing literature reviews on BP and different levels of dynamicity. Section 4 describes the research method used for the analysis of BP with different levels of dynamicity. Sections 5 presents the results of the analysis performed on the basis of the method defined in the previous section. In Section 6, we discuss the results of the analysis and answer the research questions. Section 7 then concludes the paper.

\section{The scope of the survey}

A number of approaches propose different ways of modeling and implementing dynamic BP. Their differences lie in their understandings of the concept of dynamic. Therefore, we start our survey with the concepts used to define what it is to be dynamic.

\section{The definition of the term "dynamic"}

In different dictionaries, the term dynamic is understood as continuously moving or changing ${ }^{1}$ or constant change or motion. ${ }^{2} \mathrm{~A}$ dynamic process is therefore one that constantly changes and progresses ${ }^{3}$ - a process of agile change, action, and/or progress. ${ }^{4}$ According to IGI-Global dictionary ${ }^{4}$ and authors of (Reichert \& Dadam, 2009), dynamic process change "refers to a (structural) change that is applied to the schema of a running process instance during run-time. After the change, process execution continues based on the new schema version of the process instance." Ad-hoc process change refers to a process change which is applied in an ad-hoc manner to a given process instance, and is necessary to deal with exceptions or situations not anticipated at the process design stage (Reichert \& Dadam, 2009). Adaptive process refers to the ability of the process-aware information system (PAIS) to dynamically adapt the schema of ongoing process instances during run-time. As presented in (Reichert \& Dadam, 2009), process schema evolution "refers to the continuous adaptation of the schema of a particular process type to cope with evolving needs and environmental changes." The need for a dynamic change is detected in long-running processes, and then becomes necessary in order to migrate already running process instances to the new schema version (Reichert \& Dadam, 2009). According to Oracle, ${ }^{5}$ a dynamic process is a collection of activities or tasks without a predetermined sequence of execution. It provides flexibility for knowledge workers to define the process flow at run-time based on the information available to them. Oracle allows the creation of a dynamic process by selecting a particular pattern or starting from scratch. In addition, a user should define all

\footnotetext{
${ }^{1} \mathrm{https}: / / \mathrm{www}$. ldoceonline.com/dictionary/dynamic

2 https://www.yourdictionary.com/dynamic

${ }^{3}$ https://www.collinsdictionary.com/dictionary/english/dynamic

${ }^{4}$ https://www.igi-global.com/dictionary/dynamic-process/69549

5 https://docs.oracle.com/en/cloud/paas/integration-cloud/user-processes/create-dynamicprocess1.htm|\#GUID-99737D0A-DF4C-484E-820A-D30108073951
} 
194

195

196

197

198

199

200

201

202

203

204

205

206

207

208

209

210

211

212

213

214

215

216

217

218

219

220

221

222

223

224

225

226

227

228

229

230

231

232

233

activities that can be used within a dynamic process. During run-time, knowledge workers decide the course of activities in a dynamic process, start and complete activates, assign activities to roles, and complete and close process instances. Moreover, each dynamic process has milestones that are sub-goals defined within a process, and are used to track progress.

A BP model can be seen as a scheme defining the "algorithm" of process execution (van der Aalst, Weske \& Grünbauer, 2005). During the execution of a BP, the system uses the BP model as a "recipe" to determine the sequence of activities to be executed. A BP model is described by a specific BP modeling language, such as BPMN, which plays a determining role in the way that the prescribed process can be executed. The weaker this prescription is, the easier it is to deviate from the predefined process (Pesic \& van der Aalst, 2006). However, most process models enforce the prescribed procedure without deviations. Flexible BP should allow users to deviate from the prescribed execution path (Pesic \& van der Aalst, 2006; Heinl et al., 1999).

Authors of (Vasilecas, Kalibatiene \& Lavbič, 2016) propose distinguishing BP modeling approaches according to the levels of dynamicity. The first and lowest level of dynamicity is described as using decision points, in which a human or an automated system decides what to do next according to predefined rules. Almost all of today's approaches and tools implement this level of dynamicity. The second, middle level of dynamicity is understood as the ability to automatically configure BP, like choosing an alternative template or paths for processing activities, or changing activities or their execution order in a process when context changes. Most of today's approaches fall within this level of dynamicity, a good example of which is the use of variable models (Rosa et al., 2017; Alférez et al., 2014; Milani et al., 2016). The third and highest level of dynamicity is achieved in the case of, for example, a goal-driven $\mathrm{BP}$ that can be changed at run-time according to the new conditions and the customer's needs, as in (Vasilecas et al., 2016). Therefore, these BP have no predefined sequence of activities. Summing up the defined dynamicity levels, they depend on the ability to create a BP instance according to the predefined BP model, or conversely to define specific activities and their sequences at run-time.

\section{Approaches to achieving dynamicity of BP}

All of the processes mentioned previously (i.e., ad-hoc, agile, flexible, adaptive, variable, customizable, declarative, and dynamic) can be context-sensitive, rule-based, event-based, policy-based, case-handled, etc. According to (Saidani \& Nurcan, 2006; Nunes, Werner \& Santoro, 2011), a context-aware, or context-sensitive, process is able to adapt BP instances at run-time to the changing context, which is defined by the minimum values of the variables that contain all relevant information that impacts the design and execution of a BP (Rosemann \& Recker, 2006). In (Coutaz et al., 2005), a context is a set of entities, a set of roles that entities may satisfy, a set of relations between the entities, and a set of situations that denote specific configurations of entities, roles, or relations. Moreover, context can be internal and external. An internal context is represented by the state of resources in a system, such as the availability raw materials, and an external context is represented by the state of a system environment, such as the price of raw materials in the market, as defined by a set of variables. Existing approaches allow for the definition of one type of context individually: internal, as with the current state of

Peer] Comput. Sci. reviewing PDF | (CS-2020:12:56750:2:0:NEW 24 May 2021) 
234 system resources in (Hu, Wu \& Chen, 2014), or external (Saidani \& Nurcan, 2006; Nunes, 235 Werner \& Santoro, 2011; Mejia Bernal et al., 2010) only, without considering both.

236 In rule-based BP, rules can describe different aspects by ensuring some level of BP dynamicity.

237 For example, the authors use rules to define the relationships between events, which caused

238 during BP execution when changing a state of resources, and to filter the interesting ones in their 239 proposed CEVICHE architecture (Hermosillo, Seinturier \& Duchien, 2010). When an event that 240 is important for BP adaptation is detected, the Complex Event Processing (CEP) engine notifies

241 the responsible component to adapt the BP (instance or model) with the corresponding activity at 242 run-time. Authors of (Milanovic, Gasevic \& Rocha, 2011) use BR patterns to enrich BP in terms

243 of possible cases and to increase BP flexibility. Pesic \& van der Aalst (2006) use constraints to 244 define relationships among tasks in their proposed ConDec language. At every moment during 245 the execution of a process model, there is a judgement about whether or not the model satisfies 246 the defined constraints. In (Mejia Bernal et al., 2010), the authors propose deconstructing BP into 247 an ECA (Event-Condition-Action) rule set and adapting it to the external context data, describing 248 user's priorities to provide a service. The authors describe expressing transitions between 249 activities in the form of ECA rules, where an event is generated when an activity has finished its 250 execution, a condition used to verify which workflow part is enabled, and where a rule action 251 determines the next activity that has to be executed. The adaptation at run-time is then 252 performed. All processes have a strictly defined sequence of activities, and this sequence of 253 activities can be changed according to the defined set of rules (Mejia Bernal et al., 2010).

254 Here, based on the related works, we can summarize that BRs can ensure the dynamicity of a BP 255 as follows: 1) each activity in a process is selected according to the defined conditions at BP run256 time, and 2) the content of an activity is chosen based on the changing internal and/or external 257 context. However, the rule-based approaches reviewed above do not cover both of these aspects. 258 In some papers (Xiao et al., 2011), process dynamicity is ensured through predefined process 259 fragments and the defining of their relationships, which are specified in a constraint-based way. 260 The policies contain a set of rules to select, whereby concrete fragment implementations will be 261 used in the BP. Processes are dynamically generated based on constraints and adaptation policies 262 according to their operating environments. Process fragments provide a modularized view on 263 process models (Xiao et al., 2011). Consequently, the process can be changed at run-time by 264 adding, substituting, or removing fragments, or modifying their relationships, which allows the 265 process to be adapted dynamically. In some cases, this policy-based approach is similar to a rule266 based approach, since a process schema is composed from fragments, the relationships between 267 which are specified by the predefined rules. In addition, other researchers propose to ensure 268 some level of BP dynamicity through an event-based approach (Hermosillo, Seinturier \& 269 Duchien, 2010; Hermosillo, 2012), which is discussed previously, as it uses rules to combine 270 events into one complex one. Those complex events are necessary to notify the responsible 271 component, which in turn searches for the corresponding aspect to adapt the BP.

272 In (van der Aalst, Weske \& Grünbauer, 2005), the authors proposed a case handling paradigm 273 for supporting flexible and knowledge intensive BP, which are based on data. As the authors 
274 state, case handling focuses on what can be done to achieve a business goal. The central concepts

275 in a case handling approach are the case and its data as opposed to the activities and routing rules

276 in traditional workflow ${ }^{6}$ management systems. Usually, case-handled systems present all data

277 about a case at any time to the user. In such systems, many cases can be handled in parallel and

278 these cases are logically independent. According to (Mutschler, Weber \& Reichert, 2008), in

279 case-handling a system is more flexible compared to a workflow management system, since

280 there is no error-prone "context tunneling" as in workflow based approaches. The case-handling

281 paradigm is considered as "a more flexible approach" because users work with whole cases and

282 can, for different reasons, modify the predefined process model (van der Aalst, Weske \&

283 Grünbauer, 2005).

284 Authors of (Sabatucci \& Cossentino, 2019) views dynamic workflows as a promising approach

285 to provide flexible BP execution in the dynamic business environment. Their main contribution

286 is an automated procedure to extract implicit goals from a BPMN workflow description. This

287 study is highly dependent on BPMN workflows, functional dimension of workflows, and

288 availability of services, which implement workflows. Comparing, in this review, we concentrate

289 on dynamic changes at the business level, but not at the implementation level, as presented in

290 (Sabatucci \& Cossentino, 2019).

291 The definition of a dynamic BP (DBP)

292 This research focuses on different approaches to achieving BP dynamicity. Therefore, we present

293 a study allowing us to determine what level of dynamicity is achieved by various approaches.

294 Moreover, for our survey we are going to use the definition of a dynamic BP (DBP) as follows.

295 Definition 1: A dynamic business process (DBP) is a process that is able to support structural

296 and functional changes (i.e., has no predefined activities nor sequence of activities) at DBP

297 instance run-time according to its context and rules, and that can be implemented with minimal

298 delay.

299 A context refers to an internal context and an external context of DBP. As outlined in a number

300 of papers, an external context is a set of variables and context rules defining a particular state of

301 the environment. If the current state of the environment changes, then the external context also

302 changes. An internal context is the current state of system resources. If the current state of

303 system resources changes, then the internal context also changes.

304 According to the DBP definition, the DBP requirements (DBPR) adopted from (Vasilecas,

305 Kalibatiene \& Lavbič, 2016) are defined as the following:

306 DBPR-1. DBP should not have a predefined sequence of activities.

307 DBPR-2. DBP should react to the change of the context.

308 DBPR-3. Every subsequent activity should be selected according to predefined rules and a

309 context. If there is no activity for further execution, it should be possible to do the following:

310 3.1. to terminate the execution of a DBP instance; or

311 3.2. to define a new activity and related rules for a DBP instance execution.

\footnotetext{
${ }^{6}$ As defined in (Zur Muehlen, 2004), a workflow is a formal, or implementation-specific, representation of a BP.
} 
312 DBPR-4. DBP changes can be initiated by any role involved, at any time, with possibly low 313 latency compared to a DBP execution time.

314 DBPR-5. Before selecting the next activity, the historical data detailing instances of execution of 315 the same DBP should be analyzed and the next activity selected should not cause the execution 316 of an unacceptable sequence of activities, as defined by prior experience.

317 DBPR-6. DBP execution should align with a particular business goal.

318 We argue that DBP is a BP which meets all of the requirements presented. Implementing all six 319 requirements provides more freedom in BP modeling. However, this freedom can be constrained 320 by adding BRs, which depend on the requirements of the application domain. Moreover, the advantage of implementing the proposed requirements is that it allows DBP to be goal-oriented.

322

323

324

325

326

327

328

329

330

331

332

333

334

335

336

337

338

339

340

341

342

343

344

345

346

347

348

349

350

351

\section{Related works}

Using the research strategy presented in the "Survey methodology" section, we have identified a number of existing literature reviews on BP dynamicity. There are a number that align closely with our research (Rosa et al., 2017; Pourshahid et al., 2012; Ayora et al., 2015; Cognini et al., 2014; Cognini et al., 2018; Kapuruge, Han \& Colman, 2010; Goedertier, Vanthienen \& Caron, 2015).

Authors of (Rosa et al., 2017) present a survey of papers on BP variability modeling by aiming to identify the commonalities and differences of approaches, criteria to select between different approaches, and research gaps that exist in the literature. As the authors identified, a standard process model is extended to capture process variants into a customizable process model. A model of each variant can be changed by adding or deleting process model fragments according to the context. The authors assessed their identified approaches using the 14 criteria described in their paper and produced a report that identified a number of gaps in these approaches. Firstly, they recognized a lack of effective methods and tools to support and assist users in the creation, use, and maintenance of the proposed approaches, leading to their limited adoption in practice. Another gap was that around half of the approaches reviewed have been validated through case studies. As the authors noticed, there is a lack of comparative empirical evaluations with endusers, which might provide evidence that one variability modeling approach is more usable than others in a particular setting. Though the paper presents very detailed analysis of the state-of-theart, the authors do not present their survey method, which differs from others presented in literature reviews, such as (Ivarsson \& Gorschek, 2011). Moreover, there is no access to the appendices of the research, where some important information about the survey is presented. Therefore, not all of the criteria that is outlined can be understood completely.

Pourshahid et al. (2012) present SLR on aspect-oriented approaches for BP adaptation. They have observed that current methods focus on the following: 1) composing and swapping services based on Quality of Service, cost, rules, policies, and constraints, as well as in the event of failure; 2) extracting roles and cross-cutting concerns from composite services; 3) customizing process instances based on user profiles or Service Level Agreements; 4) adapting service composition and collaboration policies; and 5) using monitoring aspects to detect undesired situations. As a result of the review, authors proposed their own aspect-oriented process

Peer] Comput. Sci. reviewing PDF | (CS-2020:12:56750:2:0:NEW 24 May 2021) 
352

353

354

355

356

357

358

359

360

361

362

363

364

365

366

367

368

369

370

371

372

373

374

375

376

377

378

379

380

381

382

383

384

385

386

387

388

389

390

391

modeling and adaptation framework, which considers organizational goals, performance, and constraints as a whole when improving BP. The main limitation of the (Pourshahid et al., 2012) study is that it focuses on service-based BP adaptation, i.e., implementation level of BP. Authors of (Ayora et al., 2015) present an evaluation of variability support in process-aware information systems (PAIS). Based on the results of their literature review, the authors presented the VIVACE framework, which allows for the systematic assessment and comparison of existing approaches to process variability. As the authors state, VIVACE enables process engineers to select the variability approach that best meets their requirements, as well as helping them in implementing PAIS supporting process variability. Specifically, VIVACE comprises a core set of variability-specific language constructs and a core set of features that foster process variability along the process lifecycle. These constructs allow the assessment of the expressiveness of existing process variability approaches regarding the modeling of process variability. Despite the advantage of the (Ayora et al., 2015) study and the detailed analysis of BP, this study is limited to variable BP only.

Authors of (Cognini et al., 2014) present a literature review on BP adaptation by aiming to find what raises the need for adaptation within the BP domain, which BP life cycle management phases require support for adaptation, which are the instruments used to express and support BP adaptation, whether there are any real experiences of BP adaptation, and what the challenges associated with the BP adaptation are. Whilst the authors have identified a large amount of interest in the analised topic, there are some gaps left in the research, namely the lack of application of research results to real BP adaptation scenarios. They identified just three real BP adaptation scenarios: the car logistic of the seaport of Bremen (Germany) (Bucchiarone, Mezzina \& Pistore, 2013), the warehouse management (Marconi et al., 2009), and the clinical (Dadam \& Reichert, 2009) scenarios. Other main issues associated with the BP adaptation include: the need for dynamic languages for BP modeling; current languages for BP modeling failing to support adaptation constructs; the adaptation of $\mathrm{BP}$ running instances; the verification of adapted $\mathrm{BP}$; and evolving BP.

In (Kapuruge, Han \& Colman, 2010), authors have analyzed BP flexibility in the scope of service composition according to the following criteria: 1) process definition flexibility according to the possibility of BP modifications during the analysis and design phases; 2) process instance flexibility according to the possibility of process instance change at run-time; 3 ) services relationship flexibility according to a service composition in terms of the relationships among the different entities of the composition. During the survey, the authors found that there is a lack of support for modeling service relationships, which describes the mutual obligations, constraints, etc., in defining the BP of a service composition. Compared to the current study, (Kapuruge, Han \& Colman, 2010) focuses on and is limited to the BP flexibility in the scope of service composition.

Authors of (Cognini et al., 2018) present a literature review on BP flexibility with a focus on software systems related aspects. They define flexibility as the ability to properly manage the coordination between challenges in organizational aspects and technical environments, and their 
392 changes. The authors' literature review is based on the guidelines presented in (Kitchenham,

393

394

395

396

397

398

399

400

401

402

403

404

405

406

407

408

409

410

411

412

413

414

415

416

417

418

419

420

421

422

423

424

425

426

427

428

429

430

431

2007). The results obtained have confirmed the increasing relevance of the BP flexibility topic, aided by the authors' analysis of papers on BP flexibility over a broader timescale, ranging from 2000 to 2015. As the authors have found, flexibility issues influence all BP life-cycle stages.

Whilst there are a number of approaches proposed to support BP flexibility, there is still a lack of application of the proposed approaches in concrete and complex cases. Moreover, the authors identified several research directions in this field that require further investigation. They are as follows: modeling languages for flexibility implementation in BP; verification of the flexible BP model; adaptation of BP instances at run-time; and evolving BP.

In (Goedertier, Vanthienen \& Caron, 2015), authors focused on the literature review of declarative BP modeling principles and languages. They have chosen eight declarative process modeling approaches and languages with distinct declarative specifications, such as BPCN (Lu, Sadiq \& Governatori, 2009), ConDec (Pesic \& van der Aalst, 2006), etc. These approaches are compared according to the state space, which is a specific configuration of the facts about entities (e.g., BP activities) in a state space corresponding to a specific context of a BP, the transition types among states, and rules (e.g., transition rules). As the authors stated, the approaches that they analyzed differ mainly on the matter of interests, because approaches were developed to represent some reality, as with the ConDec language, which expresses BRs only about sequence and its items' timing constraints. Other differences lie in a differing understanding of a state space, constraint types expressing different ways of transitions, and knowledge representation and reasoning paradigms, which use additional different ontologies. Moreover, as the authors have concluded, flexibility costs money, and therefore the efficiency of executing declarative models may be complicated. This is because of the extended possibilities of choosing suitable execution paths, managing BRs, etc.

In drawing this together, it is evident that the surveys that were analyzed examine BP dynamicity from different perspectives. These include: variability (Rosa et al., 2017; Ayora et al., 2015); aspect-oriented and services based (Pourshahid et al., 2012); service compositions (Kapuruge, Han \& Colman, 2010); flexibility (Cognini et al., 2014; 2018); and declarative (Goedertier, Vanthienen \& Caron, 2015). Therefore, the results obtained and conclusions drawn by the authors are limited to their particular respective areas. Consequently, there is a need for more general studies in the area of BP dynamicity. In this study, however, we are not going to compete with existing studies but to supplement them in terms of both time and the scale of their scope. The main advantage of the current study is that it provides the analysis of a DBP meaning from a global perspective.

\section{Survey Methodology}

In this section, a research method is presented that begins with a brief literature review of papers published on DBPs, proceeds to a detailed review of the refined set of papers, and ends with conclusions. The research method schema is presented in Figure 1, and is adapted from (Ivarsson \& Gorschek, 2011; Kitchenham, 2007; Kitchenham et al., 2009).

Peer) Comput. Sci. reviewing PDF | (CS-2020:12:56750:2:0:NEW 24 May 2021) 
432 Figure 1. The research method schema

433

434 The list of searching sources

435 As the study is focused on BP dynamicity, i.e., BP modeling approaches and their

436 implementation into software systems, relevant papers should be searched in databases covering

437 Computer Science (CS), Information Systems (IS), and Software Engineering (SE). Due to

438 technical limitations only free access sources were chosen, of which there were a limited number

439 (see Table 1). However, the initial study of sources shows that they contain a significant number

440 of papers relevant to the research questions.

441

442

Table 1. List of sources

443

444

445

\section{A search query and keywords}

446

According to the scope of the survey, keywords and a search query were defined. First, we

447 defined the main keywords taking into account synonyms and terms related to each of the three

447 concepts, as shown in Table 2 .

Table 2. Keywords used for the search

450

451

452

453

454

455

456

457

458

459

460

461

462

463

464

465

466

467

468

469

470

471

Other search terms - such as agile, ad-hoc, or customizable - were not used as keywords for the search. Adding those terms increased the number of papers found, but additional papers did not expand the knowledge provided on the research topic. They were excluded from the search but are still found together with the keywords used. The scope of the survey shows that our search query results cover the topic of BP dynamicity. The proximity operator, i.e., *, was used to find more relevant results by allowing variations of the same terms, for example business process and business processes, dynamic and dynamicity, dynamical, etc.

Secondly, the queries were combined from the keywords using Boolean operators as follows. SQ1: ("dynamic* business process*" OR "business process* dynamic*" OR "dynamic* in business process*" OR “dynamic* BP” OR "BP dynamic*” OR “dynamic* in BP”)

SQ2: ("flexib* business process*" OR "business process* flexib*" OR "flexib* in business process" OR "flexib* BP" OR "BP flexib*” OR "flexib* in BP”)

SQ3: ("variab* business process*" OR "variab* in business process*" OR "business process* variab*" OR "variab* BP" OR "variab* in BP" OR "BP variab*”)

SQ4: ("adapt* in business process*" OR "business process* adapt*" OR "adapt* business process*" OR “adapt* in BP” OR "BP adapt*” OR "adapt* BP”)

The results of the search according to the defined queries are presented in Table 3.

Table 3. Results of the performed search (May, 2019)

Peer] Comput. Sci. reviewing PDF | (CS-2020:12:56750:2:0:NEW 24 May 2021) 
472 The search in the databases was restricted to title, abstract, and keywords, except in WoS where

473 it was done according to the topic (the other option was to search a title or a full text separately).

474 Google Scholar is more a search engine than a digital database. Therefore, we used it to

475 supplement the search results and to reduce the threats caused by the specifics of some databases.

476 Other important primary quality criteria were applied during the search. Publications that

477 featured the following restrictions were excluded from the results obtained:

478 1. A publication that is non-peer-reviewed - including books, Master's/PhD theses, keynotes,

479 tutorials and editorials, etc.

480 2. A publication that is not available in the English language.

481 3. Two or several papers that are the same. Duplicates of papers were excluded using Mendeley, ${ }^{7}$ 482 since some papers are included into several databases and repeated.

483 After applying a set of primary quality criteria, the number of papers decreased from 662 to 457.

484 However, evidently there were still too many papers to perform an analysis. Therefore, an

485 additional refinement was applied to the results in order to decrease the number of papers, and to

486 ensure their relevance to the analyzed topic.

487 As a result, the titles and abstracts of the papers were additionally reviewed to exclude those that 488 were deemed irrelevant. The additional quality criteria used were defined as follows:

489 1. Exclude papers which contain relevant keywords, but within which DBP analysis is not the 490 main topic of the paper, as in the fields of: education, medicine, energy efficiency, trade-off, 491 fault identification, economic, artificial intelligence, programming, and hardware.

492 2. Exclude papers with a length of less than six pages, as such short papers present only a general 493 idea and omit details of an overall approach.

494 After the refinement of the papers obtained in the earlier stages, we were left with 229 papers to 495 be studied in further detail.

\section{Study selection}

497 From the title and abstract of a paper, only incomplete information can be gathered regarding the 498 context and the proposed approach presented in the study. Therefore, the remaining 229 papers 499 were reviewed in more detail, manually applying the following steps and deciding to include or 500 exclude the paper:

501 1. Read the abstract of the paper.

502 2. Read the introduction to the paper.

503 3. If a decision to include or exclude the paper is not made, read the discussion and conclusions.

504 4. If it is still unclear, search for the keywords in the text of the paper and evaluate their 505 contextual suitability to the scope of our study.

506 Moreover, the refined quality criteria for selecting papers were as follows:

507 1. The paper should present a method or a technique on the subject of BP dynamicity.

508 2. The paper should not present a language without its application in a case study.

509 3. The paper should present an evaluation, which can be understood as: an application, a test or 510 illustration, a toy example, a case study, an experiment, or any sort of empirical evaluation.

${ }^{7}$ https://www.mendeley.com 
511 After the application of the detailed review process, 145 papers remained for review via the 512 reading of the full text. After reading the full texts of these papers, 67 papers were selected for 513 data extraction and detailed analysis.

514 Threats to validity

515 The papers for analysis were chosen based on the strategy described previously, which included:

516 1) searching sources; 2) selection via keywords and queries; and 3) selection via quality criteria.

517 All of these variabilities were selected based on the related works analysis in the corresponding

518 BP dynamicity area. However, there exists the possibility of missing important studies, because

519 not all papers can be located using defined keywords that are related to the research questions. In

520 order to reduce these threats to validity, the following measures were taken:

521 - A manual checking of the references in the extracted papers was patiently carried out in order

522 to identify those papers that might be missed during the initial search using the keywords that we

523 had defined. In addition, a precise definition of the paper selection quality criteria that complied

524 with the research questions was enforced to avoid the incorrect exclusion of suitable papers.

525 - The snowballing search method, applied from (Jalali \& Wohlin, 2012), was used on the found

526 literature reviews on BP dynamicity approaches. We went forward by reviewing the reference

527 lists of these literature reviews by identifying papers cited in the reviews and assessing them

528 according to our defined study selection criteria. We have discovered additional 10 papers

529 meeting our inclusion criteria via this snowballing procedure.

530 - Reading the abstract and the title of the papers introduces a threat, because the abstract and the

531 title allows the exclusion of papers that are not relevant at the first glance. Even if it did not

532 necessarily reflect what is actually presented in the papers, this threat allowed us to exclude

533 papers that were definitely not relevant (Ivarsson \& Gorschek, 2011);

534 - Reading the full-text of papers and evaluating them according to the defined paper selection

535 criteria allowed us to limit a set of relevant papers and exclude papers that possessed defined

536 keywords, but that were not relevant to the area of BP dynamicity that was analyzed.

537 - The sources searched (see Table 1) were limited to the most relevant sources, and included only

538 peer-reviewed papers. Note that Google Scholar was used as a supplementary search engine.

539 Finally, to minimize the threat associated with inaccurate extraction of data, the following threats

540 to validity were used:

541 - Including only papers from journals and proceedings classified as CS, IS, and SE categories

542 limits the possibility of generalizing the results to other forums, in which SE technologies are

543 published.

544 - Primary, additional, and refined paper extraction criteria were used to select papers.

545 - All of the selected papers were assessed using the questions presented in Table 2.

546 Data extraction strategy

547 In this step, data were extracted from the selected relevant papers regarding BP dynamicity

548 according to the features defined in Table 4, and presented in the table rows. Each feature could

549 be clearly understood in the context of BP dynamicity after answering one or several questions,

550 presented within a feature. These features and questions are based on dynamic BP requirements 
551 presented in Vasilecas et al. (2016b). If a feature is not explicitly mentioned in the paper, it is 552 mapped according to this survey analysts' understanding. In some cases, a paper can describe 553 several studies. Therefore, the primary study is selected according to the scope of the survey. 554 Table 4 consists of four columns, where the first column presents research questions related to 555 the feature. The second column presents features and questions. The third column presents 556 possible answers to the questions. As can be seen, there are two types of questions. First are 557 those that concern the approach, and elicit a yes or no answer. Second are those that concern 558 either an approach or a description of the approach, eliciting a yes, part, or no answer. The fourth 559 column represents the scaling of answers, where 1 means a strong description (i.e., a feature is 560 described to the degree where a reader can understand and compare it to the same aspect in

561

562

563

564

565

566

567

568

569

570

571

572

573

574

575

576

577

578

579

580

581

582

583

584

585

586

587

588

589

590 another paper), 0.5 represents a medium description (i.e., a feature in which the study performed is mentioned or presented in brief, but not described to the degree to which a reader can clearly understand and compare it to the same feature in other paper), and 0 where there is a weak description or indeed none at all.

At the end of the examination of the approach, presented in the paper on the basis of scaling, a ranking, denoting the level of dynamicity of an approach and based on features 1-7, 9, and 10 from Table 4, and a rigor, denoting the level of description of an approach and based on features 8-11 from Table 4, are summed up. Thus, all papers are ranked according to their BP dynamicity. The larger the ranking value, the larger the dynamicity level that is achieved by the proposed approach. Also, the larger the rigor value, the larger the level of description, i.e., the better quality of approach, is achieved in the paper. Other examination features, such as problem definition, etc., can be added to Table 4 . However, they are neglected intentionally in order to optimize assessment procedure. We consider that the global aim of those studies is the same.

\section{Table 4. Data extraction template according to the requirements of DBP}

\section{The results of the data extraction are presented in the "Results" section.}

\section{Comparison of literature reviews on BP dynamicity}

Among the papers presenting BP dynamicity approaches, papers with literature reviews were also found. For the comparison of those papers we have developed assessment criteria which is based on questions presented elsewhere (Cognini et al., 2018; Ivarsson \& Gorschek, 2011; Kitchenham et al., 2009), and shown in Table 5. In the table, the first column presents the number of a question, the second presents the question itself, the third presents possible answers to the questions, the fourth presents the scale or value of an answer, the fifth notes whether the question belongs to the relevance category, and the sixth notes whether the question belongs to the rigor category. Thus, in this paper, each literature review is assessed according to the questions presented and, based the answers provided, relevance, denoting the level of similarity of an analyzed survey to the present survey, and rigor, denoting the quality and presentation of an analyzed survey, are calculated. The scaling of answers is then the same as in Table 4 . 
591 Table 5. Assessment questions for evaluating existing literature reviews

592

593

\section{Results}

594 The main results obtained during the survey of the selected papers consist of three main parts as

595

596

597

598

599

600

601

602

603

604

605

606

607

608

609

610

611

612

613

614

615

616

617

618

619

620

621

622

623

624

625

626

627

628

629

630

follows: 1) surveys on the topic of BP dynamicity; 2) papers proposing new BP dynamicity approaches; and 3) analysis of tools for DBP modeling and simulation.

\section{Comparison of literature reviews on BP dynamicity (RQ5)}

A summary of the results, obtained during the deep analysis of literature reviews according to the questions from Table 5, is presented in Table 6 and Table 7.

Table 6. Summary of reviews on DBP

Table 7. An initial data on literature reviews comparison

As can be seen from Table 7, though, the publication years of the analyzed surveys on BP dynamicity differs. The main period of the papers analyzed is in the range from 2000-2015, and the refined and overlapped period of analyzed papers is in the range from 2004-2013. The surveys analyzed and the present survey generated a set of about 500 research papers, which concern research questions on BP dynamicity. All surveys have analyzed BP dynamicity from different perspectives as follows: BP variability (Rosa et al., 2017; Ayora et al., 2015); aspect oriented (Pourshahid et al., 2012); service compositions (Kapuruge, Han \& Colman, 2010); BP flexibility (Cognini et al., 2014; 2018); and declarative BP (Goedertier, Vanthienen \& Caron, 2015). The surveys most similar to this survey are (Cognini et al., 2014; 2018). As the survey presented in (Cognini et al., 2018) is newer and more sophisticated than (Cognini et al., 2014), it was selected to compare with this survey according to the sources used. This comparison shows that $58 \%$ of the sources analyzed in this survey differ from the sources used in (Cognini et al., 2018). Such partial overlapping can be explained by the similarity of the topic analyzed.

However, as the analysis of our references shows, this survey covers the most up to date papers on BP dynamicity, including the year 2018, which could not have been be analyzed in another survey under review because they only covered papers in the period of 2000-2015. Moreover, the research questions defined in both surveys differ, and distinctions can also be seen in keywords. One additional keyword used in our search query was "dynamic" and its variations. The primary difference among this survey and that presented by (Cognini et al., 2018) lies in different paper selection criteria, i.e., exclusion and inclusion criteria. In this survey only the most

comprehensive and non-duplicated papers by the same authors were chosen for detailed analysis, but not all papers from the same authors.

Another interesting and important aspect observed during the comparison of the surveys analyzed is the quality assessment of the search that was undertaken to identify relevant papers. Only two surveys from those analyzed have presented such an assessment. In (Rosa et al., 2017), two authors assessed each approach independently, and third author combined the results, after

Peer) Comput. Sci. reviewing PDF | (CS-2020:12:56750:2:0:NEW 24 May 2021) 
631 which confirmation was finally sought from the authors of each primary paper. In (Cognini et al., 632 2018), a quite different assessment of the selected papers was employed. The data collected were 633 validated by three experts with more than 10 years of experience in BP management, along with 634 other related expertise. The feedback from experts was reconsidered by the authors in a meeting 635 to consolidate the final version of the questions. Additionally, a validation based on the 636 snowballing search method (Jalali \& Wohlin 2012) was used on the selected research papers 637 before the next steps in the analysis. Other authors do not present any assessment procedures. 638 Table 7 presents data obtained from the answering of the questions from Table 5. As can be seen 639 from the results, the maximum relevance have achieved by (Cognini et al., 2018) (8 points). This 640 can be explained by the fact that it is the most similar to the present survey. The differences 641 between both surveys were discussed previously in this section. The maximum rigor of 5.5 642 points is achieved by (Ayora et al., 2015) and (Cognini et al., 2018), denoting that the 643 presentation of surveys is at a high level in their papers.

644

645 Figure 2. An overview of rigor-ranking scores for the papers on literature reviews on BP 646 dynamicity

647

648 In Figure 2, we have presented an overview of rigor-ranking scores for the literature reviews on 649 BP dynamicity. As can be seen, the reviews analyzed have achieved middle or high levels of 650 sophistication in presenting the results of analysis on the topic of BP dynamicity. However, some 651 gaps in reviews still remain. They are as follows: presenting a research methodology (Q5 and 652 Q6) (Ayora et al., 2015); threats to validity (Q7) (Rosa et al., 2017; Cognini et al., 2014;

653 Kapuruge, Han \& Colman, 2010; Goedertier, Vanthienen \& Caron, 2015); and quality

654

655

656

657

658

659

660

661

662

663

664

665

666

667

668

669

670

assessment of the performed search (Q8 and Q9) (Ayora et al., 2015; Pourshahid et al., 2012; Cognini et al., 2014) (see Figure 3).

Figure 3. An overview of answers on the assessment of the papers on literature reviews on BP dynamicity

\section{Comparison of papers on BP dynamicity}

Here we present the results of comparison between papers on BP dynamicity. After the primary review of the full texts of papers, a set of 67 papers remained for in-depth analysis. It should be noted that similar papers from the same authors were merged by choosing the most complete and up to date paper. Figure 4 presents the number of papers on BP dynamicity selected for in-depth analysis varying by years. As can be seen from this figure, the number of papers on BP dynamicity rises slightly. The results of papers' assessments according to the predefined features of BP dynamicity (Table 4) is presented in Table 8 . They are discussed below by proceeding through each column and answering the previously defined research questions. The categorization of the analyzed papers according to the process dynamicity influencing features (Table 4) are presented in Annex 1.

Peer) Comput. Sci. reviewing PDF | (CS-2020:12:56750:2:0:NEW 24 May 2021) 
671

672

673

674

675

676

677

678

679

680

681

682

683

684

685

686

687

688

689

690

691

692

693

694

695

696

697

698

699

700

701

702

703

704

705

706

707

708

709

710

Figure 4. The number of papers on BP dynamicity selected for in-depth analysis by year

Table 8. Initial data on BP dynamicity

In Table 8, the first three columns $(1.1,1.2$, and 1.3) represent the dependency of all process instances from a predefined BP model, i.e., 1.1, 1.2, and 1.3 correspond to the features from Table 4 that influence process dynamicity. According to whether the process model is predefined or not, in $88 \%$ of the papers analyzed (59 papers), approaches consider BP dynamicity through the change of the existing process model by using: process variants, which are implemented by the restriction or extension of activities in a process instance (Rosa et al., 2017; Ayora et al., 2016; Hallerbach, Bauer \& Reichert, 2010); generic process model (Abderrahmane, Mili \& Boubaker, 2014) or process meta-model (Mattos et al., 2014), which is used to generate a process; or process cases (Sprovieri et al., 2016), when possible activities are known in advance (i.e., at design-time), but their sequencing is defined at run-time depending on the context. Other parts of the approaches analyzed (12\%: eight papers) consider that there is no predefined process model, i.e., the process is made up of process fragments (Haarmann et al., 2015) or composed of rules, like ECA rules in Mejia Bernal et al. (2010), which are selected at process instance runtime according to the context. Moreover, in only 45\% (30 papers) of approaches is it possible to modify activities at process instance run-time.

The next three columns (2.1-2.3) in Table 8, which correspond Table 4, allow us to investigate the extent to which a process is dependent on the context, which can change at run-time.

Columns 2.1 and 2.2 indicate the type of a context, i.e., external (technological evolution, new working methods, changes in laws, changes in the target goal, exceptions, economic requirements, etc. (Cognini et al., 2018)) or internal (such as an organization's resources). In about half of these papers, an external $(51 \%)$ or internal $(51 \%)$ context is considered, and in other part of papers context is not considered at all. In $27 \%$ both external and internal contexts are considered. In 58\% (39 papers) of approaches, a process instance can react to the change in an external and/or internal context at run-time.

The third set of columns (3.1-3.4) shows the use of rules in approaches. As can be seen from column 3.1, 82\% (55 papers) of approaches use rules (van Eijndhoven, Iacob \& Ponisio, 2008; Mejia Bernal et al., 2010; Santo Carvalho et al., 2013) or policies (Cao et al., 2009) to select the next activity in a process instance. However, only $9 \%$ (six papers) feature authors discussing changes in rules (3.2) and reacting to those changes (3.3) during process instance run-time. In $30 \%$ (20 papers), rules are used for other purposes, such as transformation rules that are used to generate process variants from patterns in (Abderrahmane, Mili \& Boubaker, 2014).

The fourth column, in essence, repeats or summarizes whether the proposed approach allows changes (change of activities, change of context, and change of rules) in a process instance at run-time. We found that $82 \%$ (55 papers) of the papers analyzed consider changes at process instance run-time.

Peer] Comput. Sci. reviewing PDF | (CS-2020:12:56750:2:0:NEW 24 May 2021) 
711 The fifth set of columns (5.1-5.5) presents the accumulation of experience of BP dynamicity. It 712 was found that only 18\% (12 papers) use historical data for some purpose, such as data mining, 713 to generate possible process variables in (Abderrahmane, Mili \& Boubaker, 2014), or to build a 714 model in (Mattos et al., 2014). Only 8\% (five papers) calculate values, including time, cost, etc., 715 for each executed process instance and use them to improve process results.

716 The sixth column considers whether a process is goal-oriented or not. As can be seen from the 717 results obtained, in only $28 \%$ (19 papers) of cases is there mention of the goal-orientation of a

718 process. We might conclude that other approaches assume that their processes are goal-oriented, 719 but do not express as much explicitly.

720 The seventh column shows the usage of ontology in their approaches. Our research indicated that 721 ontology is used for process model creation or knowledge about domain extraction in only $15 \%$

722 (10 papers) of approaches. The eighth set of columns (8.1 and 8.2) is used to present the 723 completeness of the description of the proposed approach. As we found, all approaches are 724 described in some way, and 37\% (25 papers) of papers present a formal or semi-formal 725 description of the proposed approach by using formulas.

726 The ninth set of columns (9.1-9.5) presents an approach to implementing BP dynamicity. In 31 727 papers, authors consider a variant-based approach, in four papers - a case-handling approach, in 72811 papers - a declarative approach, in 12 papers - a goal-based approach, and in 11 papers - an 729 "other" approach. These "other" approaches include a policy-based approach and a generic 730 process model for workflow management (Cao et al., 2009), cognitive models and a function731 behavior-structure (FBS) model (Kannengiesser et al., 2014), or service relationships (Kapuruge, 732 Han \& Colman, 2011). The tenth set of columns (10.1-10.5) is intended to describe the 733 implementation perspective of approaches. As evidenced, 75\% (50 papers) of papers had a case 734 study and/or prototype description of their approaches. In 73\% (49 papers), a clear description of 735 an implementation with text, screen shots, and code lines was presented. Only 18\% (12 papers) 736 presented validation of the results obtained, whether from experts or other such sources.

737 The answers for question 10.2 are summarized below in Table 9, to avoid enlarging Table 8.

738

739 Table 9. Technology, language or other approaches used in the implementation section of the 740 papers analyzed

741

742 The analysis of question 10.2 demonstrates that the most popular architecture used for the 743 implementation of DBP is SOA (49\%, 33 papers of the 67 analyzed). Among popular languages 744 for BP modeling are BPMN (22.39\%, used in 15 papers) and BPEL (15\%, used in 10 papers). In 745 five papers $(7.46 \%)$, the authors do not provide any information about implementation, with the 746 exception of some descriptive examples. Other implementation aspects are also interesting, as 747 with the usage of rule engines, e.g., Jboss Drools 5.1 in (Abderrahmane, Mili \& Boubaker, 748 2014), Jess Java rule Engine (Mounira \& Mahmoud, 2010; Wang \& Wang, 2006), Goh with 749 IBM WebSphere Business Modeler (Ramakrishnan, 2009). For other aspects of implementation 750 see the "Implementation aspects of DBP" section. 
751 The last set of columns (11.1 and 11.2) shows that 96\% (64 papers) had conclusions, and 18\%

752 (12 papers) discussed their results.

753 According to Table 8, possible values of ranking are in the interval $[0 ; 24]$ and possible values of

754 rigor are in the interval $[0 ; 13]$. However, as can be seen from Table 8, Figure 5, and Figure 6, all

755 of the papers analyzed fall within the ranking interval of $[1.5 ; 17]$ and the rigor interval of $[2 ; 9]$.

756 Moreover, the rigor of papers has been divided into intervals as follows:

$757-[2 ; 4)$ - low rigor, i.e., the paper has a poor description of an approach, an implementation, and

758 a discussion with conclusions ( 2 papers of 67 , colored in blue).

$759 \bullet[4 ; 7)$ - middle rigor, i.e., the paper has a fair description of these elements (46 papers of 67 ,

760 colored in red).

$761-[7 ; 9]$ - high rigor, i.e., the paper has strong a description of these elements (19 papers of 67,

762 colored in green).

763 According to ranking, papers have been divided into intervals, also, as follows:

$764 \cdot[1 ; 7)$ - low ranking, i.e., the paper has a low level of dynamicity presented by their approach.

765 In such papers the aspects analyzed (see Table 4) have weak descriptions or are not mentioned at

766 all (30 papers of 67$)$.

$767 \bullet[7 ; 14)$ - middle ranking, i.e., the paper has a fair level of dynamicity presented by their

768 approach. In such papers the aspects analyzed (see Table 4) have a fair description or some of the

769 analyzed aspects, such as process model, context or rules, and implementation, have strong

770 descriptions (35 papers of 67).

$771 \cdot[14 ; 22]$ - high ranking, i.e., the paper has a fair or strong description of all of the aspects

772 analyzed (2 papers of 67$)$.

773 Summing up, the majority of papers have middle or high rigor and low or middle ranking (Figure

7745 and Figure 6).

775 In Figure 5, we present the ranking of papers, calculated based on the results presented in Table

7768 , according to the year of each papers' publication. The size of the bubbles depends on the rigor

777 of papers per year. As can be seen from the figure, there are two periods - 2008-2011 (30

778 publications) and 2014-2016 (22 publications) - when more papers on the topic of BP

779 dynamicity were published.

780

781 Figure 5. Ranking of papers according to rigor

782

783 The number of papers according to their rigor and ranking during the two identified periods

784 (2008-2011 and 2014-2016) are presented in Table 10.

785

786

787

788

789

790

Table 10. Number of papers according to their rigor and ranking during periods

As can be seen from Table 10, in 2008-2011 half of the papers have high rigor (15 papers of 30). The remainder of the papers have low (12 papers of 30) or middle (three papers of 30) rigor in this period. In 2014-2016, almost half of the papers have high rigor (14 papers of 30). The 
791 remainder of the papers have low (two papers of 30) or middle (nine papers of 30) rigor in this

792

793

794

795

796

797

798

799

800

801

802

803

804

805

806

807

808

809

810

811

812

813

814

815

816

817

818

819

820

821

822

823

824

825

826

827

828

829

830

period. In 2008-2011, half of the papers analyzed have a low ranking, and the other half of the papers have a middle ranking (15 papers of 22). In 2014-2016, half of the papers (11 papers of 22 ) have a low ranking. The remainder of the papers have a middle ( 9 papers of 220 ) or high (2 papers of 22) ranking in this period.

In Figure 6, we present the ranking of dependency based on the rigor of papers. The size of the bubbles depends on the number of papers with the same ranking-rigor score. The red lines represent intervals of rigor and ranking, as described previously.

Figure 6. Overview of rigor-ranking scores for the papers

The number of papers according to the rigor-ranking scores are presented in Table 11.

Table 11. The number of papers according to the rigor-ranking scores

As can be seen from Table 11, the largest portion of the papers is distributed in the interval of middle to high rigor and middle to high ranking (63 papers of 67). The remaining other sets are much smaller (see Table 11 and Figure 6).

In Figure 7, we have presented the summed dependency of rankings according to the papers' publication years. The size of the bubbles depends on the rigor of the papers. Ranking and rigor is summarized by the years, and from this figure we can see that all studies can be divided into four sets as listed below:

1. Set "A" (the earlier period of 2005 - 2007) - papers of this period have low or middle rigor [2; 6 ) and low or middle ranking $[7 ; 14)$.

2. Set "B" (the middle period of 2008 - 2011) - papers of this period have above the middle rigor $[4 ; 6)$ and above the middle ranking $[7 ; 14)$.

3. Set "C+D" (the later period of $2012-2018$ ) - papers of this period have different rigor and ranking, starting from low values and finishing at high values.

In Figure 7, a sequence of numbers (red bubbles) shows the number of papers per year.

Figure 7. Ranking of papers according to years

The numbers of papers according to the rigor-ranking scores in the periods identified are presented in Table 12.

Table 12. Numbers of papers according to the rigor-ranking scores in identified periods

As can be seen from Table 12 and Figure 7, the tendency of distribution of papers according to the rigor-ranking scores in the periods identified remained the same. The largest portion of papers have a high rigor and a middle ranking. Another large, but slightly smaller, set of papers

Peer) Comput. Sci. reviewing PDF | (CS-2020:12:56750:2:0:NEW 24 May 2021) 
831 has a middle rigor and a low or middle ranking. Other sets are generally much smaller (see Table 83212 and Figure 7).

833 To analyze the evolution of research, Figure 8 shows how the variables of rigor and relevance

834 have changed over time together with the number of papers included each year. Rigor and 835 relevance are scored on the left $y$-axis, while the number of papers is given on the right y-axis.

836 Rigor is in a range of $[3.83 ; 8.00]$. Ranking is in a range of $[5.50 ; 13.00]$. The results indicate an 837 improvement in both rigor and ranking (see the linear trend line for both AVG Ranking and 838 AVG Rigor).

839

840

841

842 Implementation aspects of DBP

843 As our primary research, as presented in (Vasilecas, Kalibatiene \& Lavbič, 2016) was on DBP

844 modeling and simulation approaches and tools, in this section we review the implementation

845 architectures proposed in the papers analyzed.

846 More detailed analysis of the implementation perspectives of the selected papers was conducted

847 because of the practical interest. The authors (Hermosillo, Seinturier \& Duchien, 2010;

848 Hermosillo, 2012) propose the CEVICHE framework and deal with the architecture for DBP

849 adaptation. The main drawback of the suggested approach is that decision or variation point and

850 adaptation rules should be predefined in the BP model and CEVICHE can only handle known

851 specific cases (Pourshahid et al., 2012). Thus, the proposed framework is not general and can be

852 used to execute already known alternative processes after detecting predefined situations. The

853 authors of (van der Aalst, Weske \& Grünbauer, 2005) identified and classified the main entities

854 of case handling systems in a meta-model and implemented it in the case-handling system

855 FLOWer using a realistic example. Moreover, as the authors (van der Aalst, Weske \&

856 Grünbauer, 2005) stated, more flexibility may pose many problems, ranging from unauthorized

857 actions to incomplete cases. The authors of (van der Aalst, Pesic \& Schonenberg, 2009) state that

858 the main limitations of their proposed declarative approach are as follows: a) a constraint-based

859 approach is not very suitable for processes that are of a strict procedural nature; b) declarative

860 workflow specifications may be less readable if many (interacting) constraints are added; and c)

861 the efficiency of the Declare engine decreases when dealing with large specifications.

862 Among existing PAIS, there are highlighted: YAWL (van Der Aalst \& Ter Hofstede, 2005),

863 Flower (Dumas, van der Aalst \& Ter Hofstede, 2005), DECLARE (Pesic \& van der Aalst, 2006,

864 September) and ADEPT (Reichert, Rinderle \& Dadam, 2003), where each supports flexibility in

865 a different way. As authors of (Santo Carvalho, Santoro \& Revoredo, 2015) state that none of

866 them support adaptation in terms of adequacy for business, but only in ensuring that any

867 adjustment will not somehow corrupt the process. Moreover, the analysis and consequent

868 changes proposed in these PAIS are done manually. A decision on adaptation is not recorded,

869 nor is an analysis made regarding it. 
870 In (Hallerbach, Bauer \& Reichert, 2010), a number of Provop process variants are defined and 871 proposed through a set of change operations in Provop, which forces the deployment of all 872 process variants using conditional branching. According to (Ayora et al., 2012, September; 873 2012), this is not an example of real adaptability, as all alternatives are transformed into 874 executable versions.

875 Authors of (Jiang et al., 2016) found that expressing dynamicity through constraint-based

876 declarative approaches are not good at precisely describing the procedure of process models,

877 tending to describe all the activities of the process model and the main constraints describing the 878 relationships among these activities, as DECLARE (Pesic, Schonenberg \& van der Aalst, 2007)

879 and ConDec (Pesic \& van der Aalst, 2006). They therefore have to work together with 880 imperative approaches.

881 An approach presented in (Jiang et al., 2016) is based on vertical and horizontal activity 882 refinement. However, as the authors state, the dynamic refinement of flexible activities remains a 883 challenge in the modeling and application of flexible workflows. Authors of (Jiang, Li \& Yang, 884 2017) propose the use of a knowledge tree and various constraints to solve this issue.

885 As the analysis shows, the most significant part of these approaches is implemented as a case 886 study (as in (Mejia Bernal et al., 2010; Hermosillo, Seinturier \& Duchien, 2010), or the 887 automation of the proposed approach at some level.

\section{Analysis of the existing tools on DBP modeling and simulation}

889 For more comprehensive study, some BP modeling and simulation tools are compared in Table

89013 according to the previously defined requirements (DBPR). Table 13 shows whether a system 891 provides full $(+)$, partial (+/-) or no support (-) for a particular feature (see DBPR).

892

893

894

895

896

897

898

899

900

901

902

903

904

Table 13. Comparison of DBP modeling and simulation tools

We can determine from Table 13 that all of the five tools analyzed need an initial BP model (1). This limits the dynamicity of BP. All BP modeling and simulation tools allow the allocation of resources to activities (2.1). In some analyzed tools, like IBM Websphere and Simprocess, it is possible to define not only the cost and time attributes of the resource, but also other attributes such as volume, color, etc. It is not possible to define external context (2.2) in all five analyzed tools. Whilst all of the tools support features of rule modeling within BP; none of them support an analysis of these rules at BP runtime (3.4). Usage of historical data (4) is supported in almost all of the tools analyzed (except AssuProcess). As can be seen from Table 13, existing tools are well developed to model, analyze, and simulate static BP (5). However, those tools are not suitable for the proper simulation/execution of DBP.

905 Discussion, answers to the research questions and future work

906 In this section, we present the discussion regarding the results obtained on BP dynamicity, and 907 therefore the answers to the research questions posed in this paper.

908 The most frequently proposed approaches on BP dynamicity deal with the predefined process 909 model, in which some dynamicity is ensured through changing a process model or a process 
910 instance at the design stage or at run-time by adding or restricting some behavior. However, 911 adaptation or customization of a process based on a predefined process model allows the 912 achievement of only some level of dynamicity (RQ1). Some authors propose the generation of a 913 process model or its instance from a set of activities or process fragments. These fragments can 914 vary according to the contexts and rules at process instance run-time. In many cases, however, 915 activities or fragments, variants, and rules are predefined that limit process dynamicity (RQ1). In 916 some domains, it is difficult or impossible to predict all possible changes of a context and thus 917 predefine possible sequences of activities, fragments, or rules. Therefore, the most dynamic BP 918 should not have a predefined set and sequence of activities. Instead, a goal should be known and 919 defined. One way to achieve the goal is to apply a multi criteria process optimization. A goal920 oriented approach implies a focus on achieving some state in the system's resources, instead of 921 the execution of a predefined set and sequence of activities. The primary advantage of this 922 approach is that we achieve more dynamicity and the strong goal-orientation of a BP (RQ1). 923 According to (Cangemi \& Taylor, 2018), artificial intelligence (AI) can provide support in 924 choosing the next most suitable activity at process instance run-time, i.e., answering the question 925 of which activity should be executed. As processes become increasingly branched and 926 individualized early, AI can help to route the respective flow units through the process (Satyal et 927 al., 2018, October). Additionally, AI-algorithms can determine patterns in the data and create 928 new process variants, as the process is being executed in the shadows, without affecting 929 customers or process actors (Satyal et al., 2018, October). We offer the dynamicity of BP 930 obtained through BRs, as presented in (Vasilecas, Kalibatiene \& Lavbič, 2016). Moreover, in 931 this research the topic of AI is out of scope.

932 During the analysis of BP dynamicity in the papers selected, the difference of approaches lies 933 largely at the process instance level. These differences are as follows: whether the process 934 instance can be changed at run-time and to what extent; whether the process instance responds to 935 changes in the internal and external contexts; whether there are any rules for choosing the next 936 activity for the execution; whether the process instance is executed according to the process goal; 937 and whether the process instance uses the experience gained previously (RQ2).

938 We can now define the main features of a dynamic BP (RQ3) (see Table 14), which are 939 determined based on this SLR. As can be seen from the obtained results, the most relevant 940 features are the following: rule-based, changes at run-time, context-sensitive, and DBP 941 feasibility. The importance of the rule-based feature can be explained by the phenomenon that 942 BRs are widely agreed between researchers and practitioners as a way to express business 943 knowledge and govern BP (Valente et al., 2016; Valente et al., 2016, November; Vasilecas, 944 Kalibatiene \& Lavbič, 2016). Consequently, there is a number of researches appling busyiness 945 rules for ensuring BP dynamicity. The changes at run-time feature reflect the business's need to 946 adapt to changing environmental conditions continually. The importance of the context-sensitive 947 feature means that for the successful BP it should react not only to the changing environment, 948 but also to the needs of the customer. Finally, DBP should be implemented in a particular way to 949 support its business effectively. 
950

951

952

953

954

955

956

957

958

959

960

961

962

963

964

965

966

967

968

969

970

971

972

973

974

975

976

977

978

979

980

981

982

983

984

985

986

987

988

989

Table 14. Main features of a dynamic BP (RQ3)

Other found DBP features (i.e., goal-oriented, accumulation of experience, align with a process ontology and not predefined process model) are not so common with comparison to the previously discussed features. This is because those features are not directly expressed in a process model. BPs are designed and implemented into software systems to achieve business goals. However, many existing classic BP modeling approaches do not provide means for the direct expression of a business goal. Most often, the goal is expressed in BP by BRs. The same is with ontology, i.e., it is usually meant but not directly expressed and used for BP modeling. Summing up, the automation of nowadays BP cannot be achieved by solely focusing on process activities and using classical BP modeling techniques. It requires a holistic approach that also captures the business environment's social aspects, such as corporate strategies, organization policies, negotiations, and cooperation (Kir \& Erdogan, 2021).

The results obtained highlight the main limitations and gaps related to dynamic BP (RQ4). In the research area, surrounding this topic there is a lack of research and approaches that consider how dynamic BP achieves a goal and how this is implemented. The advantages of the mining and usage of historical data is well known in different areas. However, there are no approaches relating to the accumulation of experience during dynamic process execution and subsequent use of it for more effective goal implementation. A limited amount of research and approaches enable the rule changing during process instance execution, which is especially important when working with long-running processes.

An in-depth analysis of the selected papers, according to their perspectives on implementation, shows that the implementation and collection of experimental results remains insufficient in most research projects. Therefore, DBP modeling and implementation still requires more research. The analysis of the selected literature reviews on BP dynamicity shows that they are not analyzing dynamicity as a feature of a BP (RQ5). They analyze process variability, but not enough attention is placed on BP dynamicity. Gaps in literature reviews still remain, primarily in presenting a research methodology, considering threats to validity, and the quality of assessment of the search performed.

Moreover, the analysis of the visualized results allows us to state that a portion of these papers lack a clear description of the approaches presented. The largest portion of these papers have no description of the proposed approach, lack models on DBP in a formal language, and have no evaluation of the results obtained. At first glance, the majority of papers have some implementation of the proposed approach by presenting a case study, simulation examples, or a prototype. However, these are not complete, and perhaps the lack of an evaluation of the results obtained can be explained by the complexity of this task (RQ6).

\section{Conclusions}

In this paper, we have presented a literature review on DBP. After applying a research procedure based on keywords and inclusion and exclusion quality criteria, we identified 67 papers for

PeerJ Comput. Sci. reviewing PDF | (CS-2020:12:56750:2:0:NEW 24 May 2021) 
990 detailed study. Those papers were assessed based on the features defined, which allowed us to 991 determine a scientific ranking, denoting the level of dynamicity of the presented approach, and 992 rigor. We were also able to denote the level of description of the approach presented in each 993 paper, and to answer the research questions initially defined in this paper.

994 The processed and visualized results allow us to determine that the approaches presented reach 995 the middle level of dynamicity. We are also able to note that topics remain for further

996 development, such as the presence or absence of a more dynamic initial process model, the usage 997 of historic data for BP dynamicity including quality cost calculation, goal-orientation in DBP, 998 and the semantics of DBP.

999 The analysis of the selected approaches allows us to identify the main features of DBP as 1000 follows: an undefined process model; process instances that respond to the changing context; the 1001 sequence of process activities and content of each activity being dependent on rules; all possible 1002 changes being able to be made by any role involved at process instance run-time with possibly 1003 low latency; the selection of each process activity being aligned with a process goal; all process 1004 components being aligned with a process ontology; the selection of each process activity being 1005 aligned with historical data; and the feasibility of the process being ensured.

1006 According to the analysis of literature reviews on DBP, they tend to analyze the variability of 1007 processes, but not enough attention is given to BP dynamicity. The main issues in literature 1008 reviews remain in presenting a research methodology, threats to validity, and the quality 1009 assessment of the search being performed.

1010 The following future directions are defined:

1011

1012

1013

1014

1015

1016

1017

1018

1019

1020

1021

1022

1023

1024

1025

1026

1027

1028

1029

1030

- in depth analysis of modeling languages and standards that cover DBP;

- an interdependence analysis among the defined research questions;

- in depth analysis of context in the definition of DBP (i.e., how authors define and model these contexts? What is the relationship between ontologies and context models?);

- in depth analysis of technical details about modeling and implementing of DBP;

- extending the current study by including the newest papers on DBP;

- performing a statistical analysis of the obtained results.

\section{Acknowledgments}

The authors wish to thank Marlon Dumas for his feedback on a draft of this article.

\section{References}

Abderrahmane, L., Mili, H., \& Boubaker, A. (2014). REA-based business process adaptation. In 2014

IEEE 11th International Conference on e-Business Engineering (pp. 74-82). Guangzhou: IEEE. https://doi.org/10.1109/ICEBE.2014.24

Aiello, M., Bulanov, P., \& Groefsema, H. (2010). Requirements and tools for variability management. In 2010 IEEE 34th Annual Computer Software and Applications Conference Workshops (pp. 245-250). Seoul: IEEE. https://doi.org/10.1109/COMPSACW.2010.50

Alférez, G. H., Pelechano, V., Mazo, R., Salinesi, C., \& Diaz, D. (2014). Dynamic adaptation of service compositions with variability models. Journal of Systems and Software, 91, 24-47. https://doi.org/10.1016/j.jss.2013.06.034 
1031

1032

1033

1034

1035

1036

1037

1038

1039

1040

1041

1042

1043

1044

1045

1046

1047

1048

1049

1050

1051

1052

1053

1054

1055

1056

1057

1058

1059

1060

1061

1062

1063

1064

1065

1066

1067

1068

1069

1070

1071

1072

1073

1074

1075

Asuncion, C. H., Iacob, M. E., \& van Sinderen, M. J. (2010, October). Towards a flexible service integration through separation of business rules. In 2010 14th IEEE International Enterprise Distributed Object Computing Conference (pp. 184-193). Vitoria: IEEE. https://doi.org/10.1109/EDOC.2010.10

Awadid, A., \& Gnannouchi, S. A. (2015). Approach Based on Web Services for Business Process Adaptation. Procedia Computer Science, 64, 832 - 837. https://doi.org/10.1016/j.procs.2015.08.635

Ayora, C., Torres, V., de la Vara, J. L., \& Pelechano, V. (2016). Variability management in process families through change patterns. Information and Software Technology, 74, 86-104. https://doi.org/10.1016/j.infsof.2016.01.007

Ayora, C., Torres, V., Pelechano, V., \& Alférez, G. H. (2012). Applying CVL to business process variability management. In Proc. of the VARiability for You Workshop on Variability Modeling Made Useful for Everyone (VARY'12) (pp. 26-31). New York: ACM Press. https://doi.org/10.1145/2425415.2425421

Ayora, C., Torres, V., Reichert, M., Weber, B., \& Pelechano, V. (2012, September). Towards run-time flexibility for process families: open issues and research challenges. In International Conference on Business Process Management (pp. 477-488). Springer, Berlin, Heidelberg.

Ayora, C., Torres, V., Weber, B., Reichert, M., \& Pelechano, V. (2015). VIVACE: A framework for the systematic evaluation of variability support in process-aware information systems. Information and Software Technology, 57, 248-276. https://doi.org/10.1016/j.infsof.2014.05.009

Baresi, L., \& Guinea, S. (2005). Towards Dynamic Monitoring of WS-BPEL Processes. In Benatallah B., Casati F., Traverso P. (eds) Service-Oriented Computing - ICSOC 2005. ICSOC 2005. LNCS 3826. Heidelberg: Springer. https://doi.org/10.1007/11596141_21

Bizagi. (2015). Understanding Ad Hoc Processes. Accessed January 2016: http://help.bizagi.com/bpmsuite/en/index.html?understanding_ad_hoc_processes.htm.

Boffoli, N., Caivano, D., Castelluccia, D., \& Visaggio, G. (2012). Driving flexibility and consistency of business processes by means of product-line engineering and decision tables. In Proc. of the Third International Workshop on Product LinE Approaches in Software Engineering (pp. 33-36). IEEE Press. https://doi.org/10.1109/PLEASE.2012.6229767

Boffoli, N., Cimitile, M., \& Maggi, F. M. (2009). Managing Business Process Flexibility and Reuse through Business Process Lines. In ICSOFT (2) (pp. 61-68).

Bögl, A., Natschläger, C., \& Geist, V. (2016). Towards flexibility in business processes by mining process patterns and process instances. In 4th International Conference on Model-Driven Engineering and Software Development (MODELSWARD) (pp. 469-476). IEEE.

Borrego, D., \& Barba, I. (2014). Conformance checking and diagnosis for declarative business process models in data-aware scenarios. Expert Systems with Applications, 41(11), 5340-5352. https://doi.org/10.1016/j.eswa.2014.03.010

Bucchiarone, A., Marconi, A., Pistore, M., \& Raik, H. (2017). A context-aware framework for dynamic composition of process fragments in the internet of services. Journal of Internet Services and Applications, 8(1), 6. https://doi.org/10.1186/s13174-017-0057-0

Bucchiarone, A., Mezzina, C., \& Pistore, M. (2013). CAptLang: a language for context-aware and adaptable business processes. In Proc. of the Seventh International Workshop on Variability Modelling of Software-intensive Systems (p. 12). ACM. https://doi.org/10.1145/2430502.2430519

Bucchiarone, A., Pistore, M., Raik, H., \& Kazhamiakin, R. (2011). Adaptation of service-based business processes by context-aware replanning. In 2011 IEEE International Conference on Service-Oriented Computing and Applications (SOCA) (pp. 1-8). IEEE. https://doi.org/10.1109/SOCA.2011.6166209

Cangemi, M. P., \& Taylor, P. (2018). Harnessing Artificial Intelligence to Deliver Real-Time Intelligence and Business Process Improvements. EDPACS, 57(4), 1-6.

Peer] Comput. Sci. reviewing PDF | (CS-2020:12:56750:2:0:NEW 24 May 2021) 
1076

1077

1078

1079

1080

1081

1082

1083

1084

1085

1086

1087

1088

1089

1090

1091

1092

1093

1094

1095

1096

1097

1098

1099

1100

1101

1102

1103

1104

1105

1106

1107

1108

1109

1110

1111

1112

1113

1114

1115

1116

1117

1118

1119

1120

1121

Cao, J., Chen, J., Zhao, H., \& Li, M. (2009). A policy-based authorization model for workflow-enabled dynamic process management. Journal of Network and Computer Applications, 32(2), 412 - 422. https://doi.org/10.1016/j.jnca.2008.02.021

Châtel, P., Malenfant, J., \& Truck, I. (2010). QoS-based late-binding of service invocations in adaptive business processes. In 2010 IEEE International Conference on Web Services (ICWS) (pp. 227-234). IEEE. https://doi.org/10.1109/ICWS.2010.74

Cherif, S., Djemaa, R. B., \& Amous, I. (2015). SABPEL: Creating self-adaptive business processes. In 2015 IEEE/ACIS 14th International Conference on Computer and Information Science (ICIS) (pp. 619626). IEEE.

Cognini, R., Corradini, F., Gnesi, S., Polini, A., \& Re, B. (2014). Research challenges in business process adaptability. In the 29th Annual ACM Symposium on Applied Computing (pp. 1049-1054). ACM. https://doi.org/10.1145/2554850.2555055

Cognini, R., Corradini, F., Gnesi, S., Polini, A., \& Re, B. (2018). Business process flexibility-a systematic literature review with a software systems perspective. Information Systems Frontiers, 20(2), 343-371. https://doi.org/10.1007/s10796-016-9678-2

Coutaz, J.; Crowley, J.; Dobson, S.; Garlan, D. (2005). Context is key. Communications of the ACM, 48(3), 49-53. https://doi.org/10.1145/1047671.1047703

Czepa, C., Tran, H., Zdun, U., Kim, T. T. T., Weiss, E., \& Ruhsam, C. (2016). Ontology-based behavioral constraint authoring. In 2016 IEEE 20th International Enterprise Distributed Object Computing Workshop (EDOCW)(pp. 1-8). IEEE. https://doi.org/10.1109/EDOCW.2016.7584380

Dadam, P., \& Reichert, M. (2009). The ADEPT project: a decade of research and development for robust and flexible process support. Computer Science-Research and Development, 23(2), 81-97. https://doi.org/10.1007/s00450-009-0068-6

Deb, D., Chaki, N., \& Ghose, A. (2015). Business Process Generation by Leveraging Complete Search over a Space of Activities and Process Goals. In the 5th International Conference on Cloud Computing and Services Science - Volume 1: CLOSER (pp. 233-240). http://dx.doi.org/10.5220/0005408702330240

Demeyer, R., van Assche, M., Langevine, L., \& Vanhoof, W. (2010). Declarative workflows to efficiently manage flexible and advanced business processes. In the 12th international ACM SIGPLAN symposium on Principles and practice of declarative programming (pp. 209-218). ACM. https://doi.org/10.1145/1836089.1836116

Dumas, M., van der Aalst, W., \& Ter Hofstede, A. (Eds.). (2005). Process aware information systems (Vol. 1). Chichester: Wiley.

Dyba, T., \& Dingsoyr, T. (2008). Empirical studies of agile software development: A systematic review. Information and software technology, 50(9-10), 833-859.

Eshuis R. (2018) Feature-Oriented Composition of Declarative Artifact-Centric Process Models. In Weske M., Montali M., Weber I., vom Brocke J. (eds) Business Process Management. BPM 2018. LNCS 11080. Cham: Springer. https://doi.org/10.1007/978-3-319-98648-7 5

Goedertier S., Vanthienen J. (2006) Designing Compliant Business Processes with Obligations and Permissions. In: Eder J., Dustdar S. (eds) Business Process Management Workshops. BPM 2006. LNCS 4103. Berlin, Heidelberg: Springer. https://doi.org/10.1007/11837862_2

Goedertier, S., Vanthienen, J., \& Caron, F. (2015). Declarative business process modelling: principles and modelling languages. Enterprise Information Systems, 9(2), 161-185. https://doi.org/10.1080/17517575.2013.830340

Gong, Y., \& Janssen, M. (2012). From policy implementation to business process management: Principles for creating flexibility and agility. Government Information Quarterly, 29, S61-S71. https://doi.org/10.1016/j.giq.2011.08.004

Peer] Comput. Sci. reviewing PDF | (CS-2020:12:56750:2:0:NEW 24 May 2021) 
1122

1123

1124

1125

1126

1127

1128

1129

1130

1131

1132

1133

1134

1135

1136

1137

1138

1139

1140

1141

1142

1143

1144

1145

1146

1147

1148

1149

1150

1151

1152

1153

1154

1155

1156

1157

1158

1159

1160

1161

1162

1163

1164

1165

1166

Gottschalk, F., van der Aalst, W. M., Jansen-Vullers, M. H., \& Verbeek, H. M. W. (2008). Protos2CPN: Using colored Petri nets for configuring and testing business processes. International Journal on Software Tools for Technology Transfer, 10(1), 95-110. https://doi.org/10.1007/s10009-007-0055-9

Haarmann, S., Podlesny, N., Hewelt, M., Meyer, A., \& Weske, M. (2015). Production Case Management: A Prototypical Process Engine to Execute Flexible Business Processes. In BPM (Demos) (pp. 110-114).

Hallerbach, A., Bauer, T., \& Reichert, M. (2010). Capturing variability in business process models: the Provop approach. Journal of Software Maintenance and Evolution: Research and Practice, 22(6-7), 519-546. https://doi.org/10.1002/smr.491

Heinl, P., Horn, S., Jablonski, S., Neeb, J., Stein, K., \& Teschke, M. (1999). A comprehensive approach to flexibility in workflow management systems. In ACM SIGSOFT Software Engineering Notes (Vol. 24, No. 2, pp. 79-88). ACM. https://doi.org/10.1145/295665.295675

Hermosillo, G. (2012). Towards Creating Context-Aware Dynamically-Adaptable Business Processes Using Complex Event Processing. Software Engineering. Université des Sciences et Technologie de Lille - Lille I. English. <tel-00709303>.

Hermosillo, G., Seinturier, L., \& Duchien, L. (2010a). Using complex event processing for dynamic business process adaptation. In IEEE International Conference on Services Computing (SCC), 2010 (pp. 466-473). IEEE. https://doi.org/10.1109/SCC.2010.48

Hu G., Wu B., Chen J. (2014) Dynamic Adaptation of Business Process Based on Context Changes: A Rule-Oriented Approach. In Lomuscio A.R., Nepal S., Patrizi F., Benatallah B., Brandić I. (eds) Service-Oriented Computing - ICSOC 2013 Workshops. ICSOC 2013. LNCS 8377. Cham: Springer. https://doi.org/10.1007/978-3-319-06859-6 43

Ivarsson, M., \& Gorschek, T. (2011). A method for evaluating rigor and industrial relevance of technology evaluations. Empirical Software Engineering, 16(3), 365-395. https://doi.org/10.1007/s10664-0109146-4

Jalali, S., \& Wohlin, C. (2012). Systematic literature studies: database searches vs. backward snowballing. In the ACM-IEEE international symposium on Empirical software engineering and measurement (pp. 29-38). Lund: ACM. https://doi.org/10.1145/2372251.2372257

Jiang, Y., Li, W., \& Yang, J. (2017). A dynamic refinement approach for flexible activity based on knowledge tree and constraints. CAAI Transactions on Intelligent Systems, (2), 4.

Jiang, Y., Xiao, N., Zhang, Y., \& Zhang, L. (2016). A novel flexible activity refinement approach for improving workflow process flexibility. Computers in Industry, 80, 1-15. https://doi.org/10.1016/j.compind.2016.03.002

Jimenez-Ramirez, A., Barba, I., \& Del Valle, C. (2018). Towards a new Tool for Managing Declarative Temporal Business Process Models. (accepted no published). https://biblioteca.sistedes.es/submissions/descargas/2018/JCIS/2018-JCIS-020.pdf

Kannengiesser, U., Radmayr, M., Heininger, R., \& Meyer, N. (2014). Generating subject-oriented process models from ad-hoc interactions of cognitive agents. In the 2014 IEEE/WIC/ACM International Joint Conferences on Web Intelligence (WI) and Intelligent Agent Technologies (IAT)-Vol. 03 (pp. 440-446). IEEE Computer Society. https://doi.org/10.1109/WI-IAT.2014.200

Kapuruge, M., Han, J., \& Colman, A. (2010). Support for business process flexibility in service compositions: An evaluative survey. In 21st Australian Software Engineering Conference (ASWEC), 2010 (pp. 97-106). IEEE. http://doi.ieeecomputersociety.org/10.1109/ASWEC.2010.27

Kapuruge, M., Han, J., \& Colman, A. (2011). Controlled flexibility in business processes defined for service compositions. In 2011 IEEE international conference on Services computing (SCC) (pp. 346-353). IEEE. https://doi.org/10.1109/SCC.2011.80

Peer] Comput. Sci. reviewing PDF | (CS-2020:12:56750:2:0:NEW 24 May 2021) 
1167

1168

1169

1170

1171

1172

1173

1174

1175

1176

1177

1178

1179

1180

1181

1182

1183

1184

1185

1186

1187

1188

1189

1190

1191

1192

1193

1194

1195

1196

1197

1198

1199

1200

1201

1202

1203

1204

1205

1206

1207

1208

1209

1210

Khriss, I., Lévesque, E., Tremblay, G., \& Jacques, A. (2008). Towards adaptability support in collaborative business processes. In 2008 International MCETECH Conference on e-Technologies (pp. 34-45). IEEE. https://doi.org/10.1109/MCETECH.2008.25

Kiedrowicz, M. (2017). Dynamic business process in workflow systems. In MATEC Web of Conferences (Vol. 125, p. 02014). EDP Sciences.

Kim, D., Kim, M., \& Kim, H. (2007). Dynamic business process management based on process change patterns. In 2007 International conference on Convergence information technology (pp. 1154-1161). IEEE. https://doi.org/10.1109/ICCIT.2007.91

Kir, H., \& Erdogan, N. (2021). A knowledge-intensive adaptive business process management framework. Information Systems, 95, 101639.

Kitchenham, B. (2007). Guidelines for performing Systematic Literature Reviews in Software Engineering. Tech. rep., Keele University.

Kitchenham, B., Brereton, O. P., Budgen, D., Turner, M., Bailey, J., \& Linkman, S. (2009). Systematic literature reviews in software engineering-a systematic literature review. Information and software technology, 51(1), 7-15. https://doi.org/10.1016/j.infsof.2008.09.009

Li, H. X., \& Du, Y. Y. (2016). Business Process Adaptation Based on Process Variants. International Journal of Grid and Distributed Computing, 9(4), 121-134. https://doi.org/10.14257/ijgdc.2016.9.4.12

Liu, E., Wu, F., Pinel, F., \& Shan, Z. (2012). A two-tier data-centric framework for flexible business process management. In AMCIS 2012, 9.

Lu, R., Sadiq, S., \& Governatori, G. (2009). On managing business processes variants. Data \& Knowledge Engineering, 68(7), 642-664. https://doi.org/10.1016/j.datak.2009.02.009

Maggi, F.M., Westergaard, M., Montali, M., van der Aalst, W.M.P. (2012). Runtime Verification of LTLBased Declarative Process Models. In: Khurshid S., Sen K. (eds) Runtime Verification. RV 2011. LNCS 7186. Berlin, Heidelberg: Springer. https://doi.org/10.1007/978-3-642-29860-8 11

Marconi, A., Pistore, M., Sirbu, A., Eberle, H., Leymann, F., \& Unger, T. (2009). Enabling Adaptation of Pervasive Flows: Built-in Contextual Adaptation. In Baresi L., Chi CH., Suzuki J. (eds) ServiceOriented Computing. ServiceWave 2009, ICSOC 2009. LNCS 5900. (pp. 445-454). Berlin, Heidelberg: Springer. https://doi.org/10.1007/978-3-642-10383-4_33

Martinho, R., Domingos, D., \& Varajão, J. (2015). CF4BPMN: A BPMN Extension for Controlled Flexibility in Business Processes. Procedia Computer Science, 64, 1232-1239. https://doi.org/10.1016/j.procs.2015.08.509

Mattos, T. D. C., Santoro, F. M., Revoredo, K., \& Nunes, V. T. (2014). A formal representation for contextaware business processes. Computers in Industry, 65(8), 1193-1214. https://doi.org/10.1016/j.compind.2014.07.005

Mejia Bernal, J. F., Falcarin, P., Morisio, M., \& Dai, J. (2010). Dynamic context-aware business process: a rule-based approach supported by pattern identification. In the 2010 ACM Symposium on Applied Computing (pp. 470-474). ACM. https://doi.org/10.1145/1774088.1774186

Milani, F., Dumas, M., Ahmed, N., Matulevičius, R. (2016). Modelling families of business process variants: A decomposition driven method. Information Systems 56, 55-72. https://doi.org/10.1016/j.is.2015.09.003

Milanovic, M., Gasevic, D., \& Rocha, L. (2011). Modeling flexible business processes with business rule patterns. In 15th IEEE International Enterprise Distributed Object Computing Conference (EDOC) (pp. 65-74). IEEE. https://doi.org/10.1109/EDOC.2011.25

Peer) Comput. Sci. reviewing PDF | (CS-2020:12:56750:2:0:NEW 24 May 2021) 
1211

1212

1213

1214

1215

1216

1217

1218

1219

1220

1221

1222

1223

1224

1225

1226

1227

1228

1229

1230

1231

1232

1233

1234

1235

1236

1237

1238

1239

1240

1241

1242

1243

1244

1245

1246

1247

1248

1249

1250

1251

1252

1253

1254

1255

1256

Mounira, Z., \& Mahmoud, B. (2010). Context-aware process mining framework for Business Process flexibility. In the 12th International Conference on Information Integration and Web-based Applications \& Services (pp. 421-426). ACM. https://doi.org/10.1145/1967486.1967552

Mutschler, B., Weber, B., \& Reichert, M. (2008). Workflow management versus case handling: results from a controlled software experiment. In the 2008 ACM symposium on Applied computing (pp. 8289). ACM. https://doi.org/10.1145/1363686.1363711

Natschläger, C., Geist, V., Illibauer, C., \& Hutter, R. (2016). Modelling Business Process Variants using Graph Transformation Rules. In the 4th International Conference on Model-Driven Engineering and Software Development (pp. 65-74). SCITEPRESS - Science and and Technology Publications. https://doi.org/10.5220/0005665800650074

Nunes, V. T., Werner, C. M. L., \& Santoro, F. M. (2011). Dynamic process adaptation: A context-aware approach. In 15th International Conference on Computer Supported Cooperative Work in Design (CSCWD) (pp. 97-104). IEEE.

Oberhauser, R. (2016). A Hypermedia-Driven Approach for Adapting Processes via Adaptation Processes. In 8th International Conference on Advanced Software Engineering and Its Applications, ASEA 2015 (pp. 73-80). Institute of Electrical and Electronics Engineers Inc. https://doi.org/10.1109/ASEA

Pang S., Li Y., He H., Lin C. (2011) A model for dynamic business processes and process changes. Chinese Journal of Electronics, 20(4), 632-636.

Pesic M., \& van der Aalst W.M.P. (2006) A Declarative Approach for Flexible Business Processes Management. In Eder J., Dustdar S. (eds) Business Process Management Workshops. BPM 2006. LNCS 4103. Berlin, Heidelberg: Springer. https://doi.org/10.1007/11837862 18

Pesic M., Schonenberg M.H., Sidorova N., van der Aalst W.M.P. (2007) Constraint-Based Workflow Models: Change Made Easy. In Meersman R., Tari Z. (eds) On the Move to Meaningful Internet Systems 2007: CoopIS, DOA, ODBASE, GADA, and IS. OTM 2007. LNCS 4803. Berlin, Heidelberg: Springer. https://doi.org/10.1007/978-3-540-76848-7 7

Pesic, M., \& Van der Aalst, W. M. (2006, September). A declarative approach for flexible business processes management. In International conference on business process management (pp. 169-180). Springer, Berlin, Heidelberg.

Pesic, M., Schonenberg, H., \& van der Aalst, W. M. (2007). Declare: Full support for loosely-structured processes. In 11th IEEE International Enterprise Distributed Object Computing Conference (EDOC 2007) (pp. 287-287). IEEE.

Pourshahid, A., Amyot, D., Shamsaei, A., Mussbacher, G., \& Weiss, M. (2012). A systematic review and assessment of aspect-oriented methods applied to business process adaptation. Journal of Software, 7(8), 1816-1826. https://doi.org/10.4304/jsw.7.8.1816-1826

Prasad, R., Kumar, K. L., Paul, S. S., \& Prabha, U. S. S. (2015). Consumer centric dynamic business process customization of web service using ontology. In 2015 Science and Information Conference (SAI) (pp. 171-174). https://doi.org/10.1109/SAI.2015.7237141

Pucher, M.J. (2010). Agile-, AdHoc-, Dynamic-, Social-, or Adaptive BPM. Accessed January 2016: http://isismjpucher.wordpress.com/2010/03/30/dynamic-vs-adaptive-bpm/.

Ramakrishnan, S. (2009). On self-adaptive process-based dependable web service composition. In Computation World: Future Computing, Service Computation, Adaptive, Content, Cognitive, Patterns, ComputationWorld 2009 (pp. 173-179). https://doi.org/10.1109/ComputationWorld.2009.12

Reichert, M., \& Dadam, P. (2009). Enabling adaptive process-aware information systems with ADEPT2. In Handbook of Research on Business Process Modeling (pp. 173-203). IGI Global.

Reichert, M., \& Weber, B. (2012). Enabling flexibility in Process-Aware information systems: Challenges, Methods, Technologies. Springer Science \& Business Media.

Peer] Comput. Sci. reviewing PDF | (CS-2020:12:56750:2:0:NEW 24 May 2021) 
1257

1258

1259

1260

1261

1262

1263

1264

1265

1266

1267

1268

1269

1270

1271

1272

1273

1274

1275

1276

1277

1278

1279

1280

1281

1282

1283

1284

1285

1286

1287

1288

1289

1290

1291

1292

1293

1294

1295

1296

1297

1298

1299

1300

Reichert, M., Rinderle, S., \& Dadam, P. (2003). Adept workflow management system. In International Conference on Business Process Management (pp. 370-379). Springer, Berlin, Heidelberg.

Rong, W., Liu, K., \& Liang, L. (2008). Association Rule Based Context Modeling for Web Service Discovery. In 2008 10th IEEE Conference on E-Commerce Technology and the Fifth IEEE Conference on Enterprise Computing, E-Commerce and E-Services (pp. 299-304). IEEE. https://doi.org/10.1109/CECandEEE.2008.137

Rosa, M. L., Aalst, W. M. P. V. D., Dumas, M., \& Milani, F. P. (2017). Business Process Variability Modeling. ACM Computing Surveys, 50(1), 1-45. https://doi.org/10.1145/3041957

Rosemann, M., \& Recker, J. C. (2006). Context-aware process design: Exploring the extrinsic drivers for process flexibility. In the 18th International Conference on Advanced Information Systems Engineering. Proceedings of Workshops and Doctoral Consortium (pp. 149-158). Namur University Press.

Sabatucci, L., \& Cossentino, M. (2019). Supporting dynamic workflows with automatic extraction of goals from BPMN. ACM Transactions on Autonomous and Adaptive Systems (TAAS), 14(2), 1-38.

Saidani, O., \& Nurcan, S. (2006). A Role-Based Approach for Modeling Flexible Business Processes. In Workshop on Business Process Modelling, Development and Support 2006, BPMDS 2006, Luxembourg, (pp. 111-120).

Santo Carvalho, J. D. E., Santoro, F. M., \& Revoredo, K. (2015). A method to infer the need to update situations in business process adaptation. Computers in Industry, 71, 128-143. https://doi.org/10.1016/j.compind.2015.03.014

Santo Carvalho, J. D. E., Santoro, F. M., Revoredo, K., \& Nunes, V. T. (2013). Learning context to adapt business processes. In IEEE 17th International Conference on Computer Supported Cooperative Work in Design (CSCWD) (pp. 229-234). IEEE. https://doi.org/10.1109/CSCWD.2013.6580967

Santos, E. A. P., Francisco, R., Pesic, M., \& van der Aalst, W. M. P. (2013). Supervisory control service for supporting flexible processes. Industrial Management \& Data Systems, 113(7), 1007-1024. https://doi.org/10.1108/IMDS-10-2012-0361

Santos, E., Pimentel, J., Dermeval, D., Castro, J., \& Pastor, O. (2011). Using NFR and context to deal with adaptability in business process models. In the 2011 2nd International Workshop on Requirements@Run.Time, RE@RunTime (pp. https://doi.org/10.1109/ReRunTime.2011.6046237

Sarno, R., Pamungkas, E. W., Sunaryono, D., \& Sarwosri. (2015). Business process composition based on meta models. In 2015 International Seminar on Intelligent Technology and Its Applications, ISITIA 2015 (pp. 315-318). Institute of Electrical and Electronics Engineers Inc. https://doi.org/10.1109/ISITIA.2015.7219998

Satyal, S., Weber, I., Paik, H. Y., Di Ciccio, C., \& Mendling, J. (2018, October). Shadow testing for business process improvement. In OTM Confederated International Conferences" On the Move to Meaningful Internet Systems" (pp. 153-171). Springer, Cham.

Savickas, T., \& Vasilecas, O. (2018). An approach to business process simulation using mined probabilistic models. Computer Science and Information Systems, 15(1). https://doi.org/10.2298/CSIS170520045S

Sprovieri, D., Diaz, D., Mazo, R., \& Hinkelmann, K. (2016). Run-time planning of case-based business processes. In International Conference on Research Challenges in Information Science (Vol. 2016August). IEEE Computer Society. https://doi.org/10.1109/RCIS.2016.7549282

Sun, Y., Huang, J. Z., \& Meng, X. (2011). Integrating constraints to support legally flexible business processes. Information Systems Frontiers, 13, 171-189. https://doi.org/10.1007/s10796-009-9190-z

Peer) Comput. Sci. reviewing PDF | (CS-2020:12:56750:2:0:NEW 24 May 2021) 
1301

1302

1303

1304

1305

1306

1307

1308

1309

1310

1311

1312

1313

1314

1315

1316

1317

1318

1319

1320

1321

1322

1323

1324

1325

1326

1327

1328

1329

1330

1331

1332

1333

1334

1335

1336

1337

1338

1339

1340

1341

1342

1343

1344

1345

Ukor, R., \& Carpenter, A. (2009). Flexible Service Selection Optimization Using Meta-Metrics. In the 2009 Congress on Services - I (pp. 593-598). Washington: IEEE. https://doi.org/10.1109/SERVICESI.2009.71

Valença, G., Alves, C., Alves, V., \& Niu, N. (2013). A systematic mapping study on business process variability. International Journal of Computer Science \& Information Technology, 5(1), 1.

Valente, P., Silva, T. R., Winckler, M., \& Nunes, N. J. (2016). The Goals Approach: Enterprise ModelDriven Agile Human-Centered Software Engineering. In Human-Centered and Error-Resilient Systems Development (pp. 261-280). Springer, Cham.

Valente, P., Silva, T., Winckler, M., \& Nunes, N. (2016, November). Bridging enterprise and software engineering through an user-centered design perspective. In International Conference on Web Information Systems Engineering (pp. 349-357). Springer, Cham.

van der Aalst, W. M., \& Ter Hofstede, A. H. (2005). YAWL: yet another workflow language. Information systems, 30(4), 245-275.

van der Aalst, W. M., Pesic, M., \& Schonenberg, H. (2009). Declarative workflows: Balancing between flexibility and support. Computer Science-Research and Development, 23(2), 99-113. https://doi.org/10.1007/s00450-009-0057-9

van der Aalst, W. M., Weske, M., \& Grünbauer, D. (2005). Case handling: a new paradigm for business process support. Data \& Knowledge Engineering, 53(2), 129-162. https://doi.org/10.1016/j.datak.2004.07.003

van Eijndhoven, T., Iacob, M. E., \& Ponisio, M. L. (2008). Achieving business process flexibility with business rules. In the 12th IEEE International Enterprise Distributed Object Computing Conference, EDOC 2008 (pp. 95-104). https://doi.org/10.1109/EDOC.2008.23

Vasilecas, O., Kalibatiene, D., \& Lavbič, D. (2016). Rule-and context-based dynamic business process modelling and simulation. Journal of Systems and Software, 122, 1-15. https://doi.org/10.1016/j.jss.2016.08.048

Vasilecas, O., Savickas, T., Normantas, K., Vysockis, T., \& Kalibatiene, D. (2016). A Goal-Oriented Approach to Dynamic Business Process Simulation. In Arnicans G. et al.. (Eds.), DB\&IS (Selected Papers) (pp. 143-154). IOS Press.

Wang, M., \& Wang, H. (2006). From process logic to business logic-A cognitive approach to business process management. Information \& Management, 43(2), 179-193. https://doi.org/10.1016/j.im.2005.06.001

Wang, S., \& Capretz, M. A. M. (2007). A policy driven approach for service-oriented business rule management. In IEEE International Conference on Industrial Informatics (INDIN) (Vol. 2, pp. 713718). https://doi.org/10.1109/INDIN.2007.4384861

Weidlich, M., Smirnov, S., Wiggert, C., \& Weske, M. (2011). Flexab-Flexible Business Process Model Abstraction. In CAiSE Forum (Vol. 734, pp. 17-24).

Xia, Y., \& Wei, J. (2008). Context-driven business process adaptation for ad hoc changes. In IEEE International Conference on e-Business Engineering, ICEBE'08 (pp. 53-60). https://doi.org/10.1109/ICEBE.2008.15

Xiao, Z., Cao, D., You, C., \& Mei, H. (2011). Towards a constraint-based framework for dynamic business process adaptation. In 2011 IEEE International Conference on Services Computing (pp. 685-692). IEEE. https://doi.org/10.1109/SCC.2011.95

Yoo, S., Roh, Y. H., Song, I. C., Jeon, J. H., Kim, M. H., Kim, H. S., ... Jang, H. K. (2008). Rule-based dynamic business process modification and adaptation. In 2008 International Conference on Information Networking, ICOIN. https://doi.org/10.1109/ICOIN.2008.4472793

Peer) Comput. Sci. reviewing PDF | (CS-2020:12:56750:2:0:NEW 24 May 2021) 
1346 Yousfi, A., Saidi, R., \& Dey, A. K. (2016). Variability patterns for business processes in BPMN. Information Systems and E-Business Management, 14(3), 443-467. https://doi.org/10.1007/s10257015-0290-7

Yuliang, S., Shuai, L., Qingzhong, L., \& Haiyang, W. (2009). A flexible business process customization framework for SaaS. In 2009 WASE International Conference on Information Engineering, ICIE 2009 (Vol. 2, pp. 350-353). https://doi.org/10.1109/ICIE.2009.226 expressiveness and understandability of hierarchy in declarative business process models. Software \& Systems Modeling, 14(3), 1081-1103. https://doi.org/10.1007/s10270-013-0356-2

1355 Zur Muehlen, M. 2004. Workflow-based process controlling: foundation, design, and application of 1356 workflow-driven process information systems. Logos, Berlin. 


\section{Table $\mathbf{1}$ (on next page)}

\section{List of sources}


Table 1. List of sources

\begin{tabular}{|ll|l|}
\hline \multicolumn{2}{|l|}{ Data source } & Website \\
\hline 1. & ACM Digital Library & https://dl.acm.org \\
\hline 2. & IEEE Xplore & http://ieeexplore.ieee.org/Xplore/home.jsp \\
\hline 3. & ScienceDirect & http://www.sciencedirect.com/ \\
\hline 4. & Scopus & https://www.scopus.com/ \\
\hline 5. & Web of Science (WOS) & https://apps.webofknowledge.com/ \\
\hline 6. & Google Scholar & https://scholar.google.lt \\
\hline
\end{tabular}

2 


\section{Table 2 (on next page)}

Keywords used for the search 
Table 2. Keywords used for the search

\begin{tabular}{|l|l|l|}
\hline Main Concept & Related terms & Keywords used in the search \\
\hline Business process & BP & Business process*, BP, process \\
\hline Dynamic & dynamicity, dynamism, dynamics, & dynamic* \\
& dynamically, dynamical, adaptability, & adapt* \\
& adaptation, adaptable, adapt, adaptive, & flexib* \\
& flexible, flexibility, & variab* \\
& variable, variability & declarative \\
& declarative & \\
\hline
\end{tabular}




\section{Table 3(on next page)}

Results of the performed search (May, 2019) 
Table 3. Results of the performed search (May, 2019)

\begin{tabular}{|c|c|c|c|c|c|}
\hline Data source & SQ1 & SQ2 & SQ3 & SQ4 & Total: \\
\hline 1. ACM Digital Library & 15 & 7 & 6 & 13 & 41 \\
\hline 2. IEEE Xplore & 50 & 27 & 2 & 58 & 137 \\
\hline 3. ScienceDirect & 25 & 20 & 9 & 13 & 67 \\
\hline 4. Scopus & 120 & 118 & 41 & 94 & 373 \\
\hline 5. Web of Science (WoS) & 10 & 15 & 5 & 14 & 44 \\
\hline Total: & 220 & 187 & 63 & 205 & 662 \\
\hline
\end{tabular}

2

3 


\section{Table 4 (on next page)}

Data extraction template according to the requirements of DBP 
Table 4. Data extraction template according to the requirements of DBP

\begin{tabular}{|c|c|c|c|c|c|}
\hline RQ & $\begin{array}{l}\text { Process dynamicity influencing features that } \\
\text { are mentioned in analyzed papers }\end{array}$ & $\begin{array}{l}\text { Possible } \\
\text { answers }\end{array}$ & Scale & $\begin{array}{l}\text { Ranking } \\
\text { (RQ1) }\end{array}$ & $\begin{array}{l}\text { Rigor } \\
\text { (RQ6) }\end{array}$ \\
\hline & $\begin{array}{l}\text { Meta information: Study ID and reference of a } \\
\text { paper. }\end{array}$ & & & & \\
\hline $\begin{array}{l}\text { RQ1 } \\
\text { RQ2 } \\
\text { RQ3 } \\
\text { RQ4 }\end{array}$ & $\begin{array}{l}\text { 1. Process model predefined (Essential) (see } \\
\text { DBPR-1): } \\
\text { 1.1. Does a process have a predefined sequence } \\
\text { of activities, i.e., a predefined process model? } \\
\text { 1.2. Is a process based on meta-model, general } \\
\text { model, generic model, or abstract model? } \\
\text { 1.3. Is it possible to define additional activities } \\
\text { and to change or delete existing activities or } \\
\text { skip to other activities at process instance run- } \\
\text { time? }\end{array}$ & $\begin{array}{l}\text { Yes/No } \\
\text { Yes/No } \\
\text { Yes/Part/No }\end{array}$ & $\begin{array}{l}0 / 1 \\
0 / 1 \\
1 / 0.5 / 0\end{array}$ & $\begin{array}{l}X \\
X \\
X\end{array}$ & \\
\hline $\begin{array}{l}\text { RQ1 } \\
\text { RQ2 } \\
\text { RQ3 } \\
\text { RQ4 }\end{array}$ & $\begin{array}{l}\text { 2. Context aware (Essential) (see DBPR-2): } \\
\text { 2.1. Does an external context affect the } \\
\text { execution of the process? } \\
\text { 2.2. Does an internal context affect the } \\
\text { execution of the process? } \\
\text { 2.3. Is a process instance affected by the change } \\
\text { of a context at run-time? }\end{array}$ & $\begin{array}{l}\text { Yes/No } \\
\text { Yes/No } \\
\text { Yes/No }\end{array}$ & $\begin{array}{l}1 / 0 \\
1 / 0 \\
1 / 0\end{array}$ & $\begin{array}{l}X \\
X \\
X\end{array}$ & \\
\hline $\begin{array}{l}\text { RQ1 } \\
\text { RQ2 } \\
\text { RQ3 } \\
\text { RQ4 }\end{array}$ & $\begin{array}{l}\text { 3. Rule-based } \text { (Essential) (see DBPR-3): } \\
\text { 3.1. Is every subsequent activity in a process } \\
\text { selected according to the predefined rules at } \\
\text { process instance run-time? } \\
\text { 3.2. Is it possible to define new rules, or change } \\
\text { or delete existing rules, at process instance run- } \\
\text { time? } \\
\text { 3.3. Does process instance react to the rule } \\
\text { changes made at process instance run-time? } \\
\text { 3.4. Are rules used to solve other tasks? }\end{array}$ & $\begin{array}{l}\text { Yes/Part/No } \\
\text { Yes/No } \\
\text { Yes/No } \\
\text { Yes/No }\end{array}$ & $\begin{array}{l}1 / 0.5 / 0 \\
1 / 0 \\
1 / 0 \\
1 / 0\end{array}$ & $\begin{array}{l}X \\
X \\
X\end{array}$ & \\
\hline $\begin{array}{l}\text { RQ1 } \\
\text { RQ2 } \\
\text { RQ3 } \\
\text { RQ4 }\end{array}$ & $\begin{array}{l}\text { 4. Changes (Essential): Are changes } \\
\text { implemented at process instance run-time with } \\
\text { low latency? (see DBPR-4) }\end{array}$ & Yes/No & $1 / 0$ & $\mathrm{X}$ & \\
\hline $\begin{array}{l}\text { RQ1 } \\
\text { RQ2 } \\
\text { RQ3 } \\
\text { RQ4 }\end{array}$ & $\begin{array}{l}\text { 5. Accumulation of experience (see DBPR-5): } \\
\text { 5.1. Is the experience of each process instance } \\
\text { execution stored? } \\
\text { 5.2. Is it possible to classify executed instances } \\
\text { of a process as a "good practice" and a "bad } \\
\text { practice"? } \\
\text { 5.3. Are time, cost, etc. values calculated and } \\
\text { stored for each process instance? } \\
\text { 5.4. Is it possible to restrict the execution of } \\
\text { process instances that are named "bad } \\
\text { instances"? } \\
\text { 5.5. Is historical data used for solving other }\end{array}$ & $\begin{array}{l}\text { Yes/No } \\
\text { Yes/No } \\
\text { Yes/No } \\
\text { Yes/No } \\
\text { Yes/No }\end{array}$ & $\begin{array}{l}1 / 0 \\
1 / 0 \\
1 / 0 \\
1 / 0 \\
1 / 0\end{array}$ & $\begin{array}{l}X \\
X \\
X\end{array}$ & \\
\hline
\end{tabular}




\begin{tabular}{|c|c|c|c|c|c|}
\hline & related tasks? & & & & \\
\hline $\begin{array}{l}\text { RQ1 } \\
\text { RQ2 } \\
\text { RQ3 } \\
\text { RQ4 }\end{array}$ & $\begin{array}{l}\text { 6. Goal: Is a process goal-oriented? (see DBPR- } \\
\text { 6) }\end{array}$ & Yes/No & $1 / 0$ & $\mathrm{X}$ & \\
\hline $\begin{array}{l}\text { RQ1 } \\
\text { RQ2 } \\
\text { RQ3 } \\
\text { RQ4 }\end{array}$ & $\begin{array}{l}\text { 7. Ontology: Is domain ontology or process } \\
\text { ontology used in an approach? }\end{array}$ & Yes/No & $1 / 0$ & $\mathrm{X}$ & \\
\hline \multicolumn{6}{|c|}{$\begin{array}{l}\text { Completeness of description of process dynamicity approach and its } \\
\text { implementation }\end{array}$} \\
\hline $\begin{array}{l}\text { RQ2 } \\
\text { RQ3 } \\
\text { RQ4 } \\
\text { RQ6 }\end{array}$ & $\begin{array}{l}\text { 8. Approach description: } \\
\text { 8.1. Does the paper present a clear description } \\
\text { of the proposed approach on BP dynamicity? } \\
\text { 8.2. Does the paper present a description of the } \\
\text { proposed approach on dynamic BP in a formal } \\
\text { language? }\end{array}$ & $\begin{array}{l}\text { Yes/Part/No } \\
\text { Yes/Part/No }\end{array}$ & $\begin{array}{l}1 / 0.5 / 0 \\
1 / 0.5 / 0\end{array}$ & & $\begin{array}{l}X \\
X\end{array}$ \\
\hline $\begin{array}{l}\text { RQ1 } \\
\text { RQ2 } \\
\text { RQ3 } \\
\text { RQ4 } \\
\text { RQ6 }\end{array}$ & $\begin{array}{l}\text { 9. Dynamicity implementation approach (if } 1.1 \text {. } \\
\text { is yes): } \\
9.1 \text {. Is the process dynamicity realized through } \\
\text { variants? } \\
9.2 \text {. Is the process dynamicity realized through } \\
\text { cases? } \\
9.3 \text {. Is the process dynamicity realized through } \\
\text { a declarative approach? } \\
\text { 9.4. Is the process dynamicity realized through } \\
\text { goal-orientation? } \\
\text { 9.5. Is the process dynamicity realized through } \\
\text { other approaches? }\end{array}$ & $\begin{array}{l}\text { Yes/No } \\
\text { Yes/No } \\
\text { Yes/No } \\
\text { Yes/No } \\
\text { Yes/No }\end{array}$ & $\begin{array}{l}1 / 0 \\
1 / 0 \\
1 / 0 \\
1 / 0 \\
1 / 0\end{array}$ & $\begin{array}{l}X \\
X \\
X \\
X \\
X\end{array}$ & $\begin{array}{l}X \\
X \\
X \\
X \\
X\end{array}$ \\
\hline $\begin{array}{l}\text { RQ2 } \\
\text { RQ3 } \\
\text { RQ4 } \\
\text { RQ6 }\end{array}$ & $\begin{array}{l}\text { 10. Implementation of the proposed approach: } \\
\text { 10.1. Is any case of implementation of a } \\
\text { proposed model presented in the paper? } \\
\text { 10.2. What approach, language or technique is } \\
\text { used for the implementation of the proposed } \\
\text { approach? } \\
\text { 10.3. Does the paper present a case study or a } \\
\text { prototype or a descriptive example? } \\
\text { 10.4. Does the paper present a clear description } \\
\text { of an implementation with text, screen shots, } \\
\text { and code lines? } \\
\text { 10.5. Does the paper evaluate the results } \\
\text { obtained? }\end{array}$ & $\begin{array}{l}\text { Yes/No } \\
\text { Answer } \\
\text { Yes/Part/No } \\
\text { Yes/Part/No } \\
\text { Yes/Part/No }\end{array}$ & $\begin{array}{l}1 / 0.5 / 0 \\
1 / 0.5 / 0 \\
1 / 0.5 / 0\end{array}$ & $\mathrm{X}$ & $\begin{array}{l}X \\
X \\
X\end{array}$ \\
\hline $\begin{array}{l}\text { RQ4 } \\
\text { RQ6 }\end{array}$ & $\begin{array}{l}\text { 11. Discussion and conclusions: } \\
\text { 11.1. Does the paper present an appropriate } \\
\text { discussion on dynamicity? } \\
\text { 11.2. Does the paper present grounded } \\
\text { conclusions about dynamicity? }\end{array}$ & $\begin{array}{l}\text { Yes/Part/No } \\
\text { Yes/Part/No }\end{array}$ & $\begin{array}{l}1 / 0.5 / 0 \\
1 / 0.5 / 0\end{array}$ & & $\begin{array}{l}X \\
X\end{array}$ \\
\hline
\end{tabular}

$2{ }^{1}$ - Here a rule role is analyzed in a process. In analyzed approaches, rules are used for different tasks (3.4),

3 as with transformation rules that are used to generate the process variants from patterns in Abderrahmane 
4 et al. (2014), etc. In some approaches, like Bucchiarone et al. (2017), the rule concept is not used at all. 5 Authors use "transition relations," which in general can be termed rules.

$6 \quad 2$ - A variant-based process here means that process change can be made in predefined variation points. A 7 case-based process definition is the same as in van der Aalst et al. (2005).

$83^{3}$ - Historical data is used in some a way, for example a log file used to build a model (Mattos et al., 9 2014), etc.

104 - If a paper presents a case study or a prototype, then the answer is yes. If a paper presents a descriptive 11 example, then the answer is part. If a paper does not present any implementation, then the answer is no.

125 - This means that some type of validation, i.e., Experts or other, is presented here. 


\section{Table 5 (on next page)}

Assessment questions for evaluating existing literature reviews 
Table 5. Assessment questions for evaluating existing literature reviews

\begin{tabular}{|c|c|c|c|c|c|}
\hline No & Questions & Answers & Scale & Relevance & Rigor \\
\hline Q1 & $\begin{array}{l}\text { Whether the aims of the analyzed survey and } \\
\text { this survey match? }\end{array}$ & Yes/Part/No & $1 / 0.5 / 0$ & $\mathrm{X}$ & \\
\hline Q2 & $\begin{array}{l}\text { Whether the sources used in the analyzed } \\
\text { survey and in this survey match? }\end{array}$ & Yes/Part/No & $1 / 0.5 / 0$ & $\mathrm{X}$ & \\
\hline Q3 & $\begin{array}{l}\text { Whether the meaning of research questions in } \\
\text { the analyzed survey and in this survey similar? }\end{array}$ & Yes/Part/No & $1 / 0.5 / 0$ & $\mathrm{X}$ & \\
\hline Q4 & $\begin{array}{l}\text { Whether the search keywords in the analyzed } \\
\text { survey and this survey cover the similar field } \\
\text { of research? }\end{array}$ & Yes/Part/No & $1 / 0.5 / 0$ & $\mathrm{X}$ & \\
\hline Q5 & $\begin{array}{l}\text { Is the analyzed survey based on literature } \\
\text { review guidelines agreed in software } \\
\text { engineering? }\end{array}$ & Yes/No & $1 / 0$ & $\mathrm{X}$ & $\mathrm{X}$ \\
\hline Q6 & $\begin{array}{l}\text { Is the analyzed survey based on authors' } \\
\text { defined approach? (if previous question is No) }\end{array}$ & Yes/No & $0.5 / 0$ & $\mathrm{X}$ & $\mathrm{X}$ \\
\hline Q7 & $\begin{array}{l}\text { Does the analyzed survey identifies and } \\
\text { mitigates its threats to validity? }\end{array}$ & Yes/Part/No & $1 / 0.5 / 0$ & $\mathrm{X}$ & $\mathrm{X}$ \\
\hline Q8 & $\begin{array}{l}\text { Does the analyzed survey include a quality } \\
\text { assessment of the performed search? }\end{array}$ & Yes/Part/No & $1 / 0.5 / 0$ & $\mathrm{X}$ & $\mathrm{X}$ \\
\hline Q9 & $\begin{array}{l}\text { Does the analyzed survey include a quality } \\
\text { assessment of primary studies? }\end{array}$ & Yes/Part/No & $1 / 0.5 / 0$ & $\mathrm{X}$ & \\
\hline Q10 & $\begin{array}{l}\text { Are the results presented in the analyzed } \\
\text { survey described properly? }\end{array}$ & Yes/Part/No & $1 / 0.5 / 0$ & & $\mathrm{X}$ \\
\hline Q11 & $\begin{array}{l}\text { Does the analyzed survey have described } \\
\text { examples of flexibility or variability? }\end{array}$ & Yes/Part/No & $1 / 0.5 / 0$ & $\mathrm{X}$ & $\mathrm{X}$ \\
\hline Q12 & $\begin{array}{l}\text { Does the analyzed survey have answered to the } \\
\text { defined research questions? }\end{array}$ & Yes/Part/No & $1 / 0.5 / 0$ & $\mathrm{X}$ & $\mathrm{X}$ \\
\hline Q13 & $\begin{array}{l}\text { Does the analyzed survey have presented } \\
\text { evident conclusions? }\end{array}$ & Yes/Part/No & $1 / 0.5 / 0$ & & $\mathrm{X}$ \\
\hline \multicolumn{3}{|c|}{ Maximum value } & 12 & 11 & 8 \\
\hline \multicolumn{3}{|c|}{ Minimum value } & 0 & 0 & 0 \\
\hline
\end{tabular}

2 


\section{Table 6 (on next page)}

Summary of reviews on DBP 
Table 6. Summary of reviews on DBP

\begin{tabular}{|c|c|c|c|c|c|c|c|}
\hline Reference & Scope & $\begin{array}{l}\text { Data sources } \\
\end{array}$ & Period & Methodology & Data extraction & Quality assessment & Threats to Validity \\
\hline $\begin{array}{l}\text { (Rosa et al., } \\
2017 \text { ) }\end{array}$ & $\begin{array}{l}\text { BP variability by } \\
\text { restriction and by } \\
\text { extension }\end{array}$ & $\begin{array}{l}\text { Concentration not on } \\
\text { sources, but on particular } \\
\text { approaches }\end{array}$ & $2000-2014$ & Not presented & $\begin{array}{l}66 \text { relevant papers: } 23 \\
\text { approaches, out of which } \\
11 \text { main approaches } \\
\text { subsume the other } 12 \\
\text { approaches }\end{array}$ & Not presented & Not presented \\
\hline $\begin{array}{l}\text { (Pourshahid } \\
\text { et al., 2012) }\end{array}$ & $\begin{array}{l}\text { Aspect-oriented } \\
\text { approaches for BP } \\
\text { adaptation }\end{array}$ & One source, not specified & $2000-2012$ & $\begin{array}{l}\text { Presented, usual to } \\
\text { literature reviews }\end{array}$ & 56 papers & $\begin{array}{l}\text { Quality criteria for } \\
\text { selecting papers }\end{array}$ & $\begin{array}{l}\text { 1) Searched on article titles } \\
\text { and only one meta-search } \\
\text { engine used } \\
\text { 2) Looking at commonly } \\
\text { cited articles by the authors } \\
\text { of the papers found, and by } \\
\text { comparing the authors' } \\
\text { conclusions with some more } \\
\text { generic surveys and studies }\end{array}$ \\
\hline $\begin{array}{l}\text { (Ayora et } \\
\text { al., 2015) }\end{array}$ & $\begin{array}{l}\text { Evaluation of } \\
\text { variability support in } \\
\text { process-aware IS }\end{array}$ & $\begin{array}{l}\text { SpringerLink, IEEE } \\
\text { Xplore Digital Library, } \\
\text { ACM Digital Library, } \\
\text { Science Direct - Elsevier, } \\
\text { Wiley Inter Science, } \\
\text { World Scientific } \\
\end{array}$ & $2004-2013$ & $\begin{array}{l}\text { Presented, usual to } \\
\text { literature reviews }\end{array}$ & 63 papers & $\begin{array}{l}\text { Quality criteria for } \\
\text { selecting studies }\end{array}$ & $\begin{array}{l}\text { Selection bias, inaccuracy in } \\
\text { data extraction and analysis, } \\
\text { and reliability }\end{array}$ \\
\hline $\begin{array}{l}\text { (Cognini et } \\
\text { al., 2014) }\end{array}$ & BP adaptation & $\begin{array}{l}\text { IEEExploer, ACM } \\
\text { Digital Library, Citeseerx } \\
\text { Library, ScienceDirect, } \\
\text { Springer Link, Web Of } \\
\text { Science }\end{array}$ & $2000-2013$ & $\begin{array}{l}\text { Presented, usual to } \\
\text { literature reviews }\end{array}$ & 84 papers & $\begin{array}{l}\text { Three inclusion } \\
\text { criteria and four } \\
\text { exclusion criteria }\end{array}$ & Not presented \\
\hline $\begin{array}{l}\text { (Cognini et } \\
\text { al., 2018) }\end{array}$ & $\begin{array}{l}\text { BP flexibility with a } \\
\text { focus on software } \\
\text { systems }\end{array}$ & $\begin{array}{l}\text { IEEExplorer, ACM } \\
\text { Digital Library, Citeseerx } \\
\text { Library, Scopus Science } \\
\text { Direct, SpringerLink, } \\
\text { WOS }\end{array}$ & $2000-2015$ & $\begin{array}{l}\text { The method proposed } \\
\text { in (Kitchenham, 2007) }\end{array}$ & 164 papers & $\begin{array}{l}\text { Two inclusion } \\
\text { criteria, two exclusion } \\
\text { criteria, and seven } \\
\text { questions developed } \\
\text { by (Dyba and } \\
\text { Dingsoyr, 2008) } \\
\end{array}$ & $\begin{array}{l}\text { A validation based on the } \\
\text { snowballing search method } \\
\text { (Jalali \& Wohlin 2012) }\end{array}$ \\
\hline $\begin{array}{l}\text { (Goedertier } \\
\text { et al., 2015) }\end{array}$ & $\begin{array}{l}\text { Declarative process } \\
\text { modeling languages } \\
\text { and principles }\end{array}$ & $\begin{array}{l}\text { Concentration not on } \\
\text { sources, but on particular } \\
\text { approaches }\end{array}$ & $\begin{array}{l}\begin{array}{l}\text { Languages } \\
\text { of period } \\
1998-2009 \\
\end{array} \\
\end{array}$ & $\begin{array}{l}\text { A set of criteria is } \\
\text { chosen }\end{array}$ & 8 languages & Not discussed & Not discussed \\
\hline $\begin{array}{l}\text { (Kapuruge } \\
\text { et al., 2010) }\end{array}$ & $\begin{array}{l}\text { Process flexibility in } \\
\text { the context of service } \\
\text { compositions }\end{array}$ & Not presented & $\begin{array}{l}\text { Not } \\
\text { presented }\end{array}$ & Not presented & 7 papers & Not described & Not presented \\
\hline This study & $\begin{array}{l}\text { BP dynamicity and } \\
\text { flexibility }\end{array}$ & $\begin{array}{l}\text { ACM Digital Library, } \\
\text { IEEE Xplore, } \\
\text { ScienceDirect, Scopus, } \\
\text { WOS }\end{array}$ & $2005-2017$ & $\begin{array}{l}\text { The method proposed } \\
\text { in (Ivarsson and } \\
\text { Gorschek 2009) }\end{array}$ & 60 papers & $\begin{array}{l}\text { Three stage exclusion } \\
\text { procedure, described } \\
\text { in Section } 4\end{array}$ & Presented in Section 3.5 \\
\hline
\end{tabular}




\section{Table 7 (on next page)}

An initial data on literature reviews comparison 
Table 7. An initial data on literature reviews comparison

\begin{tabular}{|c|c|c|c|c|c|c|c|c|c|c|c|c|c|c|c|}
\hline Reference & Q1 & Q2 & Q3 & Q4 & Q5 & Q6 & Q7 & Q8 & Q9 & Q10 & Q11 & Q12 & Q13 & 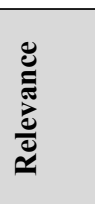 & $\stackrel{\overline{\overrightarrow{0}}}{\ddot{*}}$ \\
\hline (Rosa et al., 2017) & 0.5 & 0.5 & 0.5 & 0.5 & 0 & 1 & 0 & 1 & 0.5 & 0.5 & 1 & 0.5 & 1 & 6 & 5 \\
\hline (Pourshahid et al., 2012) & 0.5 & 0 & 0 & 0.5 & 1 & 0 & 1 & 0 & 1 & 1 & 0 & 0 & 1 & 4 & 4 \\
\hline (Ayora et al., 2015) & 0.5 & 0 & 0 & 0.5 & 1 & 0 & 1 & 0 & 1 & 1 & 1 & 1 & 0.5 & 6 & 5.5 \\
\hline (Cognini et al., 2014) & 1 & 1 & 0.5 & 1 & 1 & 0 & 0 & 0 & 1 & 1 & 0 & 1 & 1 & 6.5 & 4 \\
\hline (Cognini et al., 2018) & 1 & 1 & 0.5 & 1 & 1 & 0 & 0.5 & 1 & 1 & 1 & 0 & 1 & 1 & 8 & 5.5 \\
\hline (Kapuruge et al., 2010) & 0.5 & 0 & 0 & 0 & 0 & 1 & 0 & 0 & 0 & 0.5 & 1 & 0 & 1 & 2.5 & 3.5 \\
\hline (Goedertier et al., 2015) & 0.5 & 0 & 0 & 0.5 & 0 & 1 & 0 & 0 & 0 & 1 & 1 & 1 & 1 & 4 & 5 \\
\hline SUM & 4 & 2.5 & 1.5 & 3.5 & 4 & 2 & 2.5 & 2 & 4.5 & 5 & 3 & 3.5 & 5.5 & 33 & 27.5 \\
\hline AVG & 643 & 0.357 & 0.214 & 0.571 & 0.571 & 0.429 & 0.357 & 0.286 & 0.643 & 0.857 & 0.571 & 0.643 & 0.929 & 5.286 & 4.643 \\
\hline $\mathrm{MI}$ & 0.500 & 0.000 & 0.000 & 0.000 & 0.000 & 0.000 & 0.000 & 0.000 & 0.000 & 0.500 & 0.000 & 0.000 & 0.500 & 2.500 & 3.500 \\
\hline MAX & 1.000 & 1.000 & 0.500 & 1.000 & 1.000 & 1.000 & 1.000 & 1.000 & 1.000 & 1.000 & 1.000 & 1.000 & 1.000 & 8.000 & 5.500 \\
\hline
\end{tabular}




\section{Table 8 (on next page)}

Initial data on BP dynamicity 
Table 8. Initial data on BP dynamicity

\begin{tabular}{|c|c|c|c|c|c|c|c|c|c|c|c|c|c|c|c|c|c|c|c|c|c|c|c|c|c|c|c|c|c|c|c|c|c|}
\hline Reference & $\exists$ & $\stackrel{\Im}{\longrightarrow}$ & $\dddot{m}$ & $\vec{i}$ & $\underset{\sim}{\sim}$ & $\stackrel{m}{i}$ & $\vec{m}$ & ஸे & $\ddot{m}$ & $\stackrel{\vec{r}}{\dot{m}}$ & + & $\overrightarrow{i n}$ & $\stackrel{\sim}{n}$ & $\ddot{n}$ & $\stackrel{\vec{r}}{\vec{r}}$ & in & 0 & $r$ & $\bar{\infty}$ & $\tilde{\infty}$ & $\vec{a}$ & ă & $\ddot{a}$ & ă & $\dddot{2}$ & $\bar{\Theta}$ & $\stackrel{m}{\varrho}$ & $\stackrel{+}{\ominus}$ & $\dddot{n}$ & $\exists$ & $\stackrel{\Upsilon}{=}$ & 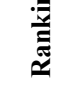 & 容 \\
\hline $\begin{array}{l}\text { (Abderrahma } \\
\text { ne et al., } \\
\text { 2014) }\end{array}$ & 0 & 0 & 1 & 1 & 1 & 0 & 1 & 0 & 0 & 1 & 1 & 0 & 0 & 0 & 0 & 1 & 0 & 1 & 1 & 0 & $\begin{array}{l}0 . \\
5\end{array}$ & 0 & 0 & 0 & 0 & 1 & 1 & 1 & 1 & 1 & 0 & 9.5 & $\begin{array}{l}6 . \\
5\end{array}$ \\
\hline $\begin{array}{l}\text { (van der Aalst } \\
\text { et al., 2005) }\end{array}$ & 1 & 0 & $\begin{array}{l}0 . \\
5\end{array}$ & 1 & 1 & 1 & 1 & 0 & 0 & 0 & 1 & 0 & 0 & 0 & 0 & $\begin{array}{l}0 . \\
5\end{array}$ & 0 & 0 & 1 & 1 & 0 & $\begin{array}{l}0 . \\
5 \\
\end{array}$ & 0 & 0 & 0 & 1 & 1 & 1 & $\begin{array}{l}0 . \\
5\end{array}$ & 0 & 1 & 8.5 & $\begin{array}{l}7 . \\
0 \\
\end{array}$ \\
\hline $\begin{array}{l}\text { (Asuncion et } \\
\text { al., 2010) }\end{array}$ & 0 & 1 & 0 & 0 & 0 & 0 & 1 & 0 & 0 & 1 & 0 & 0 & 0 & 0 & 0 & 0 & 1 & 0 & 1 & 0 & 0 & 0 & 0 & 1 & 0 & 1 & 1 & 1 & 0 & 0 & 1 & 6.0 & $\begin{array}{l}6 . \\
0\end{array}$ \\
\hline $\begin{array}{l}\text { (Awadid \& } \\
\text { Gnannouchi, } \\
\text { 2015) }\end{array}$ & 0 & 1 & 1 & 0 & 0 & 0 & 0 & 0 & 0 & 0 & 1 & 0 & 0 & 0 & 0 & 0 & 0 & 0 & $\begin{array}{l}0 . \\
5\end{array}$ & 0 & 0 & 0 & 0 & 0 & $\begin{array}{l}0 . \\
5 \\
\end{array}$ & 1 & 0 & $\begin{array}{l}0 . \\
5 \\
\end{array}$ & 0 & 0 & 1 & 4.5 & $\begin{array}{l}3 . \\
5\end{array}$ \\
\hline $\begin{array}{l}\text { (Ayora et al., } \\
2016 \text { ) }\end{array}$ & 0 & 1 & 1 & 1 & 0 & 1 & 1 & 0 & 0 & 0 & 1 & 0 & 0 & 0 & 0 & 0 & 0 & 0 & 1 & 0 & $\begin{array}{l}0 . \\
5 \\
\end{array}$ & 0 & 0 & 0 & 0 & 1 & 1 & 1 & $\begin{array}{l}0 . \\
5 \\
\end{array}$ & 1 & 0 & 7.5 & $\begin{array}{l}6 . \\
0 \\
\end{array}$ \\
\hline $\begin{array}{l}\text { (Ayora et al., } \\
2012 \text { ) }\end{array}$ & 0 & 1 & 1 & 0 & 1 & 1 & 1 & 0 & 0 & 0 & 1 & 0 & 0 & 0 & 0 & 0 & 1 & 0 & 1 & 0 & $\begin{array}{l}0 . \\
5 \\
\end{array}$ & 0 & 0 & $\begin{array}{l}0 . \\
5 \\
\end{array}$ & 0 & 1 & 1 & 1 & 0 & 0 & 1 & 9.0 & $\begin{array}{l}6 . \\
0 \\
\end{array}$ \\
\hline $\begin{array}{l}\text { (Boffoli et al., } \\
\text { 2012) }\end{array}$ & 0 & 0 & 0 & 1 & 1 & 0 & 1 & 0 & 0 & 0 & 0 & 0 & 0 & 0 & 0 & 0 & 0 & 0 & 1 & 0 & $\begin{array}{l}0 . \\
5\end{array}$ & 0 & 0 & 0 & 0 & 1 & 1 & 1 & 0 & 0 & 1 & 4.5 & $\begin{array}{l}5 . \\
5\end{array}$ \\
\hline $\begin{array}{l}\text { (Boffoli et al., } \\
2009 \text { ) }\end{array}$ & 0 & 0 & 0 & 1 & 0 & 0 & 1 & 0 & 0 & 0 & 0 & 0 & 0 & 0 & 0 & 0 & 0 & 0 & 1 & 0 & $\begin{array}{l}0 . \\
5 \\
\end{array}$ & 0 & 0 & 0 & 0 & 1 & 1 & 1 & $\begin{array}{l}0 . \\
5\end{array}$ & 1 & 1 & 3.5 & $\begin{array}{l}7 . \\
0\end{array}$ \\
\hline $\begin{array}{l}\text { (Bögl et al., } \\
\text { 2016) }\end{array}$ & 0 & 0 & 0 & 1 & 1 & 1 & 1 & 0 & 0 & 1 & 1 & 1 & 0 & 1 & 0 & 1 & 0 & 0 & 1 & 0 & $\begin{array}{l}0 . \\
5 \\
\end{array}$ & 0 & 0 & 0 & 0 & 1 & 1 & $\begin{array}{l}0 . \\
5\end{array}$ & 0 & 0 & 1 & $\begin{array}{l}10 . \\
5 \\
\end{array}$ & $\begin{array}{l}5 . \\
0\end{array}$ \\
\hline $\begin{array}{l}\text { (Borrego \& } \\
\text { Barba, 2014) }\end{array}$ & 0 & 1 & 0 & 0 & 0 & 0 & 1 & 0 & 0 & 1 & 0 & 1 & 0 & 1 & 0 & 1 & 1 & 0 & 1 & 1 & 0 & 0 & 1 & 0 & 0 & 1 & 1 & 1 & 0 & 1 & 1 & 9.0 & $\begin{array}{l}8 . \\
0\end{array}$ \\
\hline $\begin{array}{l}\text { (Bucchiarone } \\
\text { et al., 2013) }\end{array}$ & 0 & 1 & 0 & 1 & 0 & 1 & 1 & 0 & 0 & 1 & 1 & 0 & 0 & 0 & 0 & 0 & 1 & 0 & 1 & 1 & $\begin{array}{l}0 . \\
5 \\
\end{array}$ & 0 & 0 & 0 & 0 & 1 & 1 & 1 & 0 & 0 & 1 & 8.5 & $\begin{array}{l}6 . \\
5 \\
\end{array}$ \\
\hline $\begin{array}{l}\text { (Bucchiarone } \\
\text { et al., 2011) }\end{array}$ & 0 & 0 & 1 & 1 & 0 & 1 & 1 & 0 & 0 & 1 & 1 & 1 & 0 & 0 & 0 & 1 & 1 & 0 & 1 & 0 & 0 & 0 & 0 & $\begin{array}{l}0 . \\
5 \\
\end{array}$ & 0 & 1 & 1 & 1 & 1 & 0 & 1 & $\begin{array}{l}10 . \\
5 \\
\end{array}$ & $\begin{array}{l}6 . \\
5 \\
\end{array}$ \\
\hline $\begin{array}{l}\text { (Cao et al., } \\
\text { 2009) }\end{array}$ & 0 & 1 & 1 & 0 & 1 & 1 & 1 & 0 & 0 & 0 & 1 & 1 & 0 & 0 & 0 & 1 & 0 & 0 & 1 & 0 & 0 & 0 & 0 & 0 & $\begin{array}{l}0 . \\
5 \\
\end{array}$ & 1 & 1 & 1 & 0 & 0 & 1 & 9.5 & $\begin{array}{l}5 . \\
5\end{array}$ \\
\hline $\begin{array}{l}\text { (Châtel et al., } \\
\text { 2010) }\end{array}$ & 0 & 1 & 0 & 0 & 1 & 0 & 1 & 0 & 0 & 1 & 0 & 0 & 0 & 0 & 0 & 0 & 0 & 1 & 1 & 0 & $\begin{array}{l}0 . \\
5 \\
\end{array}$ & 0 & 0 & 0 & 0 & 1 & 1 & 1 & 0 & 0 & 1 & 6.5 & $\begin{array}{l}5 . \\
5\end{array}$ \\
\hline $\begin{array}{l}\text { (Cherif et al., } \\
\text { 2015) }\end{array}$ & 0 & 1 & 0 & 1 & 0 & 1 & 0 & 0 & 0 & 0 & 1 & 0 & 0 & 0 & 0 & 0 & 0 & 0 & 1 & 0 & $\begin{array}{l}0 . \\
5 \\
\end{array}$ & 0 & 0 & 0 & 0 & 1 & 1 & 1 & 0 & 0 & 1 & 5.5 & $\begin{array}{l}5 . \\
5 \\
\end{array}$ \\
\hline $\begin{array}{l}\text { (Czepa et al., } \\
2016)\end{array}$ & 0 & 1 & 1 & 0 & 1 & 1 & 1 & 1 & 1 & 1 & 1 & 0 & 0 & 0 & 0 & 0 & 0 & 1 & 1 & 0 & 0 & $\begin{array}{l}0 . \\
5 \\
\end{array}$ & 0 & 0 & 0 & 1 & 1 & 1 & 1 & 1 & 1 & $\begin{array}{l}11 . \\
5\end{array}$ & $\begin{array}{l}7 . \\
5\end{array}$ \\
\hline $\begin{array}{l}\text { (Dadam \& } \\
\text { Reichert, } \\
\text { 2009) }\end{array}$ & 0 & 0 & 1 & 0 & 1 & 1 & 1 & 0 & 0 & 1 & 1 & 0 & 0 & 0 & 0 & 0 & 0 & 0 & 1 & 0 & $\begin{array}{l}0 . \\
5 \\
\end{array}$ & 0 & 0 & 0 & 0 & 1 & 1 & 1 & 0 & 0 & 0 & 7.5 & $\begin{array}{l}4 . \\
5 \\
\end{array}$ \\
\hline $\begin{array}{l}\text { (Deb et al., } \\
2015)\end{array}$ & 0 & 1 & 0 & 1 & 0 & 0 & 1 & 0 & 0 & 0 & 0 & 0 & 0 & 0 & 0 & 0 & 1 & 0 & 1 & 1 & 0 & 0 & 0 & 1 & 0 & 1 & 1 & 1 & 1 & 0 & 1 & 6.0 & $\begin{array}{l}8 . \\
0 \\
\end{array}$ \\
\hline
\end{tabular}




\begin{tabular}{|c|c|c|c|c|c|c|c|c|c|c|c|c|c|c|c|c|c|c|c|c|c|c|c|c|c|c|c|c|c|c|c|c|c|}
\hline $\begin{array}{l}\text { (Demeyer et } \\
\text { al., 2010) }\end{array}$ & 0 & 1 & 0 & 1 & 0 & 1 & 1 & 0 & 0 & 0 & 1 & 0 & 0 & 0 & 0 & 0 & 0 & 0 & 1 & 1 & 0 & 0 & 1 & 0 & 0 & 1 & 1 & 1 & 0 & 0 & 1 & 7.0 & $\begin{array}{l}7 . \\
0\end{array}$ \\
\hline $\begin{array}{l}\text { (Gong \& } \\
\text { Janssen, } \\
\text { 2011) }\end{array}$ & 0 & 1 & 0 & 0 & 0 & 0 & 1 & 0 & 0 & 0 & 1 & 0 & 0 & 0 & 0 & 0 & 1 & 1 & 1 & 0 & 0 & 0 & $\begin{array}{l}0 . \\
5 \\
\end{array}$ & 1 & 0 & 1 & $\begin{array}{l}0 . \\
5\end{array}$ & $\begin{array}{l}0 . \\
5 \\
\end{array}$ & 0 & 1 & 1 & 7.5 & $\begin{array}{l}6 . \\
5 \\
\end{array}$ \\
\hline $\begin{array}{l}\text { (Haarmann et } \\
\text { al., 2015) }\end{array}$ & 0 & 0 & 1 & 0 & 0 & 0 & 1 & 0 & 0 & 0 & 1 & 1 & 0 & 1 & 0 & 1 & 0 & 0 & 1 & 0 & 0 & $\begin{array}{l}0 . \\
5\end{array}$ & 0 & 0 & 0 & 1 & 1 & 1 & 0 & 0 & 1 & 7.5 & $\begin{array}{l}5 . \\
5\end{array}$ \\
\hline $\begin{array}{l}\text { (Hallerbach et } \\
\text { al., 2010) }\end{array}$ & 0 & 0 & 0 & 1 & 0 & 1 & 1 & 0 & 0 & 0 & 1 & 0 & 0 & 0 & 0 & 0 & 0 & 0 & 1 & 1 & $\begin{array}{l}0 . \\
5 \\
\end{array}$ & 0 & 0 & 0 & 0 & 1 & 1 & 1 & 1 & 0 & 1 & 5.5 & $\begin{array}{l}7 . \\
5\end{array}$ \\
\hline $\begin{array}{l}\text { (Hermosillo } \\
\text { et al., 2010a) }\end{array}$ & 0 & 1 & 1 & 1 & 0 & 1 & 1 & 0 & 0 & 0 & 1 & 1 & $\begin{array}{l}0 . \\
5\end{array}$ & 0 & 0 & 0 & 0 & 0 & 1 & 1 & $\begin{array}{l}0 . \\
5 \\
\end{array}$ & 0 & 0 & 0 & 0 & 1 & $\begin{array}{l}0 . \\
5 \\
\end{array}$ & $\begin{array}{l}0 . \\
5 \\
\end{array}$ & 1 & 1 & 1 & 9.0 & $\begin{array}{l}7 . \\
5\end{array}$ \\
\hline $\begin{array}{l}\text { (Jiang et al., } \\
2016)\end{array}$ & 0 & 0 & 1 & 1 & 0 & 1 & 1 & 0 & 0 & 1 & 1 & 0 & 0 & 0 & 0 & 0 & 0 & 0 & 1 & 1 & $\begin{array}{l}0 . \\
5\end{array}$ & 0 & 0 & 0 & 0 & 1 & 1 & 1 & 1 & 0 & 1 & 7.5 & $\begin{array}{l}7 . \\
5\end{array}$ \\
\hline $\begin{array}{l}\text { (Kannengiess } \\
\text { er et al., } \\
\text { 2014) }\end{array}$ & 0 & 0 & 0 & 0 & 0 & 0 & 0 & 0 & 0 & 1 & 1 & 0 & 0 & 0 & 0 & 0 & 0 & 1 & 1 & 1 & 0 & 0 & 0 & 0 & $\begin{array}{l}0 . \\
5\end{array}$ & 1 & 1 & 1 & 0 & 0 & 1 & 4.5 & $\begin{array}{l}6 . \\
5 \\
\end{array}$ \\
\hline $\begin{array}{l}\text { (Kapuruge et } \\
\text { al., 2011) }\end{array}$ & 0 & 0 & 1 & 0 & 0 & 0 & 1 & 0 & 0 & 0 & 1 & 0 & 0 & 0 & 0 & 0 & 1 & 0 & 1 & 1 & 0 & 0 & 0 & 0 & $\begin{array}{l}0 . \\
5\end{array}$ & 1 & 1 & 1 & 0 & 0 & 1 & 5.5 & $\begin{array}{l}6 . \\
5 \\
\end{array}$ \\
\hline $\begin{array}{l}\text { (Khriss et al., } \\
2008)\end{array}$ & 1 & 1 & 1 & 0 & 1 & 1 & 0 & 0 & 0 & 0 & 1 & 0 & 0 & 0 & 0 & 0 & 0 & 0 & 1 & 0 & 0 & 0 & 0 & 0 & $\begin{array}{l}0 . \\
5\end{array}$ & 1 & 1 & 1 & 0 & 0 & 1 & 7.5 & $\begin{array}{l}5 . \\
5\end{array}$ \\
\hline $\begin{array}{l}\text { (Kim et al., } \\
\text { 2007) }\end{array}$ & 0 & 1 & 1 & 0 & 1 & 1 & 0 & 0 & 0 & 1 & 1 & 0 & 0 & 0 & 0 & 0 & 0 & 0 & 1 & 0 & $\begin{array}{l}0 . \\
5 \\
\end{array}$ & 0 & 0 & 0 & 0 & 1 & 1 & 1 & 0 & 0 & 1 & 7.5 & $\begin{array}{l}5 . \\
5\end{array}$ \\
\hline $\begin{array}{l}\text { (Li \& Du, } \\
2016)\end{array}$ & 0 & 0 & 0 & 0 & 0 & 0 & 0 & 0 & 0 & 1 & 0 & 0 & 0 & 0 & 0 & 0 & 0 & 0 & 1 & 1 & $\begin{array}{l}0 . \\
5\end{array}$ & 0 & 0 & 0 & 0 & 1 & $\begin{array}{l}0 . \\
5\end{array}$ & $\begin{array}{l}0 . \\
5\end{array}$ & 0 & 0 & 1 & 2.5 & $\begin{array}{l}5 . \\
5\end{array}$ \\
\hline $\begin{array}{l}\text { (Liu et al., } \\
\text { 2012) }\end{array}$ & 1 & 1 & 1 & 0 & 1 & 1 & 1 & 0 & 0 & 0 & 1 & 0 & 0 & 0 & 0 & 0 & 0 & 0 & 1 & 1 & 0 & 0 & 0 & 0 & $\begin{array}{l}0 . \\
5\end{array}$ & 1 & 1 & 1 & 0 & 0 & 1 & 8.5 & $\begin{array}{l}6 . \\
5 \\
\end{array}$ \\
\hline $\begin{array}{l}\text { (Marconi et } \\
\text { al., 2009) }\end{array}$ & 0 & 0 & 1 & 1 & 1 & 1 & 1 & 0 & 0 & 0 & 1 & 0 & 0 & 0 & 0 & 0 & 0 & 0 & 1 & $\begin{array}{l}0 . \\
5\end{array}$ & $\begin{array}{l}0 . \\
5 \\
\end{array}$ & 0 & 0 & 0 & 0 & 1 & 1 & 1 & 0 & 0 & 1 & 7.5 & $\begin{array}{l}6 . \\
0 \\
\end{array}$ \\
\hline $\begin{array}{l}\text { (Martinho et } \\
\text { al., 2015) }\end{array}$ & 0 & 0 & 0 & 0 & 0 & 0 & 1 & 0 & 0 & 1 & 1 & 0 & 0 & 0 & 0 & 0 & 0 & 1 & 1 & 1 & $\begin{array}{l}0 . \\
5\end{array}$ & 0 & 0 & 0 & 0 & 1 & 1 & 1 & 0 & 0 & 1 & 5.5 & $\begin{array}{l}6 . \\
5\end{array}$ \\
\hline $\begin{array}{l}\text { (Mattos et al., } \\
\text { 2014) }\end{array}$ & 0 & 0 & 1 & 1 & 0 & 1 & $\begin{array}{l}0 . \\
5 \\
\end{array}$ & 0 & 0 & 0 & 1 & 0 & 0 & 0 & 0 & 1 & 0 & 1 & 1 & 1 & 0 & 0 & 0 & 1 & 0 & 1 & 1 & 1 & 1 & 1 & 1 & 8.5 & $\begin{array}{l}9 . \\
0\end{array}$ \\
\hline $\begin{array}{l}\text { (Mejia Bernal } \\
\text { et al., 2010) }\end{array}$ & 0 & 1 & 1 & 1 & 1 & 1 & 1 & 1 & 1 & 0 & 1 & 0 & 0 & 0 & 0 & 0 & 1 & 0 & 1 & 0 & 0 & 0 & $\begin{array}{l}0 . \\
5 \\
\end{array}$ & 0 & 0 & 1 & 1 & 1 & $\begin{array}{l}0 . \\
5 \\
\end{array}$ & 0 & 1 & $\begin{array}{l}11 . \\
5\end{array}$ & $\begin{array}{l}6 . \\
0\end{array}$ \\
\hline $\begin{array}{l}\text { (Mounira \& } \\
\text { Mahmoud, } \\
\text { 2010) }\end{array}$ & 0 & 1 & 1 & 1 & 1 & 1 & 1 & 0 & 0 & 0 & 1 & 1 & 0 & 0 & 0 & 1 & 0 & 0 & 1 & 0 & 0 & 0 & 0 & 0 & $\begin{array}{l}0 . \\
5\end{array}$ & 1 & 1 & 1 & 0 & 0 & 1 & $\begin{array}{l}10 . \\
5\end{array}$ & $\begin{array}{l}5 . \\
5\end{array}$ \\
\hline $\begin{array}{l}\text { (Natschläger } \\
\text { et al., 2016) }\end{array}$ & 0 & 1 & 0 & 0 & 1 & 0 & 1 & 0 & 0 & 0 & 0 & 0 & 0 & 0 & 0 & 0 & 0 & 0 & 1 & 0 & $\begin{array}{l}0 . \\
5 \\
\end{array}$ & 0 & 0 & 0 & 0 & 1 & 1 & 1 & 0 & 0 & 1 & 4.5 & $\begin{array}{l}5 . \\
5 \\
\end{array}$ \\
\hline $\begin{array}{l}\text { (Oberhauser, } \\
2016)\end{array}$ & 0 & 0 & 1 & 0 & 1 & 1 & 1 & 0 & 0 & 0 & 1 & 0 & 0 & 0 & 0 & 0 & 0 & 0 & 1 & 0 & $\begin{array}{l}0 . \\
5 \\
\end{array}$ & 0 & 0 & 0 & 0 & 1 & 1 & $\begin{array}{l}0 . \\
5 \\
\end{array}$ & 0 & 0 & 1 & 6.5 & $\begin{array}{l}5 . \\
0\end{array}$ \\
\hline $\begin{array}{l}\text { (Prasad et al., } \\
\text { 2015) }\end{array}$ & 0 & 0 & 0 & 0 & 1 & 0 & 1 & 0 & 0 & 0 & 1 & 0 & 0 & 0 & 0 & 0 & 0 & 1 & 1 & 0 & 0 & 0 & 0 & $\begin{array}{l}0 . \\
5\end{array}$ & 0 & 1 & $\begin{array}{l}0 . \\
5 \\
\end{array}$ & $\begin{array}{l}0 . \\
5\end{array}$ & 0 & 0 & 1 & 5.5 & $\begin{array}{l}4 . \\
5\end{array}$ \\
\hline $\begin{array}{l}\text { (Ramakrishna } \\
\mathrm{n}, 2009)\end{array}$ & 0 & 1 & 0 & 0 & 1 & 0 & 0 & 0 & 0 & 1 & 1 & 0 & 0 & 0 & 0 & 0 & 0 & 1 & 1 & 0 & $\begin{array}{l}0 . \\
5\end{array}$ & 0 & 0 & 0 & 0 & 1 & $\begin{array}{l}0 . \\
5 \\
\end{array}$ & $\begin{array}{l}0 . \\
5\end{array}$ & 0 & 0 & 1 & 6.5 & $\begin{array}{l}4 . \\
5\end{array}$ \\
\hline $\begin{array}{l}\text { (Rong et al., } \\
\text { 2008) }\end{array}$ & 1 & 1 & 0 & 1 & 1 & 1 & 1 & 0 & 0 & 0 & 1 & 0 & 0 & 0 & 0 & 0 & 0 & 0 & 1 & 0 & 0 & 0 & 0 & 0 & $\begin{array}{l}0 . \\
5 \\
\end{array}$ & 1 & $\begin{array}{l}0 . \\
5\end{array}$ & $\begin{array}{l}0 . \\
5 \\
\end{array}$ & 0 & 0 & 1 & 8.5 & $\begin{array}{l}4 . \\
5 \\
\end{array}$ \\
\hline $\begin{array}{l}\text { (Saidani \& } \\
\text { Nurcan, 2006) }\end{array}$ & 0 & 0 & 0 & 0 & 1 & 0 & 1 & 0 & 0 & 0 & 0 & 0 & 0 & 0 & 0 & 0 & 1 & 0 & 1 & 0 & 0 & 0 & 0 & 0 & 0 & 0 & 0 & 0 & 0 & 0 & 1 & 3.0 & $\begin{array}{l}2 . \\
0\end{array}$ \\
\hline
\end{tabular}




\begin{tabular}{|c|c|c|c|c|c|c|c|c|c|c|c|c|c|c|c|c|c|c|c|c|c|c|c|c|c|c|c|c|c|c|c|c|c|}
\hline $\begin{array}{l}\text { (Santo } \\
\text { Carvalho et } \\
\text { al., 2015) }\end{array}$ & 0 & 1 & 0 & 1 & 0 & 1 & 1 & 1 & 1 & 0 & 1 & 1 & 0 & 1 & 0 & 1 & 1 & 1 & 1 & 1 & 0 & 0 & 0 & 1 & 0 & 1 & 1 & 1 & 1 & 0 & 1 & $\begin{array}{l}14 . \\
0\end{array}$ & $\begin{array}{l}8 . \\
0\end{array}$ \\
\hline $\begin{array}{l}\text { (Santo } \\
\text { Carvalho et } \\
\text { al., 2013) }\end{array}$ & 0 & 1 & 0 & 1 & 1 & 0 & 1 & 0 & 0 & 0 & 0 & 1 & 0 & 0 & 0 & 1 & 1 & 0 & 1 & 0 & 0 & 0 & 0 & $\begin{array}{l}0 . \\
5\end{array}$ & 0 & 1 & 1 & 1 & 0 & 0 & 1 & 8.5 & $\begin{array}{l}5 . \\
5\end{array}$ \\
\hline $\begin{array}{l}\text { (Santos et al., } \\
\text { 2013) }\end{array}$ & 0 & 0 & 1 & 1 & 0 & 0 & 1 & 0 & 0 & 1 & 1 & 0 & 0 & 0 & 0 & 0 & 0 & 0 & 1 & 1 & 0 & 0 & 1 & 0 & 0 & 1 & 1 & 1 & 0 & 0 & 1 & 7.0 & $\begin{array}{l}7 . \\
0\end{array}$ \\
\hline $\begin{array}{l}\text { (Santos et al., } \\
\text { 2011) }\end{array}$ & 0 & 1 & 0 & 1 & 0 & 1 & 0 & 0 & 0 & 1 & 1 & 0 & 0 & 0 & 0 & 0 & 0 & 0 & 1 & 0 & $\begin{array}{l}0 . \\
5\end{array}$ & 0 & 0 & 0 & 0 & 1 & $\begin{array}{l}0 . \\
5\end{array}$ & $\begin{array}{l}0 . \\
5\end{array}$ & 0 & 0 & 1 & 6.5 & $\begin{array}{l}4 . \\
5\end{array}$ \\
\hline $\begin{array}{l}\text { (Sarno et al., } \\
2015 \text { ) }\end{array}$ & 0 & 0 & 0 & 0 & 0 & 0 & 0 & 0 & 0 & 0 & 0 & 0 & 0 & 0 & 0 & 0 & 0 & 0 & 1 & 0 & $\begin{array}{l}0 . \\
5\end{array}$ & 0 & 0 & 0 & 0 & 1 & 1 & 1 & 0 & 0 & 1 & 1.5 & $\begin{array}{l}5 . \\
5\end{array}$ \\
\hline $\begin{array}{l}\text { (Sprovieri et } \\
\text { al., 2016) }\end{array}$ & 0 & 0 & $\begin{array}{l}0 . \\
5\end{array}$ & 1 & 1 & 1 & 1 & 0 & 0 & 0 & 1 & 0 & 0 & 0 & 0 & 0 & 1 & 0 & 1 & 0 & 0 & $\begin{array}{l}0 . \\
5\end{array}$ & 0 & 0 & 0 & 1 & $\begin{array}{l}0 . \\
5\end{array}$ & $\begin{array}{l}0 . \\
5\end{array}$ & $\begin{array}{l}0 . \\
5\end{array}$ & 0 & 1 & 8.0 & $\begin{array}{l}5 . \\
0\end{array}$ \\
\hline $\begin{array}{l}\text { (Sun et al., } \\
2011 \text { ) }\end{array}$ & 0 & 1 & 0 & 0 & 1 & 1 & 1 & 0 & 0 & 0 & 1 & 0 & 0 & 0 & 0 & 0 & 0 & 0 & 1 & 1 & 0 & 0 & $\begin{array}{l}0 . \\
5 \\
\end{array}$ & 0 & 0 & 1 & 1 & 1 & $\begin{array}{l}0 . \\
5\end{array}$ & 0 & 1 & 6.5 & $\begin{array}{l}7 . \\
0\end{array}$ \\
\hline $\begin{array}{l}\text { (Ukor \& } \\
\text { Carpenter, } \\
\text { 2009) }\end{array}$ & 0 & 1 & 0 & 0 & 1 & 1 & 1 & 0 & 0 & 0 & 1 & 0 & 0 & 0 & 0 & 0 & 0 & 0 & 1 & 1 & $\begin{array}{l}0 . \\
5\end{array}$ & 0 & 0 & 0 & 0 & 0 & 0 & 0 & 1 & 0 & 1 & 5.5 & $\begin{array}{l}4 . \\
5\end{array}$ \\
\hline $\begin{array}{l}\text { (van } \\
\text { Eijndhoven et } \\
\text { al., 2008) }\end{array}$ & 0 & 0 & 0 & 0 & 1 & 1 & 1 & 0 & 0 & 0 & 1 & 0 & 0 & 0 & 0 & 0 & 0 & 0 & 1 & 0 & $\begin{array}{l}0 . \\
5\end{array}$ & 0 & 0 & 0 & 0 & 1 & $\begin{array}{l}0 . \\
5\end{array}$ & $\begin{array}{l}0 . \\
5\end{array}$ & 0 & 0 & 1 & 5.5 & $\begin{array}{l}4 . \\
5\end{array}$ \\
\hline $\begin{array}{l}\text { (Wang \& } \\
\text { Capretz, } \\
\text { 2007) }\end{array}$ & 1 & 0 & 0 & 0 & 0 & 0 & 1 & 0 & 0 & 0 & 1 & 0 & 0 & 0 & 0 & 0 & 1 & 0 & 1 & 1 & $\begin{array}{l}0 . \\
5 \\
\end{array}$ & 0 & 0 & 0 & 0 & 1 & 1 & 1 & 0 & 0 & 1 & 5.5 & $\begin{array}{l}6 . \\
5\end{array}$ \\
\hline $\begin{array}{l}\text { (Weidlich et } \\
\text { al., 2011) }\end{array}$ & 0 & 0 & 0 & 0 & 0 & 0 & 1 & 0 & 0 & 1 & 0 & 0 & 0 & 0 & 0 & 0 & 0 & 0 & 1 & 1 & $\begin{array}{l}0 . \\
5\end{array}$ & 0 & 0 & 0 & 0 & 1 & 1 & 1 & 0 & 0 & 1 & 3.5 & $\begin{array}{l}6 . \\
5\end{array}$ \\
\hline $\begin{array}{l}\text { (Xia \& Wei, } \\
\text { 2008) }\end{array}$ & 0 & 1 & 0 & 1 & 1 & 1 & 1 & 0 & 0 & 1 & 1 & 1 & 0 & 0 & 0 & 0 & 1 & 0 & 1 & 1 & $\begin{array}{l}0 . \\
5\end{array}$ & 0 & 0 & 0 & 0 & 1 & 1 & 1 & 0 & 1 & 1 & $\begin{array}{l}10 . \\
5\end{array}$ & $\begin{array}{l}7 . \\
5\end{array}$ \\
\hline $\begin{array}{l}\text { (Xiao et al., } \\
\text { 2011) }\end{array}$ & 1 & 0 & 0 & 1 & 1 & 1 & 1 & 0 & 0 & 0 & 1 & 0 & 0 & 0 & 0 & 0 & 0 & 0 & 1 & 1 & 0 & 0 & 1 & 0 & 0 & 1 & 1 & 1 & 0 & 0 & 1 & 8.0 & $\begin{array}{l}7 . \\
0\end{array}$ \\
\hline $\begin{array}{l}\text { (Yoo et al., } \\
2008)\end{array}$ & 0 & 0 & 0 & 1 & 1 & 1 & 1 & 1 & 1 & 0 & 1 & 0 & 0 & 0 & 0 & 0 & 0 & 0 & 1 & 1 & 0 & 0 & 0 & 0 & $\begin{array}{l}0 . \\
5\end{array}$ & 1 & 1 & 1 & 0 & 0 & 1 & 8.5 & $\begin{array}{l}6 . \\
5 \\
\end{array}$ \\
\hline $\begin{array}{l}\text { (Yousfi et al., } \\
\text { 2016) }\end{array}$ & 0 & 0 & 0 & 1 & 0 & 1 & 1 & 0 & 0 & 0 & 1 & 0 & 0 & 0 & 0 & 0 & 1 & 0 & 1 & 1 & $\begin{array}{l}0 . \\
5\end{array}$ & 0 & 0 & 0 & 0 & 1 & 1 & 1 & 1 & 1 & 1 & 6.5 & $\begin{array}{l}8 . \\
5 \\
\end{array}$ \\
\hline $\begin{array}{l}\text { (Yuliang et } \\
\text { al., 2009) }\end{array}$ & 0 & 0 & 0 & 0 & 0 & 0 & 1 & 0 & 0 & 0 & 1 & 0 & 0 & 0 & 0 & 0 & 0 & 0 & 1 & 0 & 0 & 0 & 0 & 0 & $\begin{array}{l}0 . \\
5\end{array}$ & 1 & $\begin{array}{l}0 . \\
5\end{array}$ & $\begin{array}{l}0 . \\
5\end{array}$ & 0 & 0 & 1 & 3.5 & $\begin{array}{l}4 . \\
5\end{array}$ \\
\hline $\begin{array}{l}\text { (Gottschalk et } \\
\text { al., 2008) }\end{array}$ & 0 & 0 & 1 & 0 & 0 & 0 & 1 & 0 & 0 & 0 & 1 & 0 & 0 & 0 & 0 & 0 & 0 & 0 & 1 & 0 & $\begin{array}{l}0 . \\
5\end{array}$ & 0 & 0 & 0 & 0 & 1 & 1 & 1 & 0 & 0 & 1 & 4.5 & $\begin{array}{l}5 . \\
5\end{array}$ \\
\hline $\begin{array}{l}\text { (Maggi et al., } \\
\text { 2012) }\end{array}$ & 0 & 0 & 1 & 0 & 0 & 0 & 1 & 0 & 0 & 1 & 1 & 0 & 0 & 0 & 0 & 0 & 0 & 0 & 1 & 1 & 0 & 0 & 1 & 0 & 0 & 1 & 1 & 1 & 0 & 0 & 1 & 6.0 & $\begin{array}{l}7 . \\
0\end{array}$ \\
\hline $\begin{array}{l}\text { (Pesic \& van } \\
\text { der Aalst, } \\
2006 \text { ) }\end{array}$ & 0 & 0 & 1 & 0 & 0 & 0 & 1 & 0 & 0 & 0 & 1 & 0 & 0 & 0 & 0 & 0 & 0 & 0 & 1 & 0 & 0 & 0 & 1 & 0 & 0 & $\begin{array}{l}0 . \\
5\end{array}$ & 0 & $\begin{array}{l}0 . \\
5\end{array}$ & 0 & 0 & 1 & 4.5 & $\begin{array}{l}4 . \\
0\end{array}$ \\
\hline $\begin{array}{l}\text { (Wang \& } \\
\text { Wang, 2006) }\end{array}$ & 0 & 0 & 1 & 1 & 1 & 1 & 1 & 0 & 0 & 0 & 1 & 0 & 0 & 0 & 0 & 0 & 1 & 0 & 1 & $\begin{array}{l}0 . \\
5\end{array}$ & 0 & 0 & 1 & $\begin{array}{l}0 . \\
5\end{array}$ & 0 & $\begin{array}{l}0 . \\
5\end{array}$ & $\begin{array}{l}0 . \\
5\end{array}$ & $\begin{array}{l}0 . \\
5\end{array}$ & 0 & 0 & 1 & 9.0 & $\begin{array}{l}5 . \\
5\end{array}$ \\
\hline $\begin{array}{l}\text { (Baresi \& } \\
\text { Guinea, 2005) }\end{array}$ & 0 & 0 & 1 & 1 & 1 & 1 & 1 & 0 & 0 & 0 & 1 & 0 & 0 & 0 & 0 & 0 & 0 & 0 & 1 & 0 & 0 & 0 & 0 & 0 & $\begin{array}{l}0 . \\
5\end{array}$ & 1 & $\begin{array}{l}0 . \\
5\end{array}$ & $\begin{array}{l}0 . \\
5\end{array}$ & 0 & 0 & 1 & 7.5 & $\begin{array}{l}4 . \\
5\end{array}$ \\
\hline (van der Aalst & 0 & 0 & 1 & 0 & 0 & 0 & 1 & 0 & 0 & 0 & 1 & 0 & 0 & 0 & 0 & 0 & 0 & 0 & 1 & 0 & 0 & 0 & 1 & 0 & 0 & 1 & 1 & 1 & 0 & 0 & 1 & 5.0 & 6. \\
\hline
\end{tabular}




\begin{tabular}{|c|c|c|c|c|c|c|c|c|c|c|c|c|c|c|c|c|c|c|c|c|c|c|c|c|c|c|c|c|c|c|c|c|c|}
\hline et al., 2009) & & & & & & & & & & & & & & & & & & & & & & & & & & & & & & & & & 0 \\
\hline $\begin{array}{l}\text { (Savickas \& } \\
\text { Vasilecas, } \\
\text { 2018) }\end{array}$ & 1 & 1 & 1 & 1 & 1 & 1 & 1 & 0 & 0 & 0 & 1 & 1 & 0 & 0 & 0 & 1 & 1 & 0 & 1 & $\begin{array}{l}0 . \\
5\end{array}$ & 0 & 0 & 0 & 1 & 0 & 1 & 1 & 1 & 0 & 0 & 1 & $\begin{array}{l}13 . \\
0\end{array}$ & $\begin{array}{l}6 . \\
5\end{array}$ \\
\hline $\begin{array}{l}\text { (Milanovic et } \\
\text { al., 2011) }\end{array}$ & 0 & 0 & 1 & 1 & 0 & 1 & 0 & 1 & 1 & 0 & 1 & 0 & 0 & 0 & 0 & 0 & 0 & 0 & 1 & 0 & $\begin{array}{l}0 . \\
5\end{array}$ & 0 & 0 & 0 & 0 & 1 & $\begin{array}{l}0 . \\
5\end{array}$ & 1 & 0 & 0 & 1 & 7.5 & $\begin{array}{l}5 . \\
0\end{array}$ \\
\hline $\begin{array}{l}\text { (Bucchiarone } \\
\text { et al., 2017) }\end{array}$ & 0 & 0 & 1 & 1 & 1 & 1 & $\begin{array}{l}0 . \\
5\end{array}$ & 0 & 0 & 0 & 1 & 0 & 0 & 0 & 0 & 0 & 0 & 0 & 1 & $\begin{array}{l}0 . \\
5\end{array}$ & $\begin{array}{l}0 . \\
5\end{array}$ & 0 & 0 & 0 & 0 & 1 & 1 & 1 & 1 & 1 & 1 & 7.0 & $\begin{array}{l}8 . \\
0\end{array}$ \\
\hline $\begin{array}{l}\text { (Vasilecas et } \\
\text { al., 2016b) }\end{array}$ & 1 & 1 & 1 & 1 & 1 & 1 & 1 & 1 & 1 & 0 & 1 & 1 & 1 & 1 & 1 & 0 & 1 & 0 & 1 & 0 & 0 & 0 & 0 & 1 & 0 & 1 & 1 & 1 & 0 & 1 & 1 & $\begin{array}{l}17 . \\
0\end{array}$ & $\begin{array}{l}7 . \\
0\end{array}$ \\
\hline
\end{tabular}




\section{Table 9 (on next page)}

Technology, language or other approaches used in the implementation section of the papers analyzed 


\section{Table 9. Technology, language or other approaches used in the implementation section of the} papers analyzed

\begin{tabular}{|l|l|l|l|}
\hline Reference & $\begin{array}{l}\text { Technology, language, } \\
\text { other approach }\end{array}$ & Results \\
\hline $\begin{array}{l}\text { (Asuncion et al., 2010; Awadid \& Gnannouchi, 2015; } \\
\text { Bucchiarone et al., 2011; Châtel et al., 2010; Deb et al., 2015; } \\
\text { Gong \& Janssen, 2011; Hermosillo et al., 2010a; Kapuruge et al., } \\
\text { 2011; Khriss et al., 2008; Marconi et al., 2009; Oberhauser, 2016; } \\
\text { Prasad et al., 2015; Ramakrishnan, 2009; Rong et al., 2008; Santos } \\
\text { et al., 2011; Sun et al., 2011; Ukor \& Carpenter, 2009; Wang \& } \\
\text { Capretz, 2007; Xia \& Wei, 2008; Xiao et al., 2011; Yoo et al., } \\
\text { 2008; Yuliang et al., 2009; Baresi \& Guinea, 2005; Bucchiarone } \\
\text { et al., 2017) }\end{array}$ & & $49 \%$ \\
\hline $\begin{array}{l}\text { (van der Aalst et al., 2005; Ayora et al., 2016; Bögl et al., 2016; } \\
\text { Jiang et al., 2016; Marconi et al., 2009; Martinho et al., 2015; } \\
\text { Mattos et al., 2014; Santos et al., 2013; Santos et al., 2011; van } \\
\text { Eijndhoven et al., 2008; Yousfi et al., 2016; Milanovic et al., 2011) }\end{array}$ & & & \\
\hline $\begin{array}{l}\text { (Cherif et al., 2015; Hallerbach et al., 2010; Hermosillo et al., } \\
\text { 2010a; Kim et al., 2007; Marconi et al., 2009; Sun et al., 2011; } \\
\text { Ukor \& Carpenter, 2009; Yoo et al., 2008; Yuliang et al., 2009; } \\
\text { Baresi \& Guinea, 2005) }\end{array}$ & & & \\
\hline $\begin{array}{l}\text { (Abderrahmane et al., 2014; Asuncion et al., 2010; Sprovieri et al., } \\
\text { 2016) }\end{array}$ & MOF, MDA, CMMN & & \\
\hline (Boffoli et al., 2012; Boffoli et al., 2009; Mejia Bernal et al., & Decision tables & \\
2010) & & $10 \%$ \\
\hline $\begin{array}{l}\text { (Li \& Du, 2016; Liu et al., 2012; Mejia Bernal et al., 2010; Saidani } \\
\text { \& Nurcan, 2006; Santo Carvalho et al., 2015) }\end{array}$ & Not provide any & \\
\hline
\end{tabular}




\section{Table $\mathbf{1 0}$ (on next page)}

Number of papers according to their rigor and ranking during periods 
Table 1. Number of papers according to their rigor and ranking during periods

\begin{tabular}{|l|r|r|r|r|r|r|r|}
\hline Rigor/ranking & $\begin{array}{r}\text { low } \\
\text { rigor } \\
{[2 ; 4)}\end{array}$ & $\begin{array}{r}\text { middle } \\
\text { rigor } \\
{[4 ; 7)}\end{array}$ & $\begin{array}{r}\text { high } \\
\text { rigor } \\
{[7 ; 9]}\end{array}$ & $\begin{array}{r}\text { low } \\
\text { ranking } \\
{[1 ; 7)}\end{array}$ & $\begin{array}{r}\text { middle } \\
\text { ranking } \\
{[7 ; 14)}\end{array}$ & $\begin{array}{r}\text { high } \\
\text { ranking } \\
{[14 ; 22]}\end{array}$ & $\begin{array}{r}\text { Number } \\
\text { of } \\
\text { papers }\end{array}$ \\
\hline $2008-2011$ & 3 & 12 & 15 & 15 & 15 & 0 & 30 \\
\hline $2014-2016$ & 2 & 9 & 14 & 11 & 9 & 2 & 22 \\
\hline $\begin{array}{r}\text { Number of } \\
\text { papers }\end{array}$ & 5 & 11 & 29 & 26 & 24 & 2 & 55 \\
\hline
\end{tabular}

2 


\section{Table 11 (on next page)}

The number of papers according to the rigor-ranking scores 
Table 11. The number of papers according to the rigor-ranking scores

\begin{tabular}{|l|c|c|c|}
\hline Rigor & $\begin{array}{r}\text { Ranking ranking } \\
{[1 ; 7)}\end{array}$ & $\begin{array}{r}\text { middle ranking } \\
{[7 ; 14)}\end{array}$ & $\begin{array}{r}\text { high ranking } \\
{[14 ; 22)}\end{array}$ \\
\hline low rigor $[2 ; 4)$ & 2 & 0 & 0 \\
\hline middle rigor $[4 ; 6)$ & 15 & 13 & 0 \\
\hline high rigor $[6 ; 9]$ & 13 & 22 & 2 \\
\hline
\end{tabular}

2

3 


\section{Table 12 (on next page)}

Numbers of papers according to the rigor-ranking scores in identified periods 


\begin{tabular}{|c|c|c|c|}
\hline Rigor $\quad$ Ranking & $\begin{array}{r}\text { low ranking } \\
{[1 ; 7)(\mathrm{A} / \mathrm{B} / \mathrm{C})}\end{array}$ & $\begin{array}{l}\text { middle ranking } \\
{[7 ; 14)(\mathrm{A} / \mathrm{B} / \mathrm{C})}\end{array}$ & $\begin{array}{r}\text { high ranking } \\
{[14 ; 22)(\mathrm{A} / \mathrm{B} / \mathrm{C})}\end{array}$ \\
\hline low rigor $[2 ; 4)(\mathrm{A} / \mathrm{B} / \mathrm{C})$ & $1 / 1 / 0$ & $0 / 0 / 0$ & $0 / 0 / 0$ \\
\hline middle rigor $[4 ; 6)(\mathrm{A} / \mathrm{B} / \mathrm{C})$ & $4 / 11 / 0$ & $0 / 4 / 9$ & $0 / 0 / 0$ \\
\hline high rigor $[6 ; 9](\mathrm{A} / \mathrm{B} / \mathrm{C})$ & $2 / 11 / 0$ & $0 / 3 / 19$ & $0 / 0 / 2$ \\
\hline
\end{tabular}

2

3 


\section{Table 13 (on next page)}

Comparison of DBP modeling and simulation tools 
Table 13. Comparison of DBP modeling and simulation tools

\begin{tabular}{|c|c|c|c|c|c|}
\hline Comparison criteria & $\begin{array}{l}\text { IBM } \\
\text { Websphere }^{1} \\
\text { (v.7.0 2014) }\end{array}$ & $\begin{array}{l}\text { Simprocess }^{2} \\
\text { (v 2015) }\end{array}$ & Simul $8^{3}$ & AccuProcess $^{4}$ & $\begin{array}{l}\text { ARIS } \\
9.7^{5}\end{array}$ \\
\hline \multicolumn{6}{|c|}{ 1. Process model predefined (DBPR-1) } \\
\hline 1.1. predefined process model & + & + & + & + & + \\
\hline \multicolumn{6}{|c|}{ 2. Context predefined (DBPR-2) } \\
\hline $\begin{array}{l}2.1 \text { Internal context (or resource } \\
\text { model) could be defined before } \\
\text { simulation/execution }\end{array}$ & + & + & + & + & + \\
\hline $\begin{array}{l}2.2 \text { External context could be } \\
\text { defined before } \\
\text { simulation/execution }\end{array}$ & - & - & - & - & - \\
\hline \multicolumn{6}{|c|}{ 3. Rules predefined (DBPR-3) } \\
\hline 3.1. rules integration into $\mathrm{BP}$ & + & + & + & + & + \\
\hline 3.2. rules management & + & + & + & + & + \\
\hline 3.3. comparison of rules & + & - & - & - & $+/-$ \\
\hline 3.4. analysis of rules & + & - & - & - & - \\
\hline \multicolumn{6}{|c|}{ 4. Accumulation of experience (DBPR-5) } \\
\hline 4.1. Usage of historical data & + & + & + & + & + \\
\hline 4.2. Analysis of historical data & $+/-$ & $+/-$ & $+/-$ & - & + \\
\hline \multicolumn{6}{|c|}{ 5. Changes at runtime (DBPR-4) } \\
\hline 5.1. changes of rules & - & - & - & - & - \\
\hline 5.2. changes of context & - & - & - & - & - \\
\hline 5.3. changes of activities & - & - & $+/-$ & + & $+/-$ \\
\hline
\end{tabular}

2

31 http://www-03.ibm.com/software/products/en/modeler-advanced

$4{ }^{2} \mathrm{http}: / /$ simprocess.com

$5{ }^{3} \mathrm{http}: / / \mathrm{www} \cdot \operatorname{simul} 8 . \mathrm{com}$

$6 \quad{ }^{4} \mathrm{http} / / /$ bpmgeek.com/accuprocess-business-process-modeler

$7{ }^{5} \mathrm{http}: / / \mathrm{www}$.ariscommunity.com/business-process-simulation 
Table 14(on next page)

Main features of a dynamic BP (RQ3) 
Table 14. Main features of a dynamic BP (RQ3)

\begin{tabular}{|c|c|c|c|}
\hline Feature & Explanation & Origin & \\
\hline $\begin{array}{l}\text { Not predefined } \\
\text { process model }\end{array}$ & $\begin{array}{l}\text { The set of process activities is } \\
\text { defined partially, and additional } \\
\text { activities can be defined at run- } \\
\text { time, if needed. The sequence of } \\
\text { process activities is not } \\
\text { predefined before process } \\
\text { execution, and every next activity } \\
\text { is chosen to fit a BP goal. }\end{array}$ & $\begin{array}{l}\text { DBPR-1 } \\
\text { Table } 4 \text { feature } 1 \\
\text { Table } 8 \text {, the first three } \\
\text { columns }(1.1,1.2 \text {, and } \\
1.3)\end{array}$ & $\begin{array}{l}\text { Found in } 8 \text { of } 67 \\
\text { papers }\end{array}$ \\
\hline $\begin{array}{l}\text { Context- } \\
\text { sensitive }\end{array}$ & $\begin{array}{l}\text { Process instance should respond } \\
\text { to the changing context, which is } \\
\text { external or internal. }\end{array}$ & $\begin{array}{l}\text { DBPR-2 } \\
\text { Table } 4 \text { feature } 2 \\
\text { Table } 8 \text {, columns } 2.1 \text {, } \\
\text { 2.2, and } 2.3\end{array}$ & $\begin{array}{l}\text { Found in } 50 \text { of } \\
67 \text { papers }\end{array}$ \\
\hline Rule-based & $\begin{array}{l}\text { The sequence of process activities } \\
\text { and content of each activity } \\
\text { depend on rules, which are } \\
\text { defined, and new rules can be } \\
\text { added, if needed, at run-time. }\end{array}$ & $\begin{array}{l}\text { DBPR-3 } \\
\text { Table } 4 \text { feature } 3 \\
\text { Table } 8 \text {, columns } 3.1- \\
3.4\end{array}$ & $\begin{array}{l}\text { Found in } 55 \text { of } \\
67 \text { papers }\end{array}$ \\
\hline $\begin{array}{l}\text { Changes at } \\
\text { run-time }\end{array}$ & $\begin{array}{l}\text { All possible changes can be done } \\
\text { by any role involved at process } \\
\text { instance run-time with possibly } \\
\text { low latency. }\end{array}$ & $\begin{array}{l}\text { DBPR- } 4 \\
\text { Table } 4 \text { feature } 4 \\
\text { Table } 8 \text {, columns } 4,1.3 \text {, } \\
2.3,3.2\end{array}$ & $\begin{array}{l}\text { Found in } 55 \text { of } \\
67 \text { papers }\end{array}$ \\
\hline Goal-oriented & $\begin{array}{l}\text { The selection of each process } \\
\text { activity should be aligned with a } \\
\text { process goal. }\end{array}$ & $\begin{array}{l}\text { DBPR- } 6 \\
\text { Table } 4 \text { feature } 6 \\
\text { Table } 8 \text {, column } 6\end{array}$ & $\begin{array}{l}\text { Found in } 19 \text { of } \\
67 \text { papers }\end{array}$ \\
\hline $\begin{array}{l}\text { Aligned with a } \\
\text { process } \\
\text { ontology }\end{array}$ & $\begin{array}{l}\text { All process components should } \\
\text { be aligned with a process } \\
\text { ontology. }\end{array}$ & $\begin{array}{l}\text { Table } 4 \text { feature } 7 \\
\text { Table } 8 \text {, column } 7\end{array}$ & $\begin{array}{l}\text { Found in } 10 \text { of } \\
67 \text { papers }\end{array}$ \\
\hline $\begin{array}{l}\text { Accumulation } \\
\text { of experience }\end{array}$ & $\begin{array}{l}\text { The selection of each process } \\
\text { activity should be aligned with } \\
\text { historical data, accumulated } \\
\text { throughout this process. }\end{array}$ & $\begin{array}{l}\text { DBPR- } 5 \\
\text { Table } 4 \text { feature } 5 \\
\text { Table } 8 \text {, columns } 5.1- \\
5.5\end{array}$ & $\begin{array}{l}\text { Found in } 12 \text { of } \\
67 \text { papers }\end{array}$ \\
\hline Feasibility & $\begin{array}{l}\text { The feasibility of the process } \\
\text { should be ensured. }\end{array}$ & $\begin{array}{l}\text { Table } 4 \text { features } 9 \text { and } 10 \\
\text { Table } 8 \text {, columns } 9.1- \\
9.5,10.1-10.5\end{array}$ & $\begin{array}{l}\text { Found in } 63 \text { of } \\
67 \text { papers }\end{array}$ \\
\hline
\end{tabular}




\section{Figure 1}

\section{The research method schema}

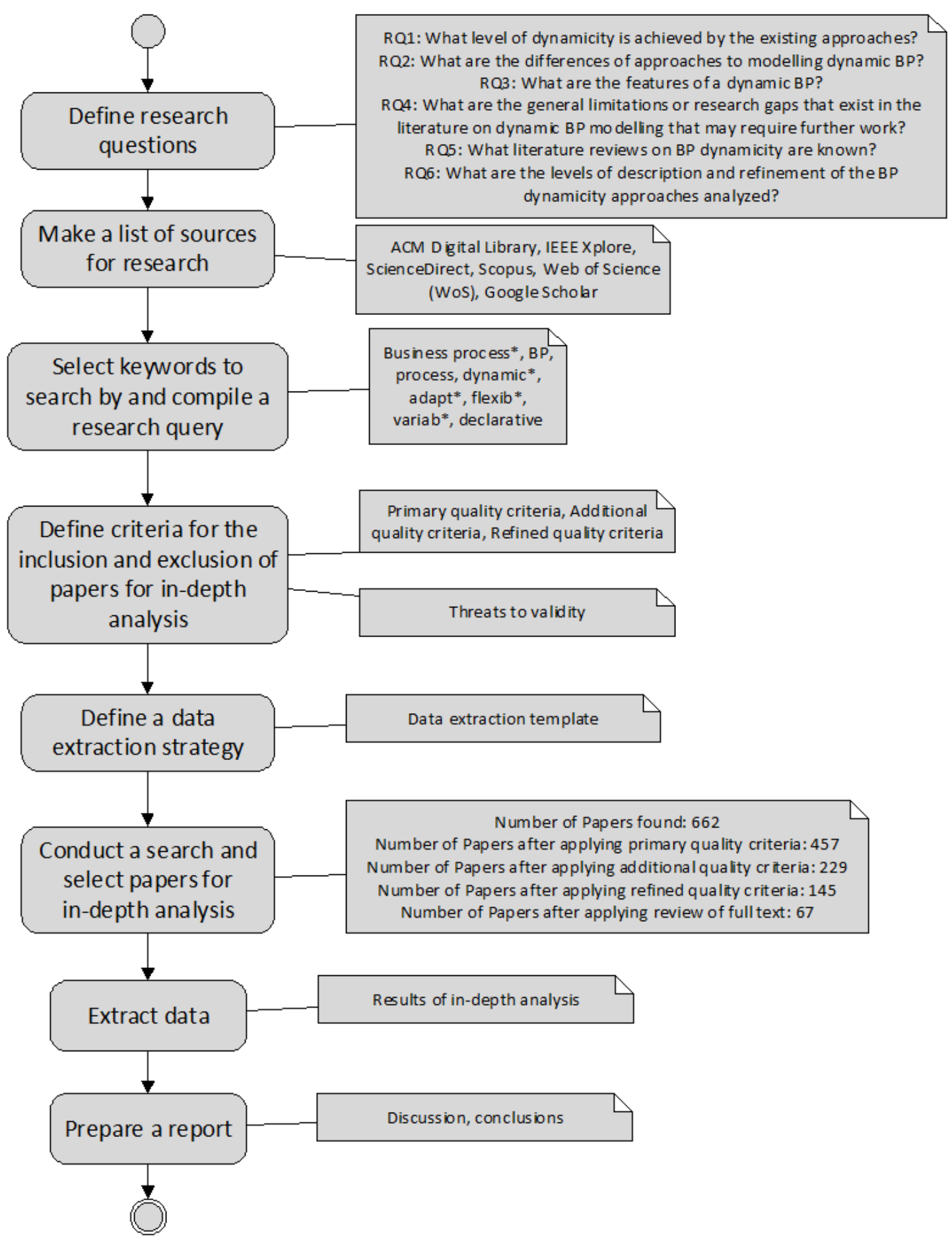


Figure 2

An overview of rigor-ranking scores for the papers on literature reviews on BP dynamicity

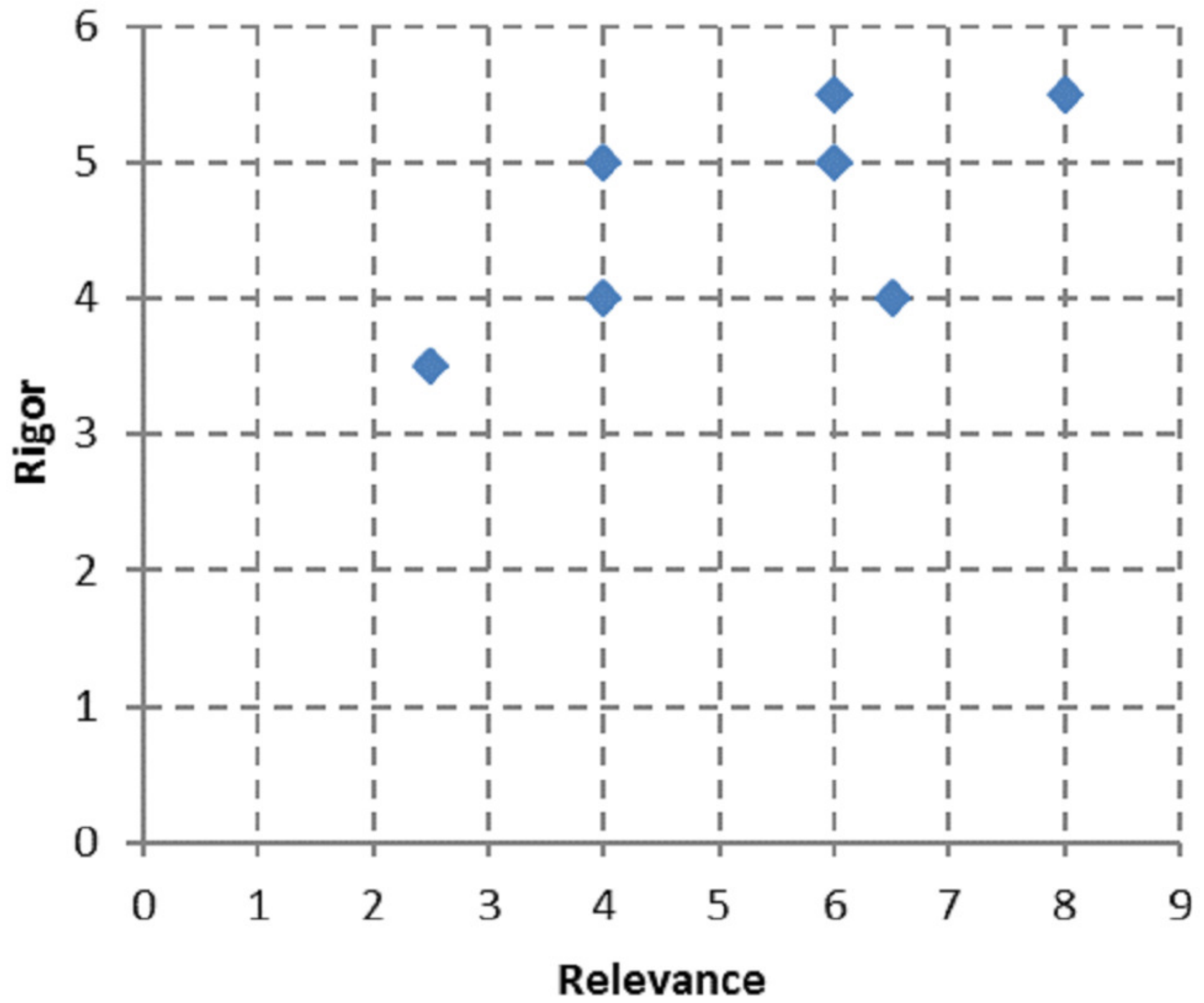


Figure 3

An overview of answers on the assessment of the papers on literature reviews on BP dynamicity

An overview of answers on the assessment of the papers on literature reviews on BP dynamicity

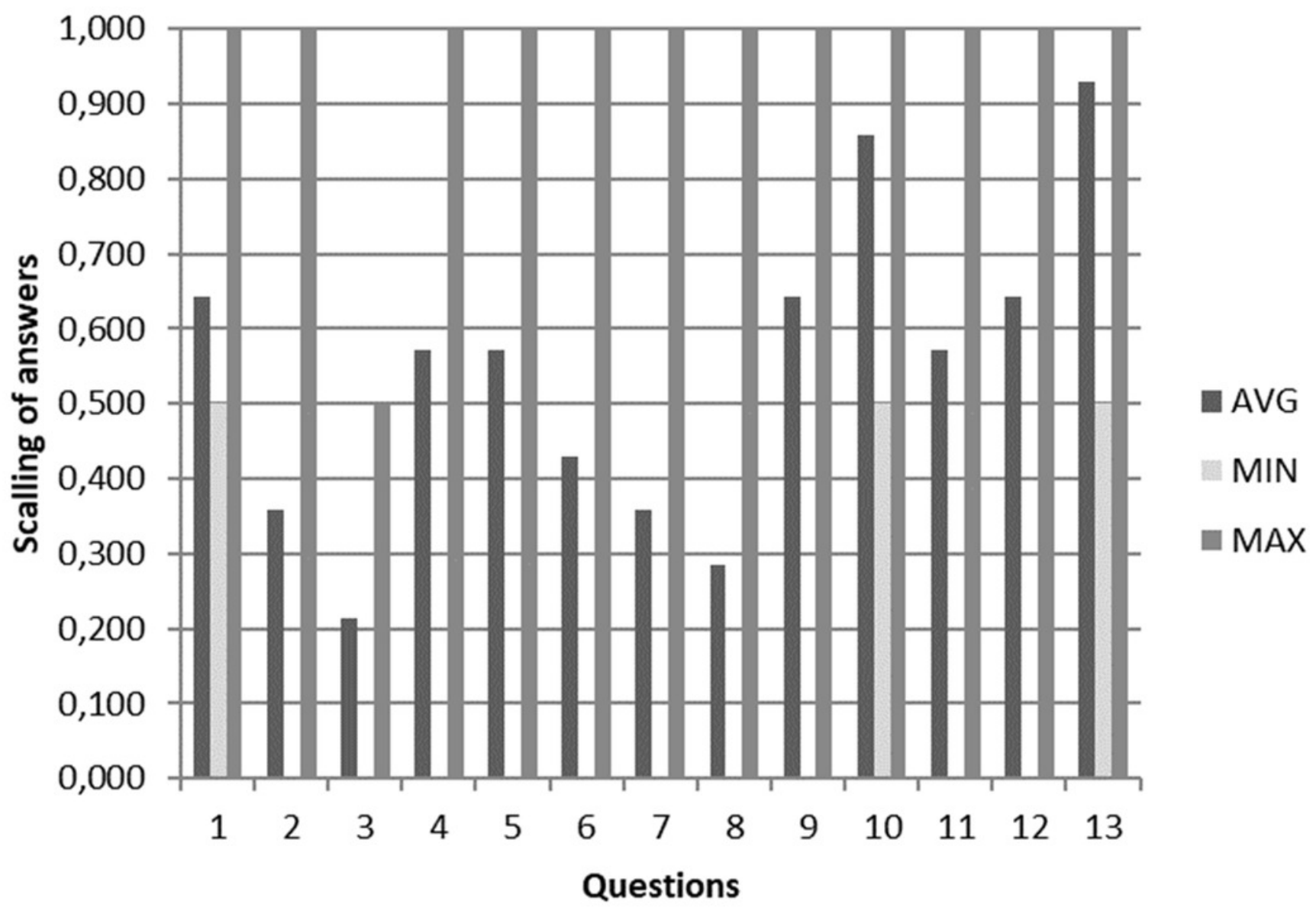


Figure 4

The number of papers on BP dynamicity selected for in-depth analysis by year

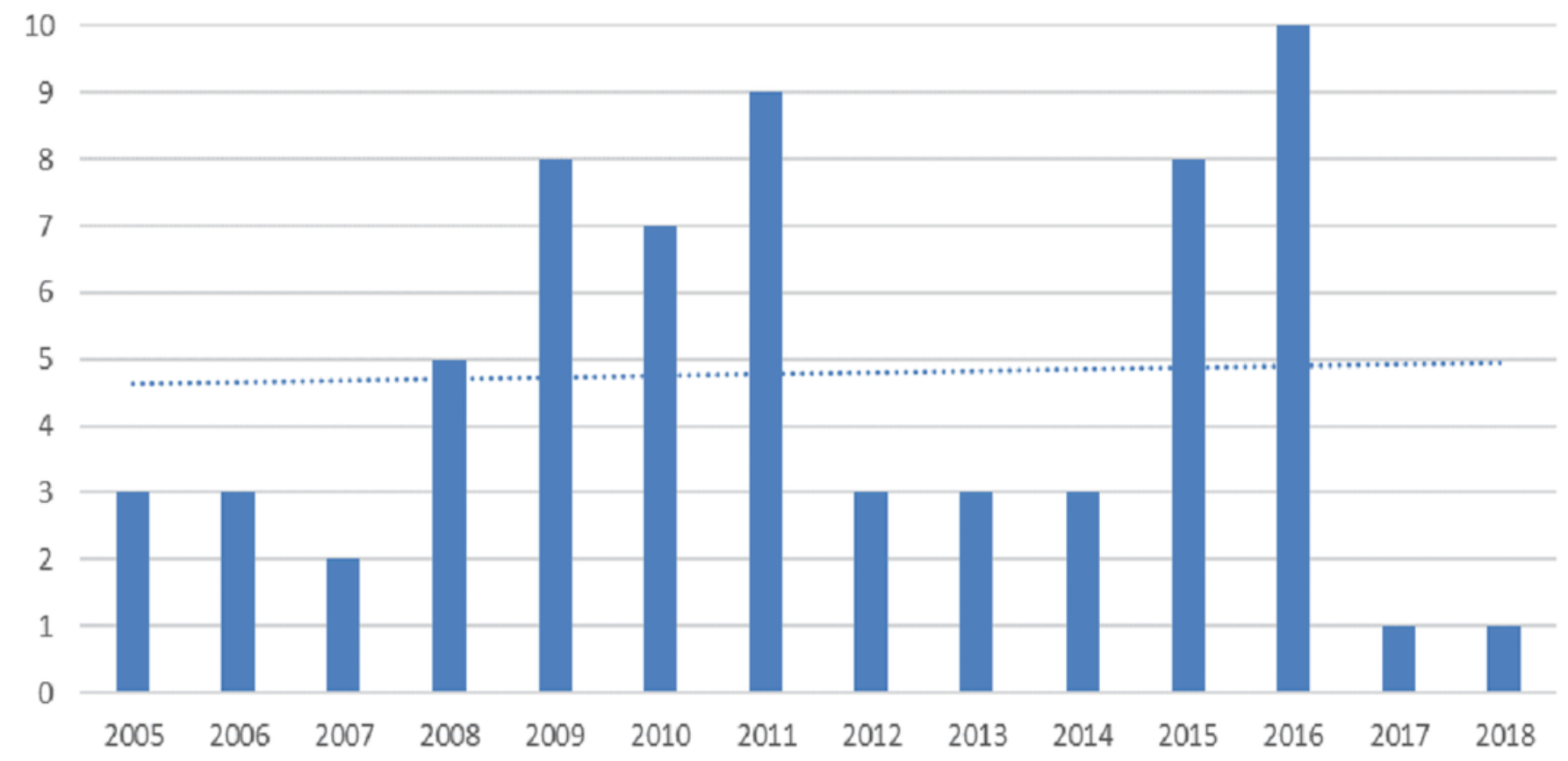


Figure 5

Ranking of papers according to rigor

Ranking of papers according to rigor

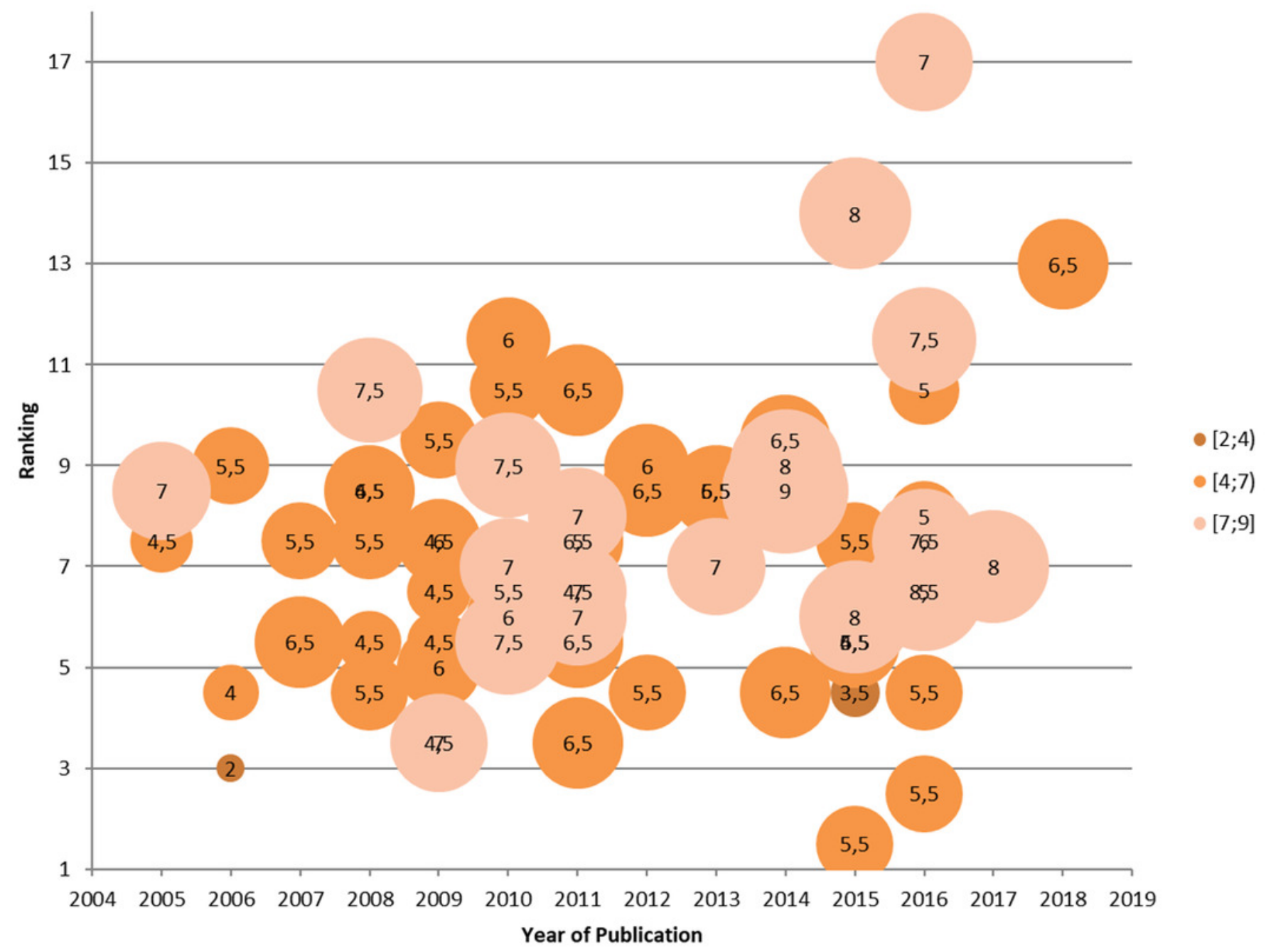


Figure 6

Overview of rigor-ranking scores for the papers

Overview of rigor-ranking scores for the papers

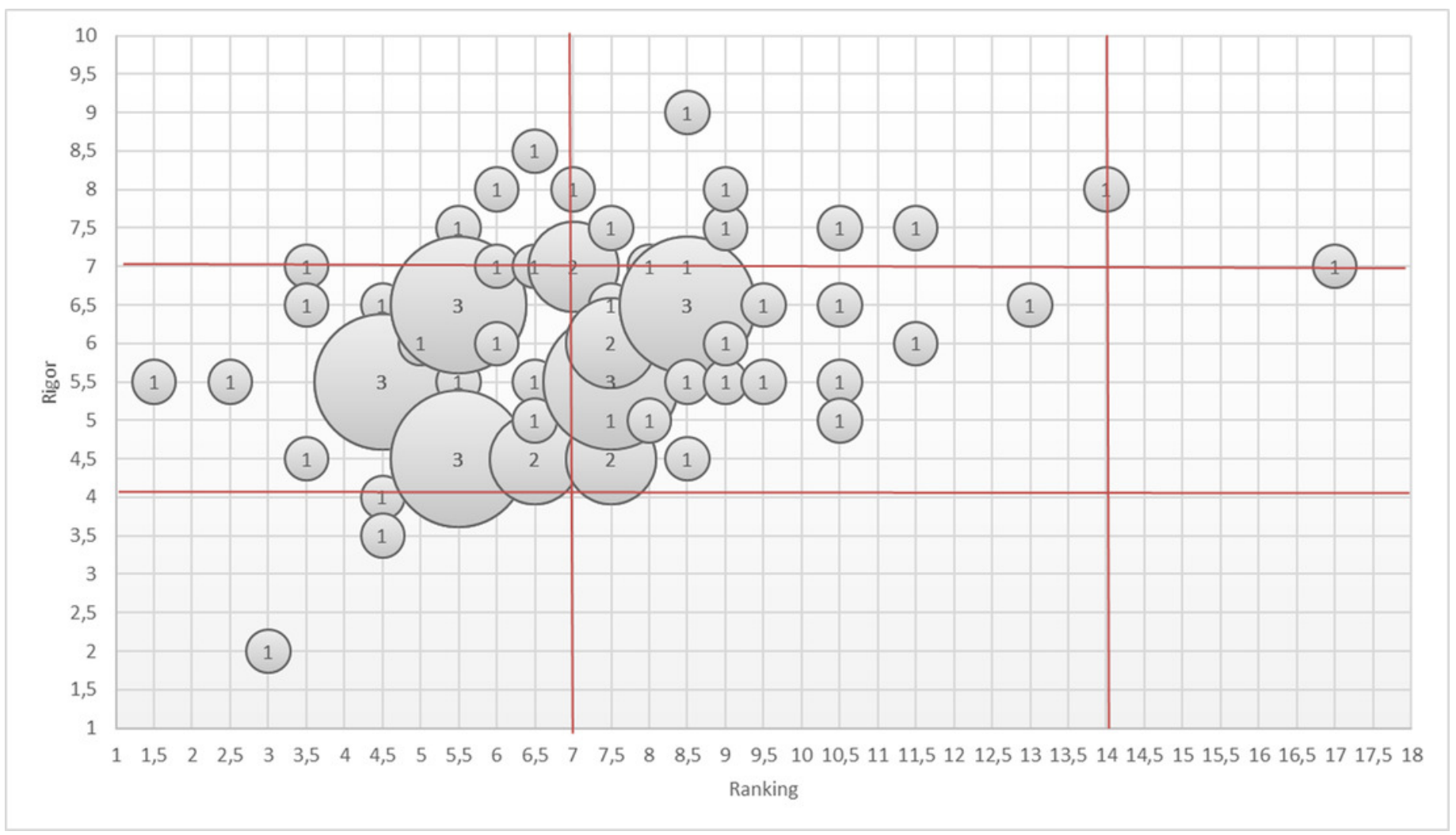




\section{Table $\mathbf{1 5}$ (on next page)}

Table 15. Categorization of references used to answer the main research questions on BP dynamicity

Appendix 1 Table 15. Categorization of references used to answer the main research questions on BP dynamicity 


\begin{tabular}{|c|c|c|}
\hline RQ & $\begin{array}{l}\text { Process dynamicity } \\
\text { influencing features }\end{array}$ & References \\
\hline RQ1 & \multicolumn{2}{|c|}{ 1. Process model predefined (Essential) (see DBPR-1): } \\
\hline \multirow[t]{3}{*}{$\begin{array}{l}\text { RQ2 } \\
\text { RQ3 } \\
\text { RQ4 }\end{array}$} & $\begin{array}{l}\text { 1.1. Does a process have a } \\
\text { predefined sequence of } \\
\text { activities, i.e., a predefined } \\
\text { process model? }\end{array}$ & $\begin{array}{l}\text { (Boffoli, Cimitile \& Maggi, 2009); (Cao et al., 2009); (Dadam \& Reichert, 2009); (Asuncion, Iacob \& van } \\
\text { Sinderen, 2010); (Châtel, Malenfant \& Truck, 2010); (Bucchiarone et al., 2011); (Ayora et al., 2012); (Boffoli et } \\
\text { al., 2012); (Bucchiarone, Mezzina \& Pistore, 2013); (Abderrahmane, Mili \& Boubaker, 2014); (Borrego \& } \\
\text { Barba, 2014); (Awadid \& Gnannouchi, 2015); (Cherif, Djemaa \& Amous, 2015); (Deb, Chaki \& Ghose, 2015); } \\
\text { (Ayora et al., 2016); (Bögl, Natschläger \& Geist, 2016); (Czepa et al., 2016); (Demeyer et al., 2010); (Gong \& } \\
\text { Janssen, 2011); (Haarmann et al., 2015); (Hallerbach, Bauer \& Reichert, 2010); (Hermosillo, Seinturier \& } \\
\text { Duchien, 2010); (Jiang et al., 2016); (Kannengiesser et al., 2014); (Kapuruge, Han \& Colman, 2011); (Kim, Kim } \\
\text { \& Kim, 2007); (Li \& Du, 2016); (Marconi et al., 2009); (Martinho, Domingos \& Varajão, 2015); (Mattos et al., } \\
\text { 2014); (Mejia Bernal et al., 2010); (Mounira \& Mahmoud, 2010); (Natschläger et al., 2016); (Oberhauser, 2016); } \\
\text { (Prasad et al., 2015); (Ramakrishnan, 2009); (Saidani \& Nurcan, 2006); (Santo Carvalho, Santoro \& Revoredo, } \\
\text { 2015); (Santo Carvalho et al., 2013); (Santos et al., 2013); (Santos et al., 2011); (Sarno et al., 2015); (Sprovieri et } \\
\text { al., 2016); (Sun, Huang \& Meng, 2011); (Ukor \& Carpenter, 2009); (van Eijndhoven, Iacob \& Ponisio, 2008); } \\
\text { (Weidlich et al., 2011); (Xia \& Wei, 2008); (Yoo et al., 2008); (Yousfi, Saidi \& Dey, 2016); (Yuliang et al., } \\
\text { 2009); (Gottschalk et al., 2008); (Maggi et al., 2012); (Pesic \& van der Aalst, 2006); (Wang \& Wang, 2006); } \\
\text { (Baresi \& Guinea, 2005); (van der Aalst, Pesic \& Schonenberg, 2009); (Milanovic, Gasevic \& Rocha, 2011) } \\
\text {;(Bucchiarone et al., 2017) }\end{array}$ \\
\hline & $\begin{array}{l}\text { 1.2. Is a process based on } \\
\text { meta-model, general model, } \\
\text { generic model, or abstract } \\
\text { model? }\end{array}$ & $\begin{array}{l}\text { (Abderrahmane, Mili \& Boubaker, 2014); (van der Aalst, Weske \& Grünbauer, 2005); (Boffoli et al., 2012); } \\
\text { (Boffoli, Cimitile \& Maggi, 2009); (Bögl, Natschläger \& Geist, 2016); (Bucchiarone et al., 2011); (Dadam \& } \\
\text { Reichert, 2009); (Haarmann et al., 2015); (Hallerbach, Bauer \& Reichert, 2010); (Jiang et al., 2016); } \\
\text { (Kannengiesser et al., 2014); (Kapuruge, Han \& Colman, 2011); (Li \& Du, 2016); (Marconi et al., 2009); } \\
\text { (Martinho, Domingos \& Varajão, 2015); (Mattos et al., 2014); (Oberhauser, 2016); (Prasad et al., 2015); } \\
\text { (Saidani \& Nurcan, 2006); (Santos et al., 2013); (Sarno et al., 2015); (Sprovieri et al., 2016); (van Eijndhoven, } \\
\text { Iacob \& Ponisio, 2008); (Wang \& Capretz, 2007); (Weidlich et al., 2011); (Xiao et al., 2011); (Yoo et al., 2008); } \\
\text { (Yousfi, Saidi \& Dey, 2016); (Yuliang et al., 2009); (Gottschalk et al., 2008); (Maggi et al., 2012); (Pesic \& van } \\
\text { der Aalst, 2006); (Wang \& Wang, 2006); (Baresi \& Guinea, 2005); (van der Aalst, Pesic \& Schonenberg, 2009); } \\
\text { (Milanovic, Gasevic \& Rocha, 2011); (Bucchiarone et al., 2017) }\end{array}$ \\
\hline & $\begin{array}{l}\text { 1.3. Is it possible to define } \\
\text { additional activities and to } \\
\text { change or delete existing } \\
\text { activities or skip to other } \\
\text { activities at process instance }\end{array}$ & $\begin{array}{l}\text { (Abderrahmane, Mili \& Boubaker, 2014); (van der Aalst, Weske \& Grünbauer, 2005); (Awadid \& Gnannouchi, } \\
\text { 2015); (Ayora et al., 2016); (Ayora et al., 2012); (Bucchiarone et al., 2011); (Cao et al., 2009); (Czepa et al., } \\
\text { 2016); (Dadam \& Reichert, 2009); (Haarmann et al., 2015); (Hermosillo, Seinturier \& Duchien, 2010); (Jiang et } \\
\text { al., 2016); (Kapuruge, Han \& Colman, 2011); (Khriss et al., 2008); (Kim, Kim \& Kim, 2007); (Liu et al., 2012); } \\
\text { (Marconi et al., 2009); (Mattos et al., 2014); (Mejia Bernal et al., 2010); (Mounira \& Mahmoud, 2010); } \\
\text { (Oberhauser, 2016); (Santos et al., 2013); (Sprovieri et al., 2016); (Gottschalk et al., 2008); (Maggi et al., 2012); }\end{array}$ \\
\hline
\end{tabular}




\begin{tabular}{|c|c|c|}
\hline RQ & $\begin{array}{l}\text { Process dynamicity } \\
\text { influencing features }\end{array}$ & References \\
\hline & run-time? & $\begin{array}{l}\text { (Pesic \& van der Aalst, 2006); (Wang \& Wang, 2006); (Baresi \& Guinea, 2005); (van der Aalst, Pesic \& } \\
\text { Schonenberg, 2009); (Savickas \& Vasilecas, 2018); (Milanovic, Gasevic \& Rocha, 2011); (Bucchiarone et al., } \\
\text { 2017); (Vasilecas, Kalibatiene \& Lavbič, 2016) }\end{array}$ \\
\hline \multirow{4}{*}{$\begin{array}{l}\text { RQ1 } \\
\text { RQ2 } \\
\text { RQ3 } \\
\text { RQ4 }\end{array}$} & \multicolumn{2}{|c|}{ 2. Context aware (Essential) (see DBPR-2): } \\
\hline & $\begin{array}{l}\text { 2.1. Does an external context } \\
\text { affect the execution of the } \\
\text { process? }\end{array}$ & $\begin{array}{l}\text { (Abderrahmane, Mili \& Boubaker, 2014); (van der Aalst, Weske \& Grünbauer, 2005); (Ayora et al., 2016); } \\
\text { (Boffoli et al., 2012); (Boffoli, Cimitile \& Maggi, 2009); (Bögl, Natschläger \& Geist, 2016); (Bucchiarone, } \\
\text { Mezzina \& Pistore, 2013); (Bucchiarone et al., 2011); (Cherif, Djemaa \& Amous, 2015); (Deb, Chaki \& Ghose, } \\
\text { 2015); (Demeyer et al., 2010); (Hallerbach, Bauer \& Reichert, 2010); (Hermosillo, Seinturier \& Duchien, 2010); } \\
\text { (Jiang et al., 2016); (Marconi et al., 2009); (Mattos et al., 2014); (Mejia Bernal et al., 2010); (Mounira \& } \\
\text { Mahmoud, 2010); (Rong, Liu \& Liang, 2008); (Santo Carvalho, Santoro \& Revoredo, 2015); (Santo Carvalho et } \\
\text { al., 2013); (Santos et al., 2013); (Santos et al., 2011); (Sprovieri et al., 2016); (Xia \& Wei, 2008); (Xiao et al., } \\
\text { 2011); (Yoo et al., 2008); (Yousfi, Saidi \& Dey, 2016); (Wang \& Wang, 2006); (Baresi \& Guinea, 2005); } \\
\text { (Savickas \& Vasilecas, 2018); (Milanovic, Gasevic \& Rocha, 2011); (Bucchiarone et al., 2017); (Vasilecas, } \\
\text { Kalibatiene \& Lavbič, 2016) }\end{array}$ \\
\hline & $\begin{array}{l}\text { 2.2. Does an internal context } \\
\text { affect the execution of the } \\
\text { process? }\end{array}$ & $\begin{array}{l}\text { (Abderrahmane, Mili \& Boubaker, 2014); (van der Aalst, Weske \& Grünbauer, 2005); (Ayora et al., 2012); } \\
\text { (Boffoli et al., 2012); (Bögl, Natschläger \& Geist, 2016); (Cao et al., 2009); (Châtel, Malenfant \& Truck, 2010); } \\
\text { (Czepa et al., 2016); (Dadam \& Reichert, 2009); (Khriss et al., 2008); (Kim, Kim \& Kim, 2007); (Liu et al., } \\
\text { 2012); (Marconi et al., 2009); (Mejia Bernal et al., 2010); (Mounira \& Mahmoud, 2010); (Natschläger et al., } \\
\text { 2016); (Oberhauser, 2016); (Prasad et al., 2015); (Ramakrishnan, 2009); (Rong, Liu \& Liang, 2008); (Saidani \& } \\
\text { Nurcan, 2006); (Santo Carvalho et al., 2013); (Sprovieri et al., 2016); (Sun, Huang \& Meng, 2011); (Ukor \& } \\
\text { Carpenter, 2009); (van Eijndhoven, Iacob \& Ponisio, 2008); (Xia \& Wei, 2008); (Xiao et al., 201 1); (Yoo et al., } \\
\text { 2008); (Wang \& Wang, 2006); (Baresi \& Guinea, 2005); (Savickas \& Vasilecas, 2018); (Bucchiarone et al., } \\
\text { 2017); (Vasilecas, Kalibatiene \& Lavbič, 2016) }\end{array}$ \\
\hline & $\begin{array}{l}\text { 2.3. Is a process instance } \\
\text { affected by the change of a } \\
\text { context at run-time? }\end{array}$ & $\begin{array}{l}\text { (van der Aalst, Weske \& Grünbauer, 2005); (Ayora et al., 2016); (Ayora et al., 2012); (Bögl, Natschläger \& } \\
\text { Geist, 2016); (Bucchiarone, Mezzina \& Pistore, 2013); (Bucchiarone et al., 2011); (Cao et al., 2009); (Cherif, } \\
\text { Djemaa \& Amous, 2015); (Czepa et al., 2016); (Dadam \& Reichert, 2009); (Demeyer et al., 2010); (Hallerbach, } \\
\text { Bauer \& Reichert, 2010); (Hermosillo, Seinturier \& Duchien, 2010); (Jiang et al., 2016); (Khriss et al., 2008); } \\
\text { (Kim, Kim \& Kim, 2007); (Liu et al., 2012); (Marconi et al., 2009); (Mattos et al., 2014); (Mejia Bernal et al., } \\
\text { 2010); (Mounira \& Mahmoud, 2010); (Oberhauser, 2016); (Rong, Liu \& Liang, 2008); (Santo Carvalho, Santoro } \\
\text { \& Revoredo, 2015); (Santos et al., 2011); (Sprovieri et al., 2016); (Sun, Huang \& Meng, 2011); (Ukor \& } \\
\text { Carpenter, 2009); (van Eijndhoven, Iacob \& Ponisio, 2008); (Xia \& Wei, 2008); (Xiao et al., 2011); (Yoo et al., } \\
\text { 2008); (Yousfi, Saidi \& Dey, 2016); (Wang \& Wang, 2006); (Baresi \& Guinea, 2005); (Savickas \& Vasilecas, } \\
\text { 2018); (Milanovic, Gasevic \& Rocha, 2011); (Bucchiarone et al., 2017); (Vasilecas, Kalibatiene \& Lavbič, 2016) }\end{array}$ \\
\hline RQ1 & \multicolumn{2}{|c|}{ 3. Rule-based ${ }^{1}$ (Essential) (see DBPR-3): } \\
\hline $\begin{array}{l}\text { RQ2 } \\
\text { RQ3 } \\
\text { RQ4 }\end{array}$ & $\begin{array}{l}\text { 3.1. Is every subsequent } \\
\text { activity in a process selected } \\
\text { according to the predefined }\end{array}$ & $\begin{array}{l}\text { (Abderrahmane, Mili \& Boubaker, 2014); (van der Aalst, Weske \& Grünbauer, 2005); (Asuncion, Iacob \& van } \\
\text { Sinderen, 2010); (Ayora et al., 2016); (Ayora et al., 2012); (Boffoli et al., 2012); (Boffoli, Cimitile \& Maggi, } \\
\text { 2009); (Bögl, Natschläger \& Geist, 2016); (Borrego \& Barba, 2014); (Bucchiarone, Mezzina \& Pistore, 2013); }\end{array}$ \\
\hline
\end{tabular}




\begin{tabular}{|c|c|c|}
\hline RQ & $\begin{array}{l}\text { Process dynamicity } \\
\text { influencing features }\end{array}$ & References \\
\hline & $\begin{array}{l}\text { rules at process instance run- } \\
\text { time? }\end{array}$ & $\begin{array}{l}\text { (Bucchiarone et al., 2011); (Cao et al., 2009); (Châtel, Malenfant \& Truck, 2010); (Czepa et al., 2016); (Dadam } \\
\text { \& Reichert, 2009); (Deb, Chaki \& Ghose, 2015); (Demeyer et al., 2010); (Gong \& Janssen, 2011); (Haarmann et } \\
\text { al., 2015); (Hallerbach, Bauer \& Reichert, 2010); (Hermosillo, Seinturier \& Duchien, 2010); (Jiang et al., 2016); } \\
\text { (Kapuruge, Han \& Colman, 2011); (Liu et al., 2012); (Marconi et al., 2009); (Martinho, Domingos \& Varajão, } \\
\text { 2015); (Mattos et al., 2014); (Mejia Bernal et al., 2010); (Mounira \& Mahmoud, 2010); (Natschläger et al.,, } \\
\text { 2016); (Oberhauser, 2016); (Prasad et al., 2015); (Rong, Liu \& Liang, 2008); (Saidani \& Nurcan, 2006); (Santo } \\
\text { Carvalho, Santoro \& Revoredo, 2015); (Santo Carvalho et al., 2013); (Santos et al., 2013); (Sprovieri et al., } \\
\text { 2016); (Sun, Huang \& Meng, 2011); (Ukor \& Carpenter, 2009); (van Eijndhoven, Iacob \& Ponisio, 2008); } \\
\text { (Wang \& Capretz, 2007); (Weidlich et al., 2011); (Xia \& Wei, 2008); (Xiao et al., 2011); (Yoo et al., 2008); } \\
\text { (Yousfi, Saidi \& Dey, 2016); (Yuliang et al., 2009); (Gottschalk et al., 2008); (Maggi et al., 2012); (Pesic \& van } \\
\text { der Aalst, 2006); (Wang \& Wang, 2006); (Baresi \& Guinea, 2005); (van der Aalst, Pesic \& Schonenberg, 2009); } \\
\text { (Savickas \& Vasilecas, 2018); (Bucchiarone et al., 2017); (Vasilecas, Kalibatiene \& Lavbič, 2016) }\end{array}$ \\
\hline & $\begin{array}{l}\text { 3.2. Is it possible to define } \\
\text { new rules, or change or delete } \\
\text { existing rules, at process } \\
\text { instance run-time? }\end{array}$ & $\begin{array}{l}\text { (Czepa et al., 2016); (Mejia Bernal et al., 2010); (Santo Carvalho, Santoro \& Revoredo, 2015); (Yoo et al., } \\
\text { 2008); (Milanovic, Gasevic \& Rocha, 2011); (Vasilecas, Kalibatiene \& Lavbič, 2016) }\end{array}$ \\
\hline & $\begin{array}{l}\text { 3.3. Does process instance } \\
\text { react to the rule changes } \\
\text { made at process instance run- } \\
\text { time? }\end{array}$ & $\begin{array}{l}\text { (Czepa et al., 2016); (Mejia Bernal et al., 2010); (Santo Carvalho, Santoro \& Revoredo, 2015); (Yoo et al., } \\
\text { 2008); (Milanovic, Gasevic \& Rocha, 2011); (Vasilecas, Kalibatiene \& Lavbič, 2016) }\end{array}$ \\
\hline & $\begin{array}{l}\text { 3.4. Are rules used to solve } \\
\text { other tasks? }\end{array}$ & $\begin{array}{l}\text { (Abderrahmane, Mili \& Boubaker, 2014); (Asuncion, Iacob \& van Sinderen, 2010); (Bögl, Natschläger \& Geist, } \\
\text { 2016); (Borrego \& Barba, 2014); (Bucchiarone, Mezzina \& Pistore, 2013); (Bucchiarone et al., 2011); (Châtel, } \\
\text { Malenfant \& Truck, 2010); (Czepa et al., 2016); (Dadam \& Reichert, 2009); (Jiang et al., 2016); (Kannengiesser } \\
\text { et al., 2014); (Kim, Kim \& Kim, 2007); (Li \& Du, 2016); (Martinho, Domingos \& Varajão, 2015); } \\
\text { (Ramakrishnan, 2009); (Santos et al., 2013); (Santos et al., 2011); (Weidlich et al., 2011); (Xia \& Wei, 2008); } \\
\text { (Maggi et al., 2012) }\end{array}$ \\
\hline $\begin{array}{l}\text { RQ1 } \\
\text { RQ2 } \\
\text { RQ3 } \\
\text { RQ4 }\end{array}$ & $\begin{array}{l}\text { 4. Changes (Essential): Are } \\
\text { changes implemented at } \\
\text { process instance run-time } \\
\text { with low latency? (see } \\
\text { DBPR-4) }\end{array}$ & $\begin{array}{l}\text { (Abderrahmane, Mili \& Boubaker, 2014); (van der Aalst, Weske \& Grünbauer, 2005); (Awadid \& Gnannouchi, } \\
\text { 2015); (Ayora et al., 2016); (Ayora et al., 2012); (Bögl, Natschläger \& Geist, 2016); (Bucchiarone, Mezzina \& } \\
\text { Pistore, 2013); (Bucchiarone et al., 2011); (Cao et al., 2009); (Cherif, Djemaa \& Amous, 2015); (Czepa et al., } \\
\text { 2016); (Dadam \& Reichert, 2009); (Demeyer et al., 2010); (Gong \& Janssen, 2011); (Haarmann et al., 2015); } \\
\text { (Hallerbach, Bauer \& Reichert, 2010); (Hermosillo, Seinturier \& Duchien, 2010); (Jiang et al., 2016); } \\
\text { (Kannengiesser et al., 2014); (Kapuruge, Han \& Colman, 2011); (Khriss et al., 2008); (Kim, Kim \& Kim, 2007); } \\
\text { (Liu et al., 2012); (Marconi et al., 2009); (Martinho, Domingos \& Varajão, 2015); (Mattos et al., 2014); (Mejia } \\
\text { Bernal et al., 2010); (Mounira \& Mahmoud, 2010); (Oberhauser, 2016); (Prasad et al., 2015); (Ramakrishnan, } \\
\text { 2009); (Rong, Liu \& Liang, 2008); (Santo Carvalho, Santoro \& Revoredo, 2015); (Santos et al., 2013); (Santos } \\
\text { et al., 2011); (Sprovieri et al., 2016); (Sun, Huang \& Meng, 2011); (Ukor \& Carpenter, 2009); (van Eijndhoven, } \\
\text { Iacob \& Ponisio, 2008); (Wang \& Capretz, 2007); (Xia \& Wei, 2008); (Xiao et al., 2011); (Yoo et al., 2008); }\end{array}$ \\
\hline
\end{tabular}




\begin{tabular}{|c|c|c|}
\hline $\mathbf{R Q}$ & $\begin{array}{l}\text { Process dynamicity } \\
\text { influencing features }\end{array}$ & References \\
\hline & & $\begin{array}{l}\text { (Yousfi, Saidi \& Dey, 2016); (Yuliang et al., 2009); (Gottschalk et al., 2008); (Maggi et al., 2012); (Pesic \& van } \\
\text { der Aalst, 2006); (Wang \& Wang, 2006); (Baresi \& Guinea, 2005); (van der Aalst, Pesic \& Schonenberg, 2009); } \\
\text { (Savickas \& Vasilecas, 2018); (Milanovic, Gasevic \& Rocha, 2011); (Bucchiarone et al., 2017); (Vasilecas, } \\
\text { Kalibatiene \& Lavbič, 2016) }\end{array}$ \\
\hline \multirow{6}{*}{$\begin{array}{l}\text { RQ1 } \\
\text { RQ2 } \\
\text { RQ3 } \\
\text { RQ4 }\end{array}$} & \multicolumn{2}{|c|}{ 5. Accumulation of experience (see DBPR-5): } \\
\hline & $\begin{array}{l}\text { 5.1. Is the experience of each } \\
\text { process instance execution } \\
\text { stored? }\end{array}$ & $\begin{array}{l}\text { (Bögl, Natschläger \& Geist, 2016); (Borrego \& Barba, 2014); (Bucchiarone et al., 2011); (Cao et al., 2009); } \\
\text { (Haarmann et al., 2015); (Hermosillo, Seinturier \& Duchien, 2010); (Mounira \& Mahmoud, 2010); (Santo } \\
\text { Carvalho, Santoro \& Revoredo, 2015); (Santo Carvalho et al., 2013); (Xia \& Wei, 2008); (Savickas \& Vasilecas, } \\
\text { 2018); (Vasilecas, Kalibatiene \& Lavbič, 2016) }\end{array}$ \\
\hline & $\begin{array}{l}5.2 \text {. Is it possible to classify } \\
\text { executed instances of a } \\
\text { process as a "good practice" } \\
\text { and a "bad practice"? }\end{array}$ & (Hermosillo, Seinturier \& Duchien, 2010); (Vasilecas, Kalibatiene \& Lavbič, 2016) \\
\hline & $\begin{array}{l}\text { 5.3. Are time, cost, etc. } \\
\text { values calculated and stored } \\
\text { for each process instance? }\end{array}$ & $\begin{array}{l}\text { (Bögl, Natschläger \& Geist, 2016); (Borrego \& Barba, 2014); (Haarmann et al., 2015); (Santo Carvalho, Santoro } \\
\text { \& Revoredo, 2015); (Vasilecas, Kalibatiene \& Lavbič, 2016) }\end{array}$ \\
\hline & $\begin{array}{l}\text { 5.4. Is it possible to restrict } \\
\text { the execution of process } \\
\text { instances that are named "bad } \\
\text { instances"? }\end{array}$ & (Vasilecas, Kalibatiene \& Lavbič, 2016) \\
\hline & $\begin{array}{l}\text { 5.5. Is historical data used for } \\
\text { solving other related tasks? }\end{array}$ & $\begin{array}{l}\text { (Abderrahmane, Mili \& Boubaker, 2014); (van der Aalst, Weske \& Grünbauer, 2005); (Bögl, Natschläger \& } \\
\text { Geist, 2016); (Borrego \& Barba, 2014); (Bucchiarone et al., 2011); (Cao et al., 2009); (Haarmann et al., 2015); } \\
\text { (Mattos et al., 2014); (Mounira \& Mahmoud, 2010); (Santo Carvalho, Santoro \& Revoredo, 2015); (Santo } \\
\text { Carvalho et al., 2013); (Savickas \& Vasilecas, 2018) }\end{array}$ \\
\hline $\begin{array}{l}\text { RQ1 } \\
\text { RQ2 } \\
\text { RQ3 } \\
\text { RQ4 }\end{array}$ & $\begin{array}{l}\text { 6. Goal: Is a process goal- } \\
\text { oriented? (see DBPR-6) }\end{array}$ & $\begin{array}{l}\text { (Asuncion, Iacob \& van Sinderen, 2010); (Ayora et al., 2012); (Borrego \& Barba, 2014); } \\
\text { (Bucchiarone, Mezzina \& Pistore, 2013); (Bucchiarone et al., 2011); (Deb, Chaki \& Ghose, 2015); } \\
\text { (Gong \& Janssen, 2011); (Kapuruge, Han \& Colman, 2011); (Mejia Bernal et al., 2010); (Saidani \& } \\
\text { Nurcan, 2006); (Santo Carvalho, Santoro \& Revoredo, 2015); (Santo Carvalho et al., 2013); (Sprovieri } \\
\text { et al., 2016); (Wang \& Capretz, 2007); (Xia \& Wei, 2008); (Yousfi, Saidi \& Dey, 2016); (Wang \& } \\
\text { Wang, 2006); (Savickas \& Vasilecas, 2018); (Vasilecas, Kalibatiene \& Lavbič, 2016) }\end{array}$ \\
\hline $\begin{array}{l}\text { RQ1 } \\
\text { RQ2 } \\
\text { RQ3 } \\
\text { RQ4 }\end{array}$ & $\begin{array}{l}\text { 7. Ontology: Is domain } \\
\text { ontology or process ontology } \\
\text { used in an approach? }\end{array}$ & $\begin{array}{l}\text { (Abderrahmane, Mili \& Boubaker, 2014); (Châtel, Malenfant \& Truck, 2010); (Czepa et al., 2016); } \\
\text { (Gong \& Janssen, 2011); (Kannengiesser et al., 2014); (Martinho, Domingos \& Varajão, 2015); } \\
\text { (Mattos et al., 2014); (Prasad et al., 2015); (Ramakrishnan, 2009); (Santo Carvalho, Santoro \& } \\
\text { Revoredo, 2015) }\end{array}$ \\
\hline RQ2 & \multicolumn{2}{|l|}{ 8. Approach description: } \\
\hline
\end{tabular}




\begin{tabular}{|c|c|c|}
\hline $\mathbf{R Q}$ & $\begin{array}{l}\text { Process dynamicity } \\
\text { influencing features }\end{array}$ & References \\
\hline \multirow[t]{2}{*}{$\begin{array}{l}\text { RQ3 } \\
\text { RQ4 } \\
\text { RQ6 }\end{array}$} & $\begin{array}{l}\text { 8.1. Does the paper present a } \\
\text { clear description of the } \\
\text { proposed approach on BP } \\
\text { dynamicity? }\end{array}$ & $\begin{array}{l}\text { (Abderrahmane, Mili \& Boubaker, 2014); (van der Aalst, Weske \& Grünbauer, 2005); (Asuncion, Iacob \& van } \\
\text { Sinderen, 2010); (Awadid \& Gnannouchi, 2015); (Ayora et al., 2016); (Ayora et al., 2012); (Boffoli et al., 2012); } \\
\text { (Boffoli, Cimitile \& Maggi, 2009); (Bögl, Natschläger \& Geist, 2016); (Borrego \& Barba, 2014); (Bucchiarone, } \\
\text { Mezzina \& Pistore, 2013); (Bucchiarone et al., 2011); (Cao et al., 2009); (Châtel, Malenfant \& Truck, 2010); } \\
\text { (Cherif, Djemaa \& Amous, 2015); (Czepa et al., 2016); (Dadam \& Reichert, 2009); (Deb, Chaki \& Ghose, } \\
\text { 2015); (Demeyer et al., 2010); (Gong \& Janssen, 2011); (Haarmann et al., 2015); (Hallerbach, Bauer \& Reichert, } \\
\text { 2010); (Hermosillo, Seinturier \& Duchien, 2010); (Jiang et al., 2016); (Kannengiesser et al., 2014); (Kapuruge, } \\
\text { Han \& Colman, 2011); (Khriss et al., 2008); (Kim, Kim \& Kim, 2007); (Li \& Du, 2016); (Liu et al., 2012); } \\
\text { (Marconi et al., 2009); (Martinho, Domingos \& Varajão, 2015); (Mattos et al., 2014); (Mejia Bernal et al., } \\
\text { 2010); (Mounira \& Mahmoud, 2010); (Natschläger et al., 2016); (Oberhauser, 2016); (Prasad et al., 2015); } \\
\text { (Ramakrishnan, 2009); (Rong, Liu \& Liang, 2008); (Saidani \& Nurcan, 2006); (Santo Carvalho, Santoro \& } \\
\text { Revoredo, 2015); (Santo Carvalho et al., 2013); (Santos et al., 2013); (Santos et al., 2011); (Sarno et al., 2015); } \\
\text { (Sprovieri et al., 2016); (Sun, Huang \& Meng, 2011); (Ukor \& Carpenter, 2009); (van Eijndhoven, Iacob \& } \\
\text { Ponisio, 2008); (Wang \& Capretz, 2007); (Weidlich et al., 2011); (Xia \& Wei, 2008); (Xiao et al., 2011); (Yoo et } \\
\text { al., 2008); (Yousfi, Saidi \& Dey, 2016); (Yuliang et al., 2009); (Gottschalk et al., 2008); (Maggi et al., 2012); } \\
\text { (Pesic \& van der Aalst, 2006); (Wang \& Wang, 2006); (Baresi \& Guinea, 2005); (van der Aalst, Pesic \& } \\
\text { Schonenberg, 2009); (Savickas \& Vasilecas, 2018); (Milanovic, Gasevic \& Rocha, 2011); (Bucchiarone et al., } \\
\text { 2017); (Vasilecas, Kalibatiene \& Lavbič, 2016) }\end{array}$ \\
\hline & $\begin{array}{l}\text { 8.2. Does the paper present a } \\
\text { description of the proposed } \\
\text { approach on dynamic BP in a } \\
\text { formal language? }\end{array}$ & $\begin{array}{l}\text { (van der Aalst, Weske \& Grünbauer, 2005); (Borrego \& Barba, 2014); (Bucchiarone, Mezzina \& Pistore, 2013); } \\
\text { (Deb, Chaki \& Ghose, 2015); (Demeyer et al., 2010); (Hallerbach, Bauer \& Reichert, 2010); (Hermosillo, } \\
\text { Seinturier \& Duchien, 2010); (Jiang et al., 2016); (Kannengiesser et al., 2014); (Kapuruge, Han \& Colman, } \\
\text { 2011); (Li \& Du, 2016); (Liu et al., 2012); (Marconi et al., 2009); (Martinho, Domingos \& Varajão, 2015); } \\
\text { (Mattos et al., 2014); (Santo Carvalho, Santoro \& Revoredo, 2015); (Santos et al., 2013); (Sun, Huang \& Meng, } \\
\text { 2011); (Ukor \& Carpenter, 2009); (Wang \& Capretz, 2007); (Weidlich et al., 2011); (Xia \& Wei, 2008); (Xiao et } \\
\text { al., 2011); (Yoo et al., 2008); (Yousfi, Saidi \& Dey, 2016); (Maggi et al., 2012); (Wang \& Wang, 2006); } \\
\text { (Savickas \& Vasilecas, 2018); (Bucchiarone et al., 2017) }\end{array}$ \\
\hline \multirow{3}{*}{$\begin{array}{l}\text { RQ1 } \\
\text { RQ2 } \\
\text { RQ3 } \\
\text { RQ4 } \\
\text { RQ6 }\end{array}$} & \multicolumn{2}{|c|}{ 9. Dynamicity implementation approach (if 1.1. is yes): } \\
\hline & $\begin{array}{l}\text { 9.1. Is the process dynamicity } \\
\text { realized through variants? }\end{array}$ & $\begin{array}{l}\text { (Abderrahmane, Mili \& Boubaker, 2014); (Ayora et al., 2016); (Ayora et al., 2012); (Boffoli et al., 2012); } \\
\text { (Boffoli, Cimitile \& Maggi, 2009); (Bögl, Natschläger \& Geist, 2016); (Bucchiarone, Mezzina \& Pistore, 2013); } \\
\text { (Châtel, Malenfant \& Truck, 2010); (Cherif, Djemaa \& Amous, 2015); (Dadam \& Reichert, 2009); (Hallerbach, } \\
\text { Bauer \& Reichert, 2010); (Hermosillo, Seinturier \& Duchien, 2010); (Jiang et al., 2016); (Kim, Kim \& Kim, } \\
\text { 2007); (Li \& Du, 2016); (Marconi et al., 2009); (Martinho, Domingos \& Varajão, 2015); (Natschläger et al., } \\
\text { 2016); (Oberhauser, 2016); (Ramakrishnan, 2009); (Santos et al., 2011); (Sarno et al., 2015); (Ukor \& Carpenter, } \\
\text { 2009); (van Eijndhoven, Iacob \& Ponisio, 2008); (Wang \& Capretz, 2007); (Weidlich et al., 2011); (Xia \& Wei, } \\
\text { 2008); (Yousfi, Saidi \& Dey, 2016); (Gottschalk et al., 2008); (Milanovic, Gasevic \& Rocha, 2011); } \\
\text { (Bucchiarone et al., 2017) }\end{array}$ \\
\hline & 9.2. Is the process dynamicity & (van der Aalst, Weske \& Grünbauer, 2005); (Czepa et al., 2016); (Haarmann et al., 2015); (Sprovieri et al., 2016) \\
\hline
\end{tabular}




\begin{tabular}{|c|c|c|}
\hline RQ & $\begin{array}{l}\text { Process dynamicity } \\
\text { influencing features }\end{array}$ & References \\
\hline & realized through cases? & \\
\hline & $\begin{array}{l}\text { 9.3. Is the process dynamicity } \\
\text { realized through a declarative } \\
\text { approach? }\end{array}$ & $\begin{array}{l}\text { (Borrego \& Barba, 2014); (Demeyer et al., 2010); (Gong \& Janssen, 2011); (Mejia Bernal et al., 2010); (Santos } \\
\text { et al., 2013); (Sun, Huang \& Meng, 2011); (Xiao et al., 2011); (Maggi et al., 2012); (Pesic \& van der Aalst, } \\
\text { 2006); (Wang \& Wang, 2006); (van der Aalst, Pesic \& Schonenberg, 2009) }\end{array}$ \\
\hline & $\begin{array}{l}\text { 9.4. Is the process dynamicity } \\
\text { realized through goal- } \\
\text { orientation? }\end{array}$ & $\begin{array}{l}\text { (Asuncion, Iacob \& van Sinderen, 2010); (Ayora et al., 2012); (Bucchiarone et al., 2011); (Deb, Chaki \& Ghose, } \\
\text { 2015); (Gong \& Janssen, 2011); (Mattos et al., 2014); (Prasad et al., 2015); (Santo Carvalho, Santoro \& } \\
\text { Revoredo, 2015); (Santo Carvalho et al., 2013); (Wang \& Wang, 2006); (Savickas \& Vasilecas, 2018); } \\
\text { (Vasilecas, Kalibatiene \& Lavbič, 2016) }\end{array}$ \\
\hline & $\begin{array}{l}\text { 9.5. Is the process dynamicity } \\
\text { realized through other } \\
\text { approaches? }\end{array}$ & $\begin{array}{l}\text { (Awadid \& Gnannouchi, 2015); (Cao et al., 2009); (Kannengiesser et al., 2014); (Kapuruge, Han \& Colman, } \\
\text { 2011); (Khriss et al., 2008); (Liu et al., 2012); (Mounira \& Mahmoud, 2010); (Rong, Liu \& Liang, 2008); (Yoo } \\
\text { et al., 2008); (Yuliang et al., 2009); (Baresi \& Guinea, 2005) }\end{array}$ \\
\hline \multirow{3}{*}{$\begin{array}{l}\text { RQ2 } \\
\text { RQ3 } \\
\text { RQ4 } \\
\text { RQ6 }\end{array}$} & \multicolumn{2}{|c|}{ 10. Implementation of the proposed approach: } \\
\hline & $\begin{array}{l}\text { 10.1. Is any case of } \\
\text { implementation of a proposed } \\
\text { model presented in the paper? }\end{array}$ & $\begin{array}{l}\text { (Abderrahmane, Mili \& Boubaker, 2014); (van der Aalst, Weske \& Grünbauer, 2005); (Asuncion, Iacob \& van } \\
\text { Sinderen, 2010); (Awadid \& Gnannouchi, 2015); (Ayora et al., 2016); (Ayora et al., 2012); (Boffoli et al., 2012); } \\
\text { (Boffoli, Cimitile \& Maggi, 2009); (Bögl, Natschläger \& Geist, 2016); (Borrego \& Barba, 2014); (Bucchiarone, } \\
\text { Mezzina \& Pistore, 2013); (Bucchiarone et al., 2011); (Cao et al., 2009); (Châtel, Malenfant \& Truck, 2010); } \\
\text { (Cherif, Djemaa \& Amous, 2015); (Czepa et al., 2016); (Dadam \& Reichert, 2009); (Deb, Chaki \& Ghose, } \\
\text { 2015); (Demeyer et al., 2010); (Gong \& Janssen, 2011); (Haarmann et al., 2015); (Hallerbach, Bauer \& Reichert,, } \\
\text { 2010); (Hermosillo, Seinturier \& Duchien, 2010); (Jiang et al., 2016); (Kannengiesser et al., 2014); (Kapuruge, } \\
\text { Han \& Colman, 2011); (Khriss et al., 2008); (Kim, Kim \& Kim, 2007); (Li \& Du, 2016); (Liu et al., 2012); } \\
\text { (Marconi et al., 2009); (Martinho, Domingos \& Varajão, 2015); (Mattos et al., 2014); (Mejia Bernal et al.,, } \\
\text { 2010); (Mounira \& Mahmoud, 2010); (Natschläger et al., 2016); (Oberhauser, 2016); (Prasad et al., 2015); } \\
\text { (Ramakrishnan, 2009); (Rong, Liu \& Liang, 2008); (Santo Carvalho, Santoro \& Revoredo, 2015); (Santo } \\
\text { Carvalho et al., 2013); (Santos et al., 2013); (Santos et al., 2011); (Sarno et al., 2015); (Sprovieri et al., 2016); } \\
\text { (Sun, Huang \& Meng, 2011); (van Eijndhoven, Iacob \& Ponisio, 2008); (Wang \& Capretz, 2007); (Weidlich et } \\
\text { al., 2011); (Xia \& Wei, 2008); (Xiao et al., 2011); (Yoo et al., 2008); (Yousfi, Saidi \& Dey, 2016); (Yuliang et } \\
\text { al., 2009); (Gottschalk et al., 2008); (Maggi et al., 2012); (Pesic \& van der Aalst, 2006); (Wang \& Wang, 2006); } \\
\text { (Baresi \& Guinea, 2005); (van der Aalst, Pesic \& Schonenberg, 2009); (Savickas \& Vasilecas, 2018); } \\
\text { (Milanovic, Gasevic \& Rocha, 2011); (Bucchiarone et al., 2017); (Vasilecas, Kalibatiene \& Lavbič, 2016) }\end{array}$ \\
\hline & $\begin{array}{l}\text { 10.3. Does the paper present } \\
\text { a case study or a prototype or } \\
\text { a descriptive example? }\end{array}$ & $\begin{array}{l}\text { (Abderrahmane, Mili \& Boubaker, 2014); (van der Aalst, Weske \& Grünbauer, 2005); (Asuncion, Iacob \& van } \\
\text { Sinderen, 2010); (Ayora et al., 2016); (Ayora et al., 2012); (Boffoli et al., 2012); (Boffoli, Cimitile \& Maggi, } \\
\text { 2009); (Bögl, Natschläger \& Geist, 2016); (Borrego \& Barba, 2014); (Bucchiarone, Mezzina \& Pistore, 2013); } \\
\text { (Bucchiarone et al., 2011); (Cao et al., 2009); (Châtel, Malenfant \& Truck, 2010); (Cherif, Djemaa \& Amous, } \\
\text { 2015); (Czepa et al., 2016); (Dadam \& Reichert, 2009); (Deb, Chaki \& Ghose, 2015); (Demeyer et al., 2010); } \\
\text { (Gong \& Janssen, 2011); (Haarmann et al., 2015); (Hallerbach, Bauer \& Reichert, 2010); (Hermosillo, Seinturier } \\
\text { \& Duchien, 2010); (Jiang et al., 2016); (Kannengiesser et al., 2014); (Kapuruge, Han \& Colman, 2011); (Khriss } \\
\text { et al., 2008); (Kim, Kim \& Kim, 2007); (Li \& Du, 2016); (Liu et al., 2012); (Marconi et al., 2009); (Martinho, }\end{array}$ \\
\hline
\end{tabular}




\begin{tabular}{|c|c|c|}
\hline RQ & $\begin{array}{l}\text { Process dynamicity } \\
\text { influencing features }\end{array}$ & References \\
\hline & & $\begin{array}{l}\text { Domingos \& Varajão, 2015); (Mattos et al., 2014); (Mejia Bernal et al., 2010); (Mounira \& Mahmoud, 2010); } \\
\text { (Natschläger et al., 2016); (Oberhauser, 2016); (Prasad et al., 2015); (Ramakrishnan, 2009); (Rong, Liu \& Liang, } \\
\text { 2008); (Santo Carvalho, Santoro \& Revoredo, 2015); (Santo Carvalho et al., 2013); (Santos et al., 2013); (Santos } \\
\text { et al., 2011); (Sarno et al., 2015); (Sprovieri et al., 2016); (Sun, Huang \& Meng, 2011); (van Eijndhoven, Iacob } \\
\text { \& Ponisio, 2008); (Wang \& Capretz, 2007); (Weidlich et al., 2011); (Xia \& Wei, 2008); (Xiao et al., 2011); } \\
\text { (Yoo et al., 2008); (Yousfi, Saidi \& Dey, 2016); (Yuliang et al., 2009); (Gottschalk et al., 2008); (Maggi et al., } \\
\text { 2012); (Wang \& Wang, 2006); (Baresi \& Guinea, 2005); (van der Aalst, Pesic \& Schonenberg, 2009); (Savickas } \\
\text { \& Vasilecas, 2018); (Milanovic, Gasevic \& Rocha, 2011); (Bucchiarone et al., 2017); (Vasilecas, Kalibatiene \& } \\
\text { Lavbič, 2016) }\end{array}$ \\
\hline & $\begin{array}{l}\text { 10.4. Does the paper present } \\
\text { a clear description of an } \\
\text { implementation with text, } \\
\text { screen shots, and code lines? }\end{array}$ & $\begin{array}{l}\text { (Abderrahmane, Mili \& Boubaker, 2014); (van der Aalst, Weske \& Grünbauer, 2005); (Asuncion, Iacob \& van } \\
\text { Sinderen, 2010); (Awadid \& Gnannouchi, 2015); (Ayora et al., 2016); (Ayora et al., 2012); (Boffoli et al., 2012); } \\
\text { (Boffoli, Cimitile \& Maggi, 2009); (Bögl, Natschläger \& Geist, 2016); (Borrego \& Barba, 2014); (Bucchiarone, } \\
\text { Mezzina \& Pistore, 2013); (Bucchiarone et al., 2011); (Cao et al., 2009); (Châtel, Malenfant \& Truck, 2010); } \\
\text { (Cherif, Djemaa \& Amous, 2015); (Czepa et al., 2016); (Dadam \& Reichert, 2009); (Deb, Chaki \& Ghose, } \\
\text { 2015); (Demeyer et al., 2010); (Gong \& Janssen, 2011); (Haarmann et al., 2015); (Hallerbach, Bauer \& Reichert, } \\
\text { 2010); (Hermosillo, Seinturier \& Duchien, 2010); (Jiang et al., 2016); (Kannengiesser et al., 2014); (Kapuruge, } \\
\text { Han \& Colman, 2011); (Khriss et al., 2008); (Kim, Kim \& Kim, 2007); (Li \& Du, 2016); (Liu et al., 2012); } \\
\text { (Marconi et al., 2009); (Martinho, Domingos \& Varajão, 2015); (Mattos et al.,, 2014); (Mejia Bernal et al., } \\
\text { 2010); (Mounira \& Mahmoud, 2010); (Natschläger et al., 2016); (Oberhauser, 2016); (Prasad et al., 2015); } \\
\text { (Ramakrishnan, 2009); (Rong, Liu \& Liang, 2008); (Santo Carvalho, Santoro \& Revoredo, 2015); (Santo } \\
\text { Carvalho et al., 2013); (Santos et al., 2013); (Santos et al., 2011); (Sarno et al., 2015); (Sprovieri et al., 2016); } \\
\text { (Sun, Huang \& Meng, 2011); (van Eijndhoven, Iacob \& Ponisio, 2008); (Wang \& Capretz, 2007); (Weidlich et } \\
\text { al., 2011); (Xia \& Wei, 2008); (Xiao et al., 2011); (Yoo et al., 2008); (Yousfi, Saidi \& Dey, 2016); (Yuliang et } \\
\text { al., 2009); (Gottschalk et al., 2008); (Maggi et al., 2012); (Pesic \& van der Aalst, 2006); (Wang \& Wang, 2006); } \\
\text { (Baresi \& Guinea, 2005); (van der Aalst, Pesic \& Schonenberg, 2009); (Savickas \& Vasilecas, 2018); } \\
\text { (Milanovic, Gasevic \& Rocha, 2011); (Bucchiarone et al., 2017); (Vasilecas, Kalibatiene \& Lavbič, 2016) }\end{array}$ \\
\hline & $\begin{array}{l}\text { 10.5. Does the paper evaluate } \\
\text { the results obtained? }\end{array}$ & $\begin{array}{l}\text { (Abderrahmane, Mili \& Boubaker, 2014); (van der Aalst, Weske \& Grünbauer, 2005); (Ayora et al., 2016); } \\
\text { (Boffoli, Cimitile \& Maggi, 2009); (Bucchiarone et al., 2011); (Czepa et al., 2016); (Deb, Chaki \& Ghose, } \\
\text { 2015); (Hallerbach, Bauer \& Reichert, 2010); (Hermosillo, Seinturier \& Duchien, 2010); (Jiang et al., 2016); } \\
\text { (Mattos et al., 2014); (Mejia Bernal et al., 2010); (Santo Carvalho, Santoro \& Revoredo, 2015); (Sprovieri et al., } \\
\text { 2016); (Sun, Huang \& Meng, 2011); (Ukor \& Carpenter, 2009); (Yousfi, Saidi \& Dey, 2016); (Bucchiarone et } \\
\text { al., 2017) }\end{array}$ \\
\hline RQ4 & \multicolumn{2}{|c|}{ 11. Discussion and conclusions: } \\
\hline RQ6 & $\begin{array}{l}\text { 11.1. Does the paper present } \\
\text { an appropriate discussion on } \\
\text { dynamicity? }\end{array}$ & $\begin{array}{l}\text { (Abderrahmane, Mili \& Boubaker, 2014); (Ayora et al., 2016); (Boffoli, Cimitile \& Maggi, 2009); (Borrego \& } \\
\text { Barba, 2014); (Czepa et al., 2016); (Gong \& Janssen, 2011); (Hermosillo, Seinturier \& Duchien, 2010); (Mattos } \\
\text { et al., 2014); (Xia \& Wei, 2008); (Yousfi, Saidi \& Dey, 2016); (Bucchiarone et al., 2017); (Vasilecas, } \\
\text { Kalibatiene \& Lavbič, 2016) }\end{array}$ \\
\hline
\end{tabular}




\begin{tabular}{|l|l|l|}
\hline RQ & $\begin{array}{l}\text { Process dynamicity } \\
\text { influencing features }\end{array}$ & References \\
\hline $\begin{array}{l}\text { 11.2. Does the paper present } \\
\text { grounded conclusions about } \\
\text { dynamicity? }\end{array}$ & (van der Aalst, Weske \& Grünbauer, 2005); (Asuncion, Iacob \& van Sinderen, 2010); (Awadid \& Gnannouchi, \\
& 2015); (Ayora et al., 2012); (Boffoli et al., 2012); (Boffoli, Cimitile \& Maggi, 2009); (Bögl, Natschläger \& \\
& Geist, 2016); (Borrego \& Barba, 2014); (Bucchiarone, Mezzina \& Pistore, 2013); (Bucchiarone et al., 2011); \\
& (Cao et al., 2009); (Châtel, Malenfant \& Truck, 2010); (Cherif, Djemaa \& Amous, 2015); (Czepa et al., 2016); \\
& (Deb, Chaki \& Ghose, 2015); (Demeyer et al., 2010); (Gong \& Janssen, 2011); (Haarmann et al., 2015); \\
& (Hallerbach, Bauer \& Reichert, 2010); (Hermosillo, Seinturier \& Duchien, 2010); (Jiang et al., 2016); \\
& (Kannengiesser et al., 2014); (Kapuruge, Han \& Colman, 2011); (Khriss et al., 2008); (Kim, Kim \& Kim, 2007); \\
& (Li \& Du, 2016); (Liu et al., 2012); (Marconi et al., 2009); (Martinho, Domingos \& Varajão, 2015); (Mattos et \\
& al., 2014); (Mejia Bernal et al., 2010); (Mounira \& Mahmoud, 2010); (Natschläger et al., 2016); (Oberhauser, \\
& 2016); (Prasad et al., 2015); (Ramakrishnan, 2009); (Rong, Liu \& Liang, 2008); (Saidani \& Nurcan, 2006); \\
& (Santo Carvalho, Santoro \& Revoredo, 2015); (Santo Carvalho et al., 2013); (Santos et al., 2013); (Santos et al., \\
& 2011); (Sarno et al., 2015); (Sprovieri et al., 2016); (Sun, Huang \& Meng, 2011); (Ukor \& Carpenter, 2009); \\
& (van Eijndhoven, Iacob \& Ponisio, 2008); (Wang \& Capretz, 2007); (Weidlich et al., 2011); (Xia \& Wei, 2008); \\
& (Xiao et al., 2011); (Yoo et al., 2008); (Yousfi, Saidi \& Dey, 2016); (Yuliang et al., 2009); (Gottschalk et al., \\
& 2008); (Maggi et al., 2012); (Pesic \& van der Aalst, 2006); (Wang \& Wang, 2006); (Baresi \& Guinea, 2005); \\
& (van der Aalst, Pesic \& Schonenberg, 2009); (Savickas \& Vasilecas, 2018); (Milanovic, Gasevic \& Rocha, \\
& 2011); (Bucchiarone et al., 2017); (Vasilecas, Kalibatiene \& Lavbič, 2016) \\
\hline
\end{tabular}


Figure 7

Ranking of papers according to years

Ranking of papers according to years

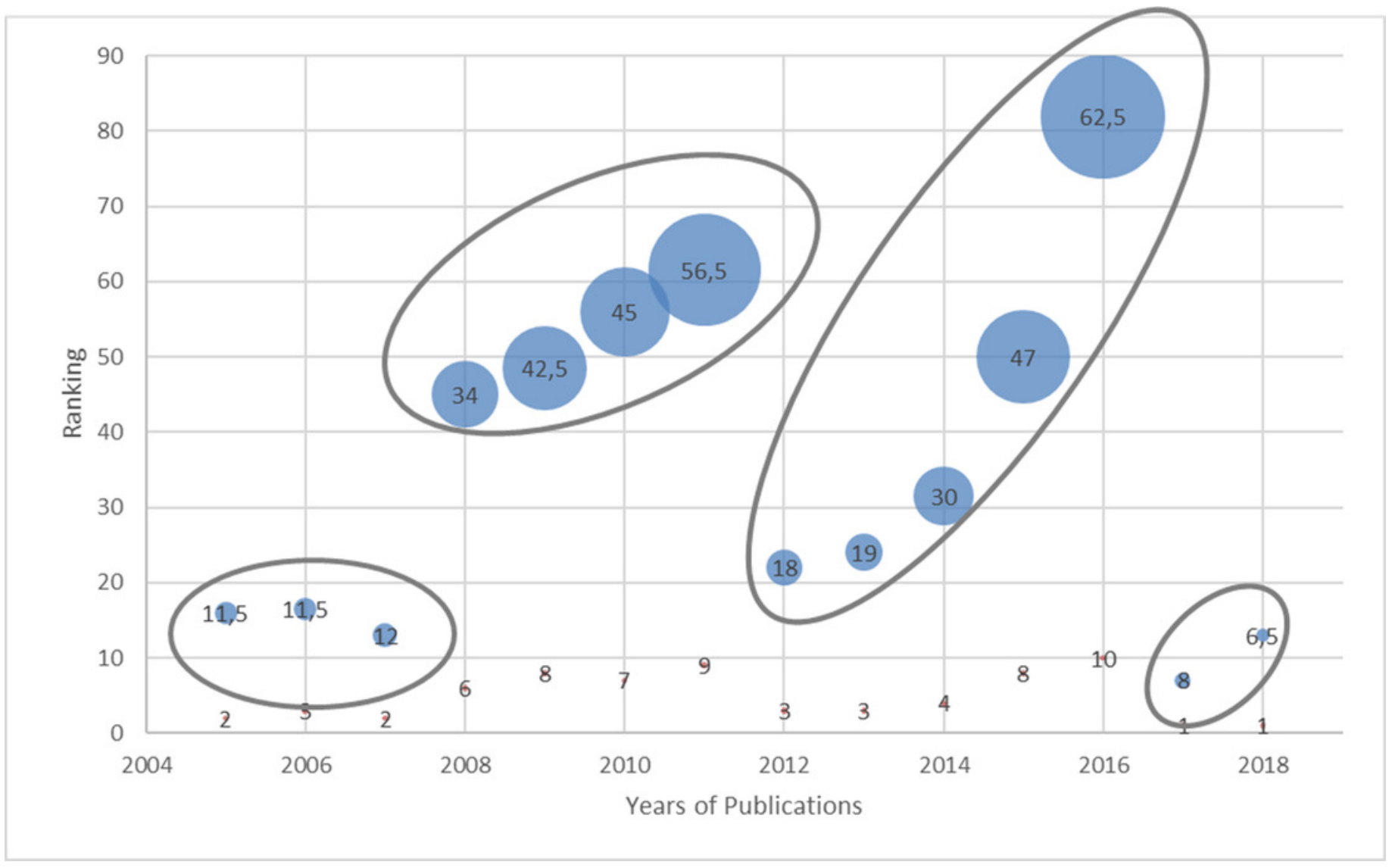




\section{Figure 8}

\section{The evolution of research on BP dynamicity}

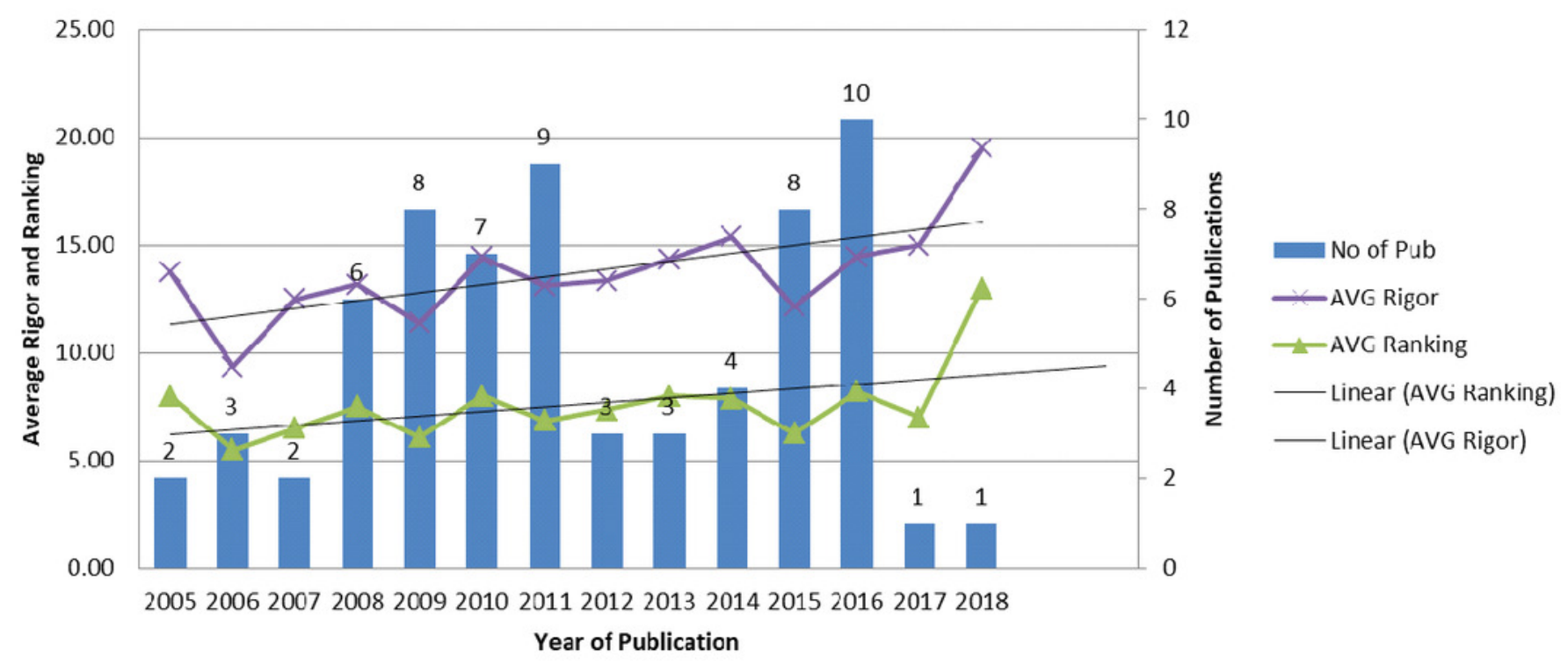

